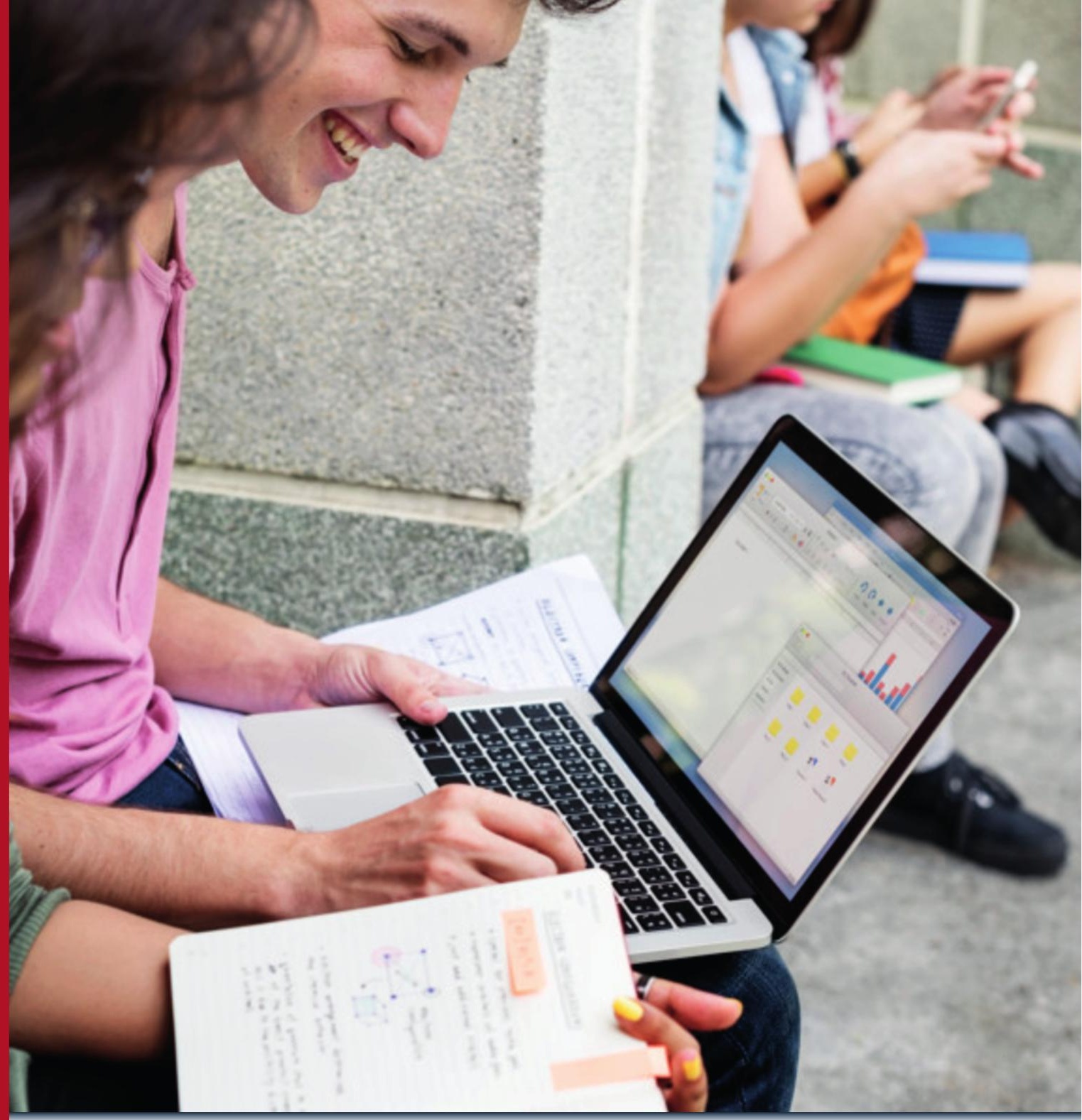

\title{
RETOS Y DESAFIOS DE LA EDUCACIÓN MEDIADA POR TIC EN TIEMPOS DE
}

COVID-19

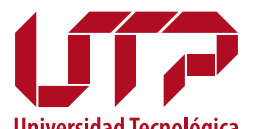

Universidad Tecnológica de Pereira

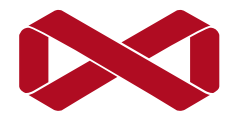

Editorial UTP 
Jairo Ordilio Torres Moreno (Tadó, Chocó, Colombia)

Doctor de Administración de Negocios de la Atlantic International University (AIU), Economista de la Universidad Libre de Pereira, Docente Titular en la Universidad Tecnológica de Pereira.

Ha publicado artículos en la revistas especializadas

jairoordilio@utp.edu.co 


\section{RETOS Y DESAFIOS DE LA EDUCACIÓN MEDIADA POR TIC EN TIEMPOS DE}

\section{COVID-19}

Jairo Ordilio Torres Moreno

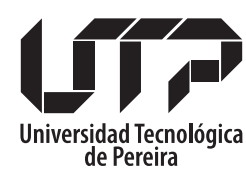

Facultad de Tecnología

Colección Textos Académicos

2020 


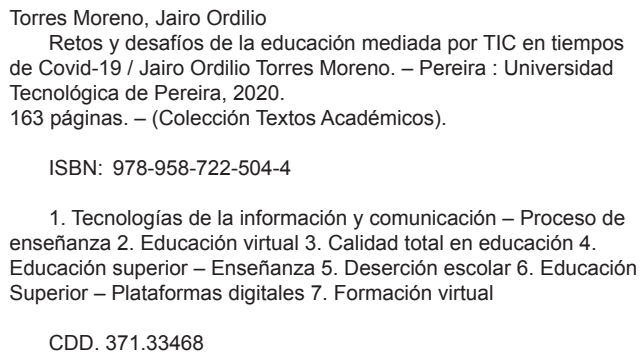

RETOS Y DESAFIOS DE LA EDUCACIÓN MEDIADA POR TIC EN TIEMPOS DE COVID-19

(C) Jairo Ordilio Torres Moreno

(C) Universidad Tecnológica de Pereira

eISBN: 978-958-722-504-4

Imágen de Cubierta:Tomado de https:/image.freepik.com/foto-gratis/alumnos-haciendotareas-parque_53876-42624.jpg

Universidad Tecnológica de Pereira

Vicerrectoría de Investigaciones, Innovación y Extensión

Editorial Universidad Tecnológica de Pereira

Pereira, Colombia

\section{Coordinador editorial:}

Luis Miguel Vargas Valencia

luismvargas@utp.edu.co

Teléfono 3137381

Edificio 9, Biblioteca Central "Jorge Roa Martínez"

Cra. 27 No. 10-02 Los Álamos, Pereira, Colombia

www.utp.edu.co

\section{Montaje y producción:}

María Alejandra Henao Jiménez

Universidad Tecnológica de Pereira

Pereira 


\section{CONTENIDO}

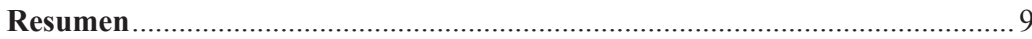

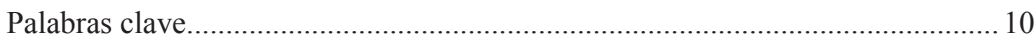

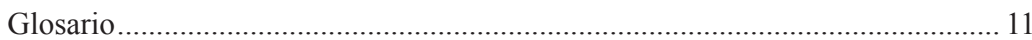

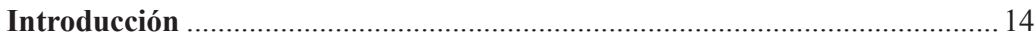

1. La Educación y las Tecnologías de Información y las Comunicaciones .......... 15

1.1 Teoría General sobre la educación y la administración de IES ............... 15

1.2 Contexto de la educación en Colombia ...................................................... 24

1.3 Marco normativo de la educación en Colombia........................................ 35

1.4 Marco referencial de las TIC en el campo de la educación......................37

2. Desarrollo y Fundamentación de la Monografía ................................................42

2.1 Ámbito de las TIC en la Educación Superior .......................................... 43

2.2 Uso y apropiación de las TIC en Colombia.............................................51

2.3 Situación actual y Retos de la Educación Superior mediada

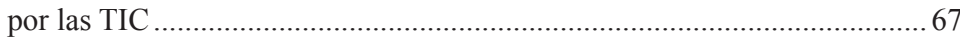

2.3.1 Situación actual de las Instituciones de Educación Superior en Colombia.

2.3.2 Evaluación Educación mediada por TIC en tiempos de Covid-19 Universidad Libre de Pereira y Escuela Superior de Administración Pública ESAP -Quindío Risaralda-

2.3.2.1Evaluación Educación mediada por TIC Universidad Libre de Pereira................................................................................. 95

2.3.2.2Evaluación Educación mediada por TIC Escuela Superior de Administración Pública ESAP Territorial Quindío Risaralda...... 113 2.3.3 Retos y desafíos de las Instituciones de Educación Superior para integración de las TIC en Programas educativos.

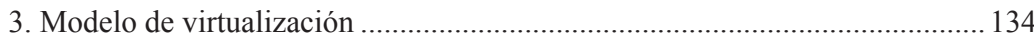

3.1 Caso práctico de virtualización de asignaturas en la UTP..................... 134

3.2 Plan de estudio académico asignatura Formulación y Evaluación de Proyectos................................................................................... 145

3.3 Cobertura asignatura Formulación y Evaluación de Proyectos

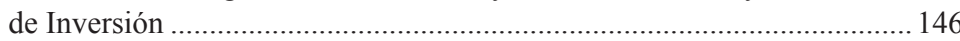

3.4 Plataforma tecnológica - univirtual.utp.edu.co ................................... 147

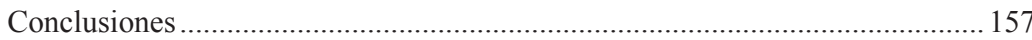

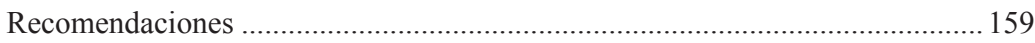

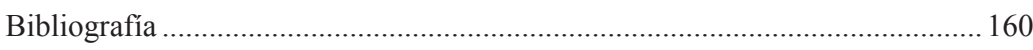

\section{Lista de gráficas}

Gráfica 1. Puntaje de pruebas PISA (2015-2018) ................................................. 31

Gráfica 2. Beneficios del uso de las TIC.................................................................. 51

Gráfica 3. Las TIC y el trabajo colaborativo ............................................................. 52

Gráfica 4. Actividades realizadas en Internet........................................................ 52 
Gráfica 5. Aplicaciones descargadas de Internet....................................................... 53

Gráfica 6. Frecuencia de acceso a redes sociales.................................................... 53

Gráfica 7. Uso de plataformas más frecuentes ........................................................ 54

Gráfica 8. Adquisición del conocimiento para uso de internet 54

Gráfica 9. Inserción de nuevas tecnologías como aporte a la cultura 55

Gráfica 10. Teléfono móvil propio .......................................................................... 55

Gráfica 11. Relación de estudiantes por terminales por departamento $\quad 60$

Gráfica 12. Índice Global de Competitividad ...................................................... 61

Gráfica 13. Entornos virtuales utilizados por estudiantes en la educación 63

Gráfica 14. Entornos virtuales utilizados por docentes en la educación: $\quad 64$

Gráfica 15. Opinión de docentes sobre el uso de las TIC en la educación $\quad 64$

Gráfica 16. Opinión de profesionales sobre el uso de las TIC en la educación 65

Gráfica 17. Estrategias aplicadas para la enseñanza según opinión de

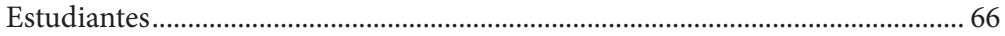

Gráfica 18. Métodos utilizados para la formación en proyectos según opinión

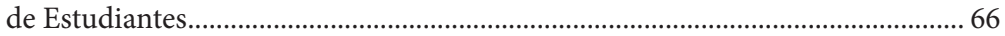

Gráfica 19. Métodos con aprendizajes significativos según opinión de

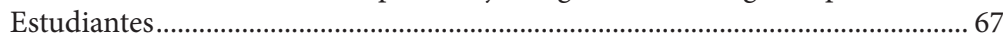

Gráfica 20. Tasa bruta de cobertura de la educación superior (2009-2014) 69

Gráfica 21. Matrícula en instituciones de educación superior según nivel de

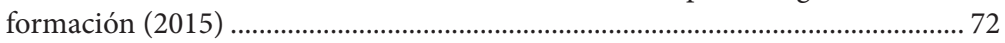

Gráfica 22. Deserción por nivel de formación académica (2015) 77

Gráfica 23. Estudiantes y docentes afecados en el mundo por cuenta del

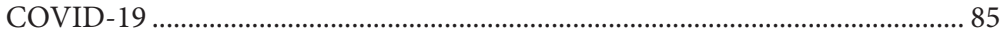

Gráfica 24. Estado de la conectividad por regiones del mundo 86

Grafica 25. Matrícula primer curso en pregrado en IES....................................... 87

Grafica 26. Matrícula en programas académicos presenciales en IE $\quad 88$

Grafica 27. Matrícula en programas académicos virtuales en IES 89

Gráfica 28. Rango de edad estudiantes................................................................. 96

Gráfica 29. Género de estudiantes ...............................................................................96

Gráfica 30. Dispositivos electrónicos usados ...................................................... 96

Gráfica 31. Nivel de conectividad ...............................................................................97

Gráfica 32. Accesibilidad al entorno virtual ........................................................ 98

Gráfica 33. Entorno virtual de aprendizaje.......................................................... 99

Gráfica 34. Herramientas Tecnológicas (Plataforma Teams) 99

Gráfica 35. Nivel de uso y apropiación de las TIC............................................... 100

Gráfica 36. Plan de contingencia para atender problemas técnicos 101

Gráfica 37. Habilidades, conocimientos y actitudes de docentes en la

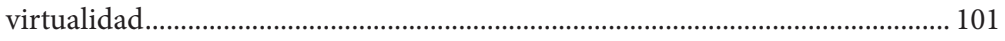

Gráfica 38. Grado de satisfacción de estudiantes con plataforma

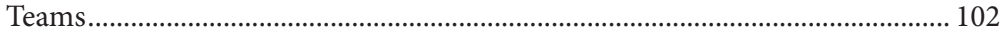

Gráfica 39. Aceptación del curso en plataforma virtual (Temas) 102

Gráfica 40. Aceptación del programa en plataforma virtual

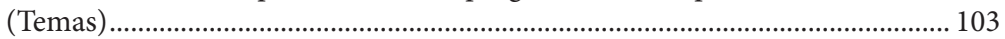

Gráfica 41. Oportunidades de mejora para el programa con mediación de

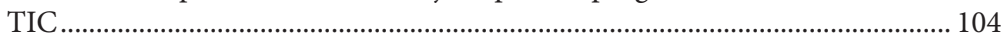

Gráfica 42. Requerimientos prioritarios de estudiantes para continuar el programa 
Gráfica 43. Preferencias sobre modalidad de educación 105

Gráfica 44. Contribución de las TIC a la calidad de la educación 106

Gráfico 45. Objetivos de la asignatura................................................................. 107

Gráfica 46. Correspondencia de contenidos con objetivos de la

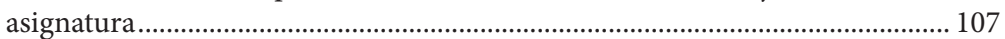

Gráfica 47. Medios de publicación de Contenidos de la asignatura 108

Gráfica 48. Coherencia de las actividades con objetivos de la

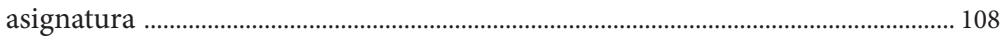

Gráfica 49. Motivación de Docentes para participación de estudiantes en

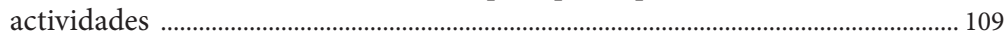

Gráfica 50. Fomento del trabajo individual y colaborativo 110

Gráfica 51. Cantidad de actividades con relación al tiempo

disponible ................................................................................................................. 110

Gráfica 52. Contribución de los conocimientos a la formación integral del

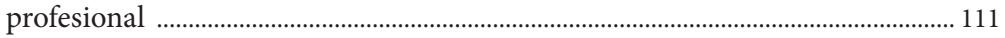

Gráfica 53. Transferencia de conocimientos al ámbito laboral 112

Gráfica 54. Criterios para evaluación de las actividades 112

Gráfica 55. Correspondencia de la evaluación con los objetivos del

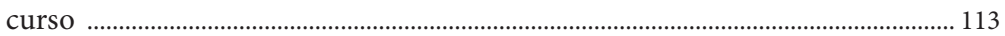

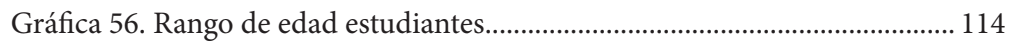

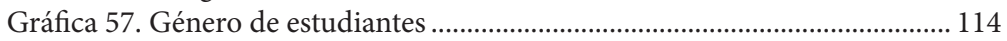

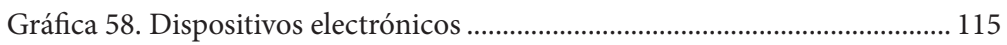

Gráfica 59. Nivel de la conectividad ..................................................................... 116

Gráfica 60. Accesibilidad al entorno virtual ........................................................... 116

Gráfica 61. Entorno virtual de aprendizaje......................................................... 117

Gráfica 62. Herramientas Tecnológicas (Plataforma Teams) 117

Gráfica 63. Nivel de uso y apropiación de TIC ................................................... 118

Gráfica 64. Plan de contingencia para atender problemas técnicos $\quad 119$

Gráfica 65. Habilidades, conocimientos y actitudes de los docentes en la

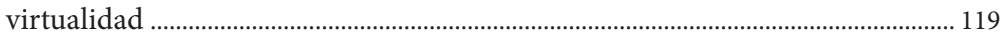

Gráfica 66. Grado de satisfacción de estudiantes en clases asistidas en

plataforma Teams................................................................................................ 120

Gráfica 67. Viabilidad para continuar el curso mediante plataforma

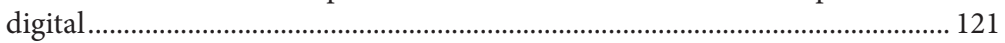

Gráfica 68. Continuación del programa con clases mediadas por plataformas

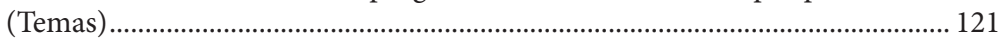

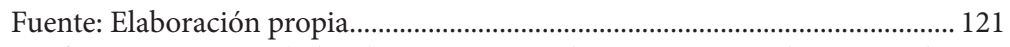

Gráfica 69. Oportunidades de mejora para el programa con clases asistidas

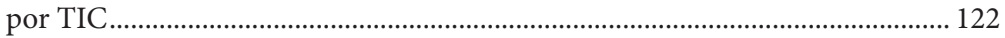

Gráfica 70. Requerimientos prioritarios de estudiantes para continuar en el

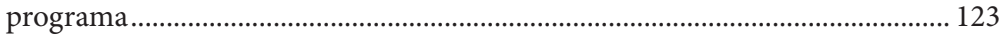

Gráfica 71. Preferencias de estudiantes sobre modalidad de

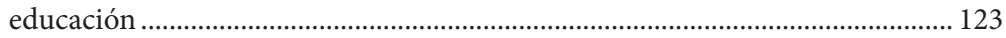

Gráfica 72. Las TIC, entornos virtuales y calidad de la educación 124

Gráfica 73. Objetivos de las asignaturas ................................................................... 125

Gráfica 74. Correspondencia de los contenidos con objetivos de las

asignaturas ................................................................................................................... 125

Gráfica 75. Coherencia de las actividades con los objetivos de las 
asignaturas

Gráfica 76. Docentes promoviendo participación de estudiantes en actividades

Gráfica 77. Fomento de trabajo individual y colaborativo para la enseñanza y

aprendizaje.

Gráfica 78. Cantidad de actividades con relación al tiempo disponible de

estudiantes

Gráfica 79. Contribución de los conocimientos a la formación integral del

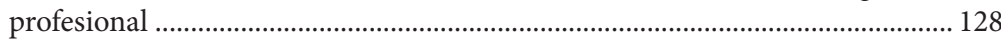

Gráfica 80. Transferencia de conocimientos al ámbito laboral 129

Gráfica 81. Criterios para evaluación de las actividades..................................... 129

Gráfica 82. Correspondencia de la evaluación con objetivos del

curso

\section{Lista de Tablas}

Tabla 1. Matrícula y tasa bruta de cobertura educación superior a nivel de pregrado

Tabla 2. Tasa bruta de cobertura de la educación superior $\quad 70$

Fuente: Universidad de los Andes. La educación superior en Colombia, 201870

Tabla 3. Instituciones de educación superior ......................................................... 71

Tabla 4. Matrículas universidades públicas a nivel de pregrado profesional 73

Tabla 5. Matrículas en las universidades privadas a nivel de pregrado

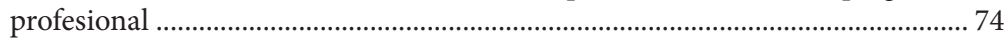

Tabla 6. Deserción anual por área de conocimiento y nivel de formación

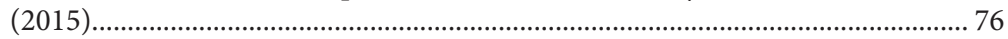

Tabla 7. Deserción por cohorte por área del conocimiento (2015) 77

Tabla 8. Docentes e educación superior................................................................. 79

Tabla 9. Gasto del Estado en educación superior (porcentaje del PIB) $\quad 80$

Tabla 10. Resultados de las pruebas genéricas Saber Pro (2012) 80

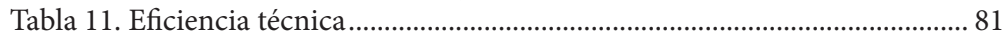

Tabla 12. Contenidos de la asignatura................................................................. 143

\section{Lista de figuras}

Figura 1. Fases del proceso de enseñanza y aprendizaje...................................... 137

Figura 2. Diseño Instruccional -Taxonomía de Bloom-...................................... 139

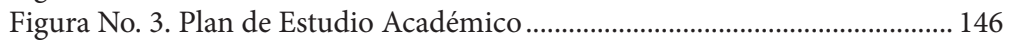

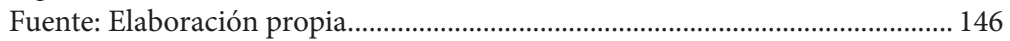

\section{Lista de imágenes}

Imagen 1: Ingreso a la plataforma virtual .......................................................... 148

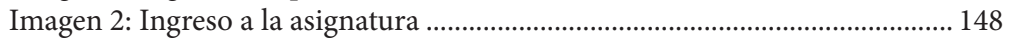

Imagen 3: Ingreso a los cursos asignados .......................................................... 148

Imagen 4: Ingreso al tablero para programación de tareas y

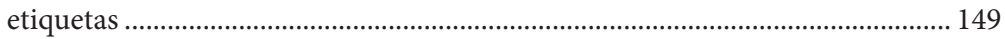

Imagen 5: Ingreso al salón virtual para programar encuentros sincrónicos. 
Imagen 6: Ingreso al módulo I Fundamentación y Formulación del Proyecto.

Imagen 7: Ingreso a los contenidos de la Lección 1 La Planeación y los Proyectos - Módulo 1 .

Imagen8: Ingreso a los contenidos de la Lección 2 El cíclo del proyecto -

Módulo 1

Imagen 9: Ingreso a los contenidos de la Lección 3 El Marco Lógico - Módulo 1 ......

Imagen 10: Ingreso al Módulo 2 Estudios de Factibilidad del

Proyecto.

Imagen 11: Ingreso a los contenidos de la Lección 1 Estudio de Mercado

Módulo 2

Imagen 12: Ingreso a los contenidos de la Lección 2 Estudio Técnico y Organizacional - Módulo 2

Imagen 13: Ingreso a los contenidos de la Lección 3 Estudio Económico y

Financiero - Módulo 2

Imagen 14: Ingreso al Módulo 3 El Sistema Financiero y Fuentes de Financiación

Imagen 15: Ingreso a los contenidos la Lección 1 El Sistema Financiero -

Módulo 3

Imagen 16: Ingreso al Módulo 4 Evaluación del Impacto Ambiental y Social

del Proyecto

Imagen 17: Ingreso a los contenidos de la Lección 1 Evaluación Social -

Módulo 4.

Imagen 18: Ingreso a los contenidos de la Lección 1 Evaluación Social -

Módulo 4

Imagen 19: Ingreso a los contenidos de la Lección 2 Evaluación Ambiental -

Módulo 4

Imagen 20: Ingreso a Consolidación del Proyecto final 



\section{Resumen}

El presente trabajo está orientado a estudiar los efectos ocasionados por la emergencia del COVID-19, en las Instituciones de Educación Superior y destacar la importancia del uso de las Tecnologías de la Información y las Comunicaciones -TIC- tanto en el campo de la educación, como para las diferentes actividades, administrativas, empresariales y sociales. El estudio resalta que, a pesar dela contribución que las TIC pueden hacer para el desarrollo económico y social y ambiental, todavía se tienen grandes brechas en el país en conectividad, uso y apropiación de las Tecnologías Información y las Comunicaciones, especialmente, en el ámbito de la educación.

En las circunstancias actuales, ha quedado demostrado que los métodos tradicionales de formación en las Instituciones de Educación Superior no han permitido la apropiación de las TIC en los procesos de enseñanza y aprendizaje, lo cual se convierte en un gran desafío para diseñar e implementar estrategias orientadas a 
mejorar la capacidad instalada, integrando equipos tecnológicos, infraestructura, plataformas y herramientas virtuales que permitan hacerle frente a las exigencias de la educación del siglo XXI, a través de entornos virtuales que garanticen la calidad, accesibilidad y la flexibilidad.

Si bien, el fenómeno COVID-19 ha mostrado las debilidades que se tienen en materia del uso de las TIC, también es cierto, que este fenómeno ha dejado planteadas grandes oportunidades para una transformación en la implementación de métodos, herramientas y recursos que pueden contribuir eficientemente a una educación de calidad incluyente, para mantener y mejorar indicadores de cobertura (número de matriculados), número de instituciones y programas, nivel de formación de docentes, las tasas de deserción, la financiación de las instituciones educativas, los resultados de logro académico y la eficiencia en el manejo de recursos.

La metodología usada en el estudio de investigación tuvo un enfoque cualitativo y cuantitativo, ya que los resultados permitieron hacer interpretaciones y análisis sobre valores cuantificables, de calidad y pertinencia sobre la educación mediada por TIC. Esta investigación fue de tipo descriptiva-explicativa, con análisis correlacional multivariado.

Palabras clave: TIC, educación, entornos virtuales, enseñanza-aprendizaje, calidad, cobertura, deserción, accesibilidad, flexibilidad, modelo pedagógico, PEI, virtualidad, conectividad, contenidos, currículo, didáctica, plataforma, brecha digital, COVID-19 


\section{Glosario}

Formación y Aprendizaje: conjunto de características pedagógicas y cognitivas $y$, las distintas maneras en que un individuo puede aprender. Se refiere a los medios y recursos que se disponen para orientar los procesos de enseñanza hacia una la educación.

- Competencias: forma de saber y hacer en determinados contextos y ámbitos; son las capacidades, los conocimientos, habilidades y pensamientos, que le generan capacidades a las personas para desempeñarse de manera eficiente.

- Tecnologías de la información y las comunicaciones (TIC): TIC el conjunto de recursos, herramientas, equipos, programas informáticos, aplicaciones, redes y medios, que permiten la compilación, procesamiento, almacenamiento, transmisión de información, como voz, datos, texto, video e imágenes. 
Didáctica: disciplina científico-pedagógica que tiene como objeto de estudio los procesos y métodos de enseñanza.

- Ambientes virtuales: espacio intangible que permite la interacción a distancia de varios usuariospor medio de computadoras, Smartphone, Tablet utilizando diferentes redes sociales, a través del internet.

- Innovación: se refiere a un cambio que introduce novedades en la implementación de nuevos productos o servicios.

b-Learning: modelo que trata de recoger las ventajas del modelo virtual tratando de evitar sus inconvenientes, aprovecha la importancia del grupo, el ritmo de aprendizaje y el contacto directo con el profesor de la enseñanza presencial, pero trata de desarrollar en los alumnos la capacidad de auto organizarse, habilidades para la comunicación escrita, y estilos de aprendizaje autónomo.

- e-learning: modelo que permite llevar la formación fuera de las aulas, permitiendo al alumno aprender también fuera de las mismas.

Mobile learning o m-learning (aprendizaje móvil): Modelo de aprendizaje a través de dispositivos móviles (Smartphone, PDA, computadora portátil, Tablet) concebido como un acceso a programas formativos desde dispositivos móviles sin cables, o aprendizaje en contextos, en donde el centro de atención es la movilidad de los aprendices, interactuando con tecnología portátil o fija.

- CNA: Consejo Nacional de Acreditación, órgano responsable de verificar el cumplimiento de requisitos para la acreditación de las Instituciones de Educación Superior y la certificación internacional de programas educativos. 
- CESU: Consejo Nacional de Educación Superior, órgano responsable de establecer el modelo y las políticas de acreditación de alta calidad.

- PISA: pruebas internacionales que miden los resultados de las buenas prácticas docentes y el aprendizaje de los estudiantes, sirve para evaluar la funcionalidad del sistema educativo de los países, de educación, salud, agua potable y saneamiento básico. CONPES: Consejo Nacional de Política Económica y Social, es la máxima autoridad nacional de planeación y organismo asesor del Gobierno en todos los aspectos relacionados con el desarrollo económico, social y ambiental del país. En el ámbito social, para este estudio se resaltan las políticas orientadas a mejorar la calidad de la educación en Colombia.

COVID-19: es el nombre dado a la patología causada por la infección por el Coronavirus del Síndrome Respiratorio Agudo Severo o Grave. La enfermedad es causada por un virus (SARS).

- Eficiencia: capacidad de lograr un resultado o efecto con el mínimo de recursos y en el menor tiempo posible.

- Eficacia: nivel de consecución de metas y objetivos, es decir, la capacidad de lograr lo presupuestado con la óptima utilización de los recursos.

- Competitividad: capacidad de las instituciones y empresas para diseñar, desarrollar, producir bienes y servicios en condiciones adecuadas para hacerle frente a la competencia del mercado.

-Contenidos curriculares: estrategias y procesos que implican una secuencia de acciones para lograr habilidades y destrezas intelectuales. Los contenidos curriculares definen la fundamentación y el énfasis de los programas, para garantizar el perfil del profesional en las diferentes disciplinas. 


\section{Introducción}

Este trabajo fue orientado a indagar cómo es el estado de la educación mediada por las TIC en Colombia y, a su vez, cuáles son los retos y desafíos que, a manera de oportunidades, se tienen a partir de esta coyuntura de emergencia decretada por el Gobierno Nacional por efectos del COVID-19. Esta pandemia, indudablemente, obliga a las instituciones de educación superior a reinventar sus modelos y métodos de formación, procurando la integración de los entornos virtuales a partir del uso y apropiación de las Tecnologías de Información y Comunicaciones.

El trabajo comprende un abordaje desde las teorías de la educación traídas al contexto de nuestro país con su marco normativo, pasando por un marco referencial de cómo las TIC se han integrado al modelo de formación. Luego, hace un recorrido por el ámbito de las TIC en los procesos de formación en Colombia, indagando sobre el nivel de uso y apropiación de las herramientas y en tornos virtuales en la enseñanza y aprendizaje. 
A partir de este estado del arte, se hace una aproximación sobre los retos y desafíos de la educación mediada por las TIC, que obligará a revisar los proyectos educativos Institucionales (PEI) para ajustar programas y currículos en las instituciones de educación superior que respondan a las exigencias de la educación del siglo XXI.

Así mismo, se presentan los resultados de un ejercicio piloto de evaluación de la educación mediada por plataformas digitales en la Universidad Libre de Pereira y la Escuela Superior de Administración Pública ESAP Territorial Quindío Risaralda, en el primer semestre de 2020-1 en tiempos de COVID-19. Adicionalmente, se presenta un modelo de virtualización de la asignatura Formulación y Evaluación de Proyectos de Inversión implementado en la Universidad Tecnológica de Pereira como una buena práctica con excelentes resultados, que puede ser replicado en otras universidades.

\section{La Educación y las Tecnologías de Información y las Comunicaciones (TIC) ${ }^{1}$}

\subsection{Teorías generales sobre la educación y la Administración ${ }^{2}$}

Las teorías educativas se remontan hasta la época de Sócrates, Platón y Aristóteles (García Santos, 2017)

Según Sócrates (470 a.C. - id., 399 a.C.), la ciencia siempre tiene una incidencia ética al crear un espacio para el hombre, en el cual éste se conocerá y obrará en consecuencia, la ética y la ciencia no solo son complementarias, sino que además tienen un punto en común que las hace solidarias, esto es, las nociones universales. La pedagogía socrática planteaba que la ética es tanto

1 Importancia de las TIC en los procesos de enseñanza-aprendizaje. Universidad Sergio Arboleda, 2019, pág. 97 y 163. Repository.usergioarboleda.edu.co: https://repository.usergioarboleda. edu.co/handle/11232/1335

2 Espacio el Latinocom. Teorías de la educación, Zoila Libertad García Santos, 2017, pág. 5-20 
más personal cuanto más cerca está de lo universal, el hombre no puede conocerse a sí mismo, no puede ser auto consciente, sin conocer con precisión, con el rigor de la ciencia, el mundo y la sociedad que lo rodea. Por lo tanto, Sócrates confronta con preguntas y respuestas al hombre con su ignorancia, para forzarlo a saber. Este método impone la necesidad de un conocimiento científico de las cosas, a este autor se le conoce por su frase célebre "Solo sé, que nada sé".

Por su parte, Platón (c. 427-347 a. C.) es considerado uno de los pilares de la filosofía occidental que más ha influido en la educación y el pensamiento moderno dedicó su vida a la enseñanza, pero en ningún momento dejo de lado su vocación política y literaria. La teoría clásica en educación se puede considerar a través del modelo liberal, basado en La República de Platón, donde se plantea un proceso disciplinado y exigente, un currículo donde las materias se presentan en una secuencia lógica y coherente para lograr el aprendizaje. Así mismo, destacó Platón, que la educación puede definirse como el proceso de socialización de los individuos, ya que, al educarnos, somos capaces de asimilar y aprender conocimientos. Este pensador también sostiene que

todas las capacidades intelectuales del hombre radican en el alma, pero estas no brotan ni se mueven por agentes exteriores, sino por esfuerzos interiores generados por la razón. La ciencia no reside en las sensaciones sino en el razonamiento sobre las sensaciones, puesto que solo por el razonamiento puede describirse la ciencia y la verdad y es imposible conseguirlo.

Platón habló de la "mayéutica", que consiste en sacar del alma los conocimientos guardados, induce a la búsqueda de la verdad mediante la reflexión, no permite la transmisión de saberes construidos por otros en la memoria de los alumnos y purifica lo negativo de la mente del hombre. Sostuvo así mismo, que la dialéctica es el instrumento del conocimiento del bien, es el método del saber supremo, es el medio para acceder a la verdad y 
la sabiduría es el uso de la razón, lo cual sucede cuando la razón se apodera del alma. En el diálogo de la templanza Platón dice: "la sabiduría y el ser sabio consiste, no en saber lo que sabe y lo que no sabe, sino sólo qué se sabe y qué no se sabe" (2001a: 124).

También sostiene Platón que la educación es el proceso que le permite al hombre tomar conciencia de la existencia de otra realidad, y más plena, a la que está llamado, de la que procede y hacia la que dirige. Por tanto, "la educación es la desalineación, la ciencia es liberación y la filosofía es alumbramiento" y que "cuando la razón se apodera del alma se llega a la sabiduría" (Platón, 2001a: 175).

Aristóteles (384 a. C.-Calcis, 322 a. C.) fue reconocido durante siglos como el filósofo y científico por excelencia, nos enseñó a pensar $y$, la forma de divulgar sus pensamientos fue muy similar a la de Platón, es decir, por medio de diálogos y razonamientos. La educación busca como objetivo pensar en libertad, puesto que es una condición para la realización del ser humano, un ingrediente esencial de la vida que singulariza a nuestra especie y se traduce en el deseo de conocer y simbolizar (Victor Gómez Pin, 2016); solía afirmar que la educación nunca termina pues es un proceso de perfeccionamiento $y$, por lo tanto, dicho proceso dura toda la vida de la persona. Realizó muchos estudios de la naturaleza tales como física, metafísica, ética, política, lógica, matemáticas, biología, retórica y poética, que resultaron fundamentales en la evolución del pensamiento humano, por ello, se le consideró realista. Aristóteles afirma que se requiere un salto intuitivo final para alcanzar la conclusión apropiada, esto es, por lo que denomina el acto de la "razón intuitiva", por ello, una de las tareas fundamentales del maestro, es proporcionar al estudiante las experiencias concretas necesarias para realizar ese juicio reflexivo final que conduce al conocimiento definitivo. Aristóteles dividió el desarrollo educativo en cinco etapas: la primera etapa de la infancia se caracteriza por los movimientos corporales, en la 
segunda etapa adquiere habilidades físicas y los juegos, la tercera etapa es de imitación, la cuarta y quinta etapa (21 años) es de la educación

Las teorías que tratan los procesos de adquisición del conocimiento han tenido durante este último siglo un gran desarrollo debido a los avances de la psicología y las teorías instruccionales que han tratado de sistematizar los mecanismos asociados a los procesos mentales que hacen posible el aprendizaje. Entre estas corrientes de pensamiento se destacan teorías de reconocidos autores contemporáneos en materia de educación y pedagogía del aprendizaje sustentadas en el conductismo y el cognitivismo. Entre estos se encuentran, por un lado, John B. Watson (1878-1958) y Edward Lee Thorndike, ambos precursores del conductismo y defensores del empleo de procedimientos estrictamente experimentales para estudiar el comportamiento observable (la conducta) y de la teoría del conexionismo, a saber, la existencia de una serie de conexiones entre un estímulo y una respuesta (ley del efecto) .

En el ámbito de la educación, luego aparecen otras teorías asociadas a los procesos mentales que hacen posible el aprendizaje a partir de la psicopedagogía, entre estas tenemos las Teorías Cognitivas y las teorías del Constructivismo pedagógico. En este nuevo paradigma de la psicopedagogía se eligió un lema "Aprender a Aprender" como única guía fiable en una sociedad donde el conocimiento se creaba, acumulaba y renovaba continuamente, aquí el profesor debía guiar al estudiante a través de preguntas y otros retos, motivando situaciones concretas para convertir al estudiante en el constructor de su propio aprendizaje (Serramona, 1997), para que el conocimiento fuera el resultado directo de una construcción individual desarrollada en un proceso interior.

En las Teorías Cognitivas, el término Cognitivo hace referencia a actividades intelectuales internas como la percepción, interpretación y pensamiento, entre estos precursores se destacan 
Botella y Feixas (1998) quienes explican que la psicología cognitiva representó una reacción a la inadecuación de los modelos conductistas de estímulo-respuesta. La teoría cognitiva del aprendizaje propuesta por David Ausubel (1976) se centra en el aprendizaje que se produce en un contexto educativo en donde predominan los procesos de instrucción, esto es, los procesos de enseñanza-aprendizaje de conceptos científicos a partir de los conceptos formados en la vida cotidiana. Este autor establece la distinción entre aprendizaje significativo y repetitivo según el vínculo existente entre el nuevo material objeto de interiorización y los conocimientos previos, así como, experiencias anteriores que posee el alumno. Dentro de esta corriente también se encuentra el diseño de la instrucción basado en el conductismo a partir de la taxonomía formulada por Bloom (1956) y Gagné (1985).

Gagné (1987), en su teoría insiste en la primacía del aprendizaje cognitivo, por su aplicabilidad a la enseñanza y ofrece esquemas formales que pueden servir para orientar la práctica y la investigación, sin embargo, concibe el aprendizaje como cambio de conducta y da importancia a los resultados inmediatos, olvidando los resultados definitivos que aparecen después de un largo proceso de aprendizaje; su teoría exige definir los objetivos en términos de conductas observables, de objetivos operativos donde se presenten resultados, procesos y condiciones; presenta 5 tipos de aprendizajes, habilidades intelectuales, estrategias cognitivas, información verbal, destrezas motoras y actitudes, su teoría pretende ofrecer fundamentos que guíen al profesor en la planificación de su instrucción. Para Gagné, aprendizaje e instrucción, son dos dimensiones de una misma teoría pues ambas, se pueden estudiar conjuntamente, trata de proporcionar pautas de trabajo para la selección y ordenación de los contenidos y las estrategias de enseñanza para los diseñadores de programas. El fundamento básico de la teoría es que para lograr ciertos resultados de aprendizaje es preciso conocer: a) las condiciones internas que intervienen en el proceso $\mathrm{y}$ b) las condiciones externas que favorecen el aprendizaje óptimo. 
Sobre las teorías del Constructivismo pedagógico, que parten de la postura de una determinada interpretación sobre cómo se conoce y cómo se aprende para disponer las condiciones y diseñar los ambientes que sean necesarios al fomento del aprendizaje. El constructivismo es una respuesta a los problemas del ser humano ante el volumen de información y medios electrónicos que facilitan y promueven la comunicación, haciendo énfasis en la búsqueda epistemológica sobre cómo se conoce la realidad y como se aprende, esto es, el origen y desarrollo del conocimiento y la cultura; los principales exponentes de estas teorías fueron Piaget (1980) y Vygotsky (2009) ${ }^{3}$, quienes son precursores de lo que hoy se denomina psicología cognitiva y también constructivistas en tanto son precursores de estas teorías contemporáneas

Por su parte, Piaget (1896-1980), autor de la teoría del desarrollo cognoscitivo, se fundamentó en la naturaleza y el desarrollo de la inteligencia humana, planteó que la infancia del individuo juega un papel vital y activo con el crecimiento de la inteligencia y que el niño aprende a través de hacer y explorar activamente, así mismo, fue reconocido mundialmente por su trabajo en psicología evolutiva ya que descubrió que existen diferentes estadios de desarrollo cognitivo en los niños como son: sensorio-motor (de 1 a 5 años), preoperatorio (de 2 a 7 años), operaciones concretas concretar (de 7 a 11 años) y operaciones formales (de 12 años en adelante). Su trabajo ha permitido conocer el desarrollo del conocimiento del niño y del adolescente y reconoce la importancia del afecto y la emoción en la conformación de la personalidad y el desarrollo cognoscitivo. La explicación de la interacción entre sujeto y ambiente a través de los procesos de adaptación y acomodación de los individuos al objeto, así como los de asimilación (modificación o construcción) del objeto tienen particular importancia para la organización de contenidos, el diseño y utilización de materiales en el aula.

3 Sulle, Adriana; Bur, Ricardo; Stasiejko, Halina y Celotto, Ileana (2014), Lev Vigotsky, narrativas y construcción de interpretaciones acerca de su biografía y su legado. Anuario de Investigaciones, XXI, 193-199. 
Por otra parte, Vygotsky (1896-1924) se basa en el aprendizaje sociocultural de cada individuo y en el medio en el cual se desarrolla; así, el aprendizaje se logra en una interacción en el que influyen mediadores que guían a las personas a desarrollar sus capacidades cognitivas (esto se denominó la zona de desarrollo próximo), destacó en su obra la importancia del entorno en el desarrollo de los niños, considerando al medio social como pieza clave en el proceso de aprendizaje, destacó también que la actividad social permite explicar los cambios en la conciencia de los alumnos, oponiéndose con éste planteamiento a la teoría de Piaget. La teoría histórico cultural presentada por Vygotsky señala su concepción acerca del desarrollo de las funciones psíquicas superiores del hombre, fue “...el primer intento sistemático de reestructuración de la psicología sobre la base de un enfoque histórico acerca de la psiquis del hombre, el concepto clave es la zona de desarrollo próximo (ZDP), (Vygotsky, 1977,1979) que sirve de puente entre la importancia de la interacción social y el desarrollo psicológico individual, esta zona representa la distancia entre lo que el niño realiza independientemente y por sí mismo (nivel actual de desarrollo) y a dónde puede llegar con la ayuda de adulos o compañeros (nivel de desarrollo próximo).

En esta misma línea se encuentra Celestin Freinet (18961966) creador de la escuela nueva proponiendo una pedagogía vinculada de forma directa a los intereses de los niños, colocándolos en un rol activo. Esta escuela tiene una pedagogía única que vincula la escuela con el medio social; este fue también creador de actividades artísticas de motivación y expresión

Desde otros ámbitos, Ovide Decroly (1871-1932) introdujo la relación que existe entre globalización e intereses, centrando sus estudios en el análisis de la percepción infantil, esto es, a partir de los intereses de los niños, explica los procedimientos de captación de la realidad de los mismos, que se dan a través de las totalidades $y$, concluye que es necesario aplicar métodos educativos que estén en sintonía con la forma de percibir el mundo de los individuos 
Dentro de los modelos pedagógicos de enseñanza-aprendizaje se identifican el constructivismo y el aprendizaje significativo (cuyos exponentes tradicionales son Jerrold Zacharias, Jerrold R. Zacharias, Alexander Sutherland Neill, Skinner y Anton Makarenko) fundamentado en la didáctica. Jean-Jacques Rousseau (1712-1778) aparece con su teoría "progresista" que trata de ayudar al alumno en su proceso educativo de forma que éste sea percibido como un proceso "natural", estas teorías tienen su origen en el desarrollo de las ideas sociales, afirmó así mismo, que la educación es una forma de dominio social, es decir, que unos se imponen sobre otros mediante el conocimiento. Arruada Penteado (1982) definió la didáctica como un conjunto de métodos, técnicas o procedimientos que procuran guiar, orientar, dirigir e instrumentar con eficacia y economía el proceso de aprendizaje.

18

Paulo Freire (1921-1997) ${ }^{4}$ es creador de una pedagogía donde los individuos se forman a través de situaciones de la vida cotidiana, en ella se plantean dos momentos: en el primer momento el individuo deberá tomar conciencia de la realidad en la que vive como sujeto de opresión; en un segundo momento, los oprimidos lucharán contra los opresores para liberarse. Este planteó la pedagogía del oprimido (Freire-1974), que es aquella que se elabora desde y por el oprimido para que tenga la oportunidad de descubrirse y reconquistarse en forma reflexiva, como sujeto de su propio destino histórico comprometido con la historia, para que de esa manera se transforme la realidad en que se vive y enseguida esta pedagogía pase a ser la de los hombres en proceso de permanente liberación, permanente búsqueda de sí mismos y permanente conquista de su realidad. En esta misma línea Mario Kaplún (2002), apoyado en las formas de apropiación de la realidad de Freire, plantea algunas ideas para conocer la

4 García Hoz, V. La educación liberadora según Paulo Freire, Rev. Esp. De Pedag. 1974, Págs. 171-174 
concepción de la educación que se origina en las prácticas de nuestra comunicación, y, propone dos modelos conductistas y un tercero donde plantea la posibilidad de revalorar el proceso de crecimiento individual en el trabajo colectivo.

En otro contexto, dado que las Instituciones de Educación Superior (IES) en procura de la calidad y el cumplimiento de la misión fundamentada en la docencia, investigación y proyección social (extensión) deben tener un estamento administrativo que garantice el uso eficiente de los recursos, lo cual está en concordancia con los factores 11 y 12 para la evaluación de alta calidad de los programas académicos (organización, administración y financiación del programa académico, y, recursos físicos y tecnológicos) por lo que cobra importancia revisar las teorías administrativas que se han destacado. En este contexto, para comprender los fenómenos de las organizaciones, se consultaron teorías organizacionales con énfasis en procesos y funciones, teorías administrativas que tratan de las relaciones humanas y teorías emergentes fundamentadas en los recursos. No obstante, este trabajo enfatizó en las teorías de los mandos superiores debido a su relación con el uso eficiente y eficaz de los recursos.

En el campo de las teorías organizacionales se destacan Frederick Taylor (1856-1915), con su estudio sobre los procesos, y Henry Fayol (1841-1925), con su idea de la estructura y funciones en su obra Administratión industrielle et genérale. Este también enfatizó en las relaciones sociales y destacó el reconocimiento y la motivación como los factores sociales y psicológicos más importantes para la productividad en el trabajo. Respecto a las teorías administrativas se trabajó con Elton Mayo (1880-1949) y Abraham Maslow (1908-1970), quienes fundamentaron sus estudios en las relaciones humanas dando origen a la escuela humanística de administración, la cual resalta los sentimientos, las actitudes, la complejidad motivacional y otros aspectos del sujeto relacionados con la productividad. 
En cuanto a las teorías emergentes, se encuentra la teoría de los mandos superiores basada en la alineación de los recursos con las capacidades de la organización y su entorno, cuyos precursores fueron Grant (1991), Barney (1991) y Wernerfelt (1984).

Sobre las tecnologías de información y las comunicaciones se destacan algunas tesis doctorales que han planteado modelos de blended-learning diseñado bajo principios socio constructivistas que orientan el proceso de formación para el trabajo hacia la práctica. Entre estos está el trabajo realizado por Alfonso Bustos Sánchez (2014), para la Universidad Nacional Autónoma de México, Carlos Arturo Vega Lebrún, en su tesis Integración de herramientas tecnológicas de información. Portales colaborativos de trabajo, como soporte en la administración del conocimiento de la Universidad Popular Autónoma del Estado de Puebla, México, 2005.

\subsection{Contexto de la educación en Colombia}

Como antecedentes de la educación en Colombia se pueden describir los siguientes:

La politica educativa del Ministerio de Educación Nacional 2011-2014 tiene como lema "Educación de Calidad, el Camino para la Prosperidad" y busca aportar al desarrollo del capital humano y social del país. Así mismo, el Plan nacional decenal de educación 2006-2016 expone los desafíos que tiene la educación en Colombia, en cuanto a fines y calidad dela educación (globalización y autonomía), para garantizar un sistema educativo articulado y coherente en sus diferentes niveles (incluyendo la educación para el trabajo y el desarrollo humano) y para responder a las exigencias socioeconómicas, políticas, culturales y legales de la sociedad colombiana. Ante este diagnóstico, el plan establece la renovación pedagógica a partir del uso de las TIC en la educación, la ciencia y la tecnología, las que deben estar integradas a la educación y la equidad (acceso, permanencia y calidad). 
Por su parte, el Plan nacional de desarrollo 2014-2018, “Todos por un nuevo país", aprobado por la Ley 1753 de 2015, determinó que la educación es el eje principal sobre el cual se fundamenta el desarrollo de la nación, es decir: la educación de calidad permite a las personas adquirir los conocimientos y las competencias necesarias para participar en actividades productivas y acceder a ingresos y activos que contribuyan a su movilidad social. De esta forma, la educación se convierte en la herramienta más poderosa para promover la equidad y la paz. En este mismo ámbito, el Ministerio de las TIC planteó como iniciativa la propuesta Educación y TIC incluyendo software para interacción (2015), cuyo objetivo es fomentar y promocionar las TIC en la comunidad académica mediante el uso y la apropiación de una plataforma de interacción y comunicación que beneficie a toda la comunidad educativa (padres, alumnos, docentes y directivos). En el Plan Nacional de Desarrollo 2018-2022 "Pacto por Colombia", en el Pacto por la Equidad" define la política social moderna centrada en la familia, eficiente, de calidad y conectada a mercados, uno de sus programas está orientado a la "educación de calidad para un futuro con oportunidades para todos". Aquí, se define la educación como la herramienta más poderosa para promover la movilidad social y para la construcción de equidad.

Esta política de la educación está en armonía con lo planteado por el Plan Decenal de Educación 2016-2026, priorizando en este sentido a la población rural, a fin de cerrar brechas existentes entre el campo y la ciudad. De esta forma, se busca consolidar un sistema educativo cuyo propósito fundamental sea garantizar las condiciones para que las personas alcancen su desarrollo integral y contribuyan al desarrollo del país en términos de equidad, legalidad y emprendimiento, en concordancia con lo establecido por los Objetivos de Desarrollo Sostenible y los compromisos adquiridos con la OCDE. Para lograr esta visión, resulta primordial el diálogo permanente con la ciudadanía y con los grupos de interés en el sector. 
Con lo anterior se busca que todas las instituciones de educación cuenten con la capacidad instalada en condiciones de pertinencia, seguridad, comodidad y accesibilidad, que permita la implementación de las estrategias en torno al mejoramiento de la cobertura y calidad en la educación.

Por su parte, en el programa todos por una educación de calidad contempla en su literal b) "Fortalecimiento de Competencias para la Vida" se reconoce la forma como los estudiantes acceden a la información, se comunican y relacionan ha cambiado de manera importante en las últimas décadas debido a la incorporación de las TIC en la vida moderna. Esto le genera al sector educativo la oportunidad de desarrollar en los estudiantes y docentes las competencias necesarias para usar y aprovechar las tecnologías y nuevos medios en procura de la innovación y la gestión del conocimiento.

En el Objetivo quinto del plan se contempla "Apuesta para impulsar una educación superior incluyente y de calidad" y se definen estrategias para la educación virtual, a través de este objetivo se fomentará la oferta de programas virtuales y a distancia, adecuados a las necesidades poblacionales y territoriales y con condiciones de calidad que tienen como base la expedición de lineamientos por parte del Ministerio de Educación Nacional. De igual forma, con el apoyo del Ministerio de Tecnologías de la Información y las Comunicaciones, se fomentará la oferta de estos programas, así como la creación de espacios de ciencia, tecnología e innovación acordes a las dinámicas internacionales sobre la materia, esto se encuentra también en documentos de apoyo del Departamento Nacional de Planeación (DNP).

Lo anterior es coherente con el informe presentado a la OCDE (2016) sobre la evaluación de la educación y las competencias, pues esto debe entenderse como un sistema integral desde la atención y la educación de la primera infancia hasta la educación superior. 
En este contexto, cada día, las Tecnologías de la Información y las Comunicaciones (TIC) cobran más importancia; por esto, los educadores, pedagogos, estudiantes, profesionales y empresarios deben estar a la vanguardia para el uso y apropiación de estas herramientas. La implementación de entornos virtuales de aprendizaje, así como espacios de interacción para la reflexión, el trabajo colaborativo y la toma de decisiones en tiempo oportuno, hace parte de las estrategias de modernización que es preciso implementar en las instituciones de educación, públicas y privadas, empresas y gremios, conforme a las exigencias de la globalización y las tendencias de los tiempos modernos.

Respecto de la calidad de la educación es importante resaltar que el Ministerio de Educación Nacional desarrolló un proceso de construcción de una visión conjunta de calidad de la educación superior, a través de talleres "Calidad ES de Todos", en los que se evidenció la necesidad no solo de fortalecer el Sistema de Aseguramiento de la Calidad de la Educación Superior, sino también, el Sistema Nacional de Acreditación, con el fin de incentivar la consistencia de la alta calidad desde una perspectiva de diversidad institucional. De otra parte, se destacan también los avances obtenidos con la formulación del Decreto 1330 de 2019 que "adopta los conceptos de calidad y de Sistema de Aseguramiento de la Calidad de la Educación Superior" los cuales señalan una nueva dinámica nacional respecto a la calidad, todo lo anterior fue producto de una reflexión académica y participativa, donde se evaluaron las capacidades y procesos de los programas académicos y las instituciones, así como, los resultados académicos que vinculan el aprendizaje de los estudiantes, para armonizar objetivos y estrategias del registro calificado y de la acreditación, para promover el avance sistemático y coordinado de los esfuerzos de actores que contribuyen al desarrollo de la educación superior.

5 Ministerio de Educación Nacional. Revisión de políticas nacionales de educación, 2016, pág 19-69. 
En este sentido, el Consejo Nacional de Acreditación (CNA) ha estado comprometido con procesos de acreditación y certificación internacional como la certificación expedida por la Internacional Network for Quality Assurance Agncies in Higher Education INQAAHE, renovada en 2017, y en 2019 con la Red Iberoamericana para el Aseguramiento de la Calidad en la Educación Superior - RIACES y que acoge las recomendaciones correspondientes como oportunidades de mejora.

Atendiendo las consideraciones de las instituciones de comunidades académicas y científicas el Consejo Nacional de Educación Superior $(\mathrm{CESU})^{6}$ consideró pertinente actualizar el modelo de acreditación en alta calidad por lo tanto, se expide el Acuerdo No 2 del $1^{\circ}$ de julio de 2020 "Por medio del cual se actualiza el modelo de acreditación en alta calidad", cuyo objetivo es "actualizar el modelo de acreditación en alta calidad para programas académicos e instituciones y promover la alta calidad como atributo necesario de la educación superior, a fin de lograr que estudiantes, profesores, egresados, empleadores, y la sociedad en su conjunto, reconozcan en la acreditación de programas académicos e instituciones una condición distintiva autónoma, nacional e internacional, que atiende el mejoramiento de la calidad de la educación superior, en armonía con las dinámicas sociales, culturales, científicas, tecnológicas y de innovación”. Este acuerdo contempla además los alcances y referentes conceptuales, acreditación de alta calidad, principios y tipos de acreditación, Sistema de Aseguramiento de la Calidad, Sistema Nacional de Acreditación y su articulación, componentes del modelo de acreditación en alta calidad, trámite de acreditación en alta calidad, renovación de la acreditación en alta calidad, situaciones acerca de la acreditación en alta calidad, guías, régimen de transición y vigencia.

6 Consejo Nacional de Educación Superior (CESU). Acuerdo No 2 del $1^{\circ}$ de julio de 2020, '8-58 "Por medio del cual se actualiza el modelo de acreditación en alta calidad". 
Para la acreditación de alta calidad se evalúan factores y características, tales como: proyecto educativo del programa e identidad institucional, estudiantes, profesores, egresados, aspectos académicos y resultados de aprendizaje, permanencia y graduación, interacción con el entorno nacional e internacional, aportes de la investigación, la innovación, el desarrollo tecnológico y la creación, asociados al programa académico, bienestar de la comunidad académica del programa, medios educativos y ambientes de aprendizaje, organización, administración y financiación del programa académico, recursos físicos y tecnológicos

La alta calidad en las Instituciones de Educación Superior se reconoce también, por tener un gobierno que ofrece estabilidad institucional y que se ejerce a través de un sistema de normas, reglamentos y estrategias, dirigidos al servicio de los intereses generales y al cumplimiento de la misión y el proyecto educativo institucional (PEI) bajo criterios de ética, efectividad, calidad, integridad, transparencia, inclusión y participación de los miembros de la comunidad académica. Esto está contemplado en el artículo 20 de éste acuerdo Factor No 2 "Gobierno Institucional y Transparencia”, característica cuatro referida al buen gobierno y máximos órganos de decisión, característica cinco relacionada con grupos de interés y característica seis referido a la rendición de cuentas.

Como autoridades responsables de los procesos para el aseguramiento de la calidad se encuentran el Sistema Nacional de Acreditación cuyo objetivo es garantizar que las IES cumplen los mas altos requisitos de calidad y el Consejo Nacional de Acreditación (CNA), quien hace el reconocimiento de acreditación de programas académicos. Como quiera que estos procesos son voluntarios, actualmente, hay en el país 88 Instituciones de Educación Superior acreditadas en alta calidad, de las 360 Instituciones existentes, de acuerdo con estadísticas del Sistema Nacional de Información de la Educación Superior (SNIES). En 
este sentido, la apuesta del Ministerio de Educación es mejorar la calidad de la educación superior de la mano con todos los involucrados.

Para hablar de calidad en la educación se deben analizar también las siguientes características de las políticas educativas: equidad, eficiencia y eficacia; la primera se refiere a la cobertura que se logra con los programas y el acceso a los distintos niveles de educación, esto es, hacer más con menos recursos; la segunda al hecho de que los recursos estipulados para esa labor estén siendo usados en la forma correcta y se logren los resultados esperados; finalmente, la tercera hace referencia a que los estudiantes sean efectivamente formados en las instituciones; es decir, que quienes estén en el sistema asistan a las clases, terminen satisfactoriamente los estudios y sean buenos profesionales (Unicef, 2000). En este sentido, a pesar de los esfuerzos realizados por el Ministerio de Educación, el CESU, el CNA y las IES, existen serios cuestionamientos sobre la calidad de la educación en Colombia a la luz de los resultados de las pruebas PISA, SABER y otras de éste tipo, atribuibles al Sistema Educativo implementado en Colombia. Si bien, las pruebas PISA y SABER, miden una parte de la calidad del sistema educativo, no evalúan todos los componentes que inciden en la calidad de la educación.

Respecto de la calidad de la educación en Colombia sostiene Julián de Zubiría, en entrevista con la revista semana el 28 de marzo de 2019 "En los planes de desarrollo no aparecen programas o proyectos que potencien la calidad de la educación con otras metas, por ejemplo, una educación que desarrolle capacidades para pensar de manera crítica, donde se reflexione y se analice la vida humana y el entorno social en el cual existimos; tampoco interesa cómo formar para tener comunicaciones asertivas y basadas en razones; $y$, menos en cómo educar para convivir en paz, sin violencia, actuando dentro del marco de la legalidad y con un sentido ético de la vida humana y del medio ambiente (La calidad de la educación, gran ausente en el Plan de Desarrollo)". 
Por tanto, además de las pruebas SABER y PISA, el país requiere discutir y acordar, con los actores del sector, estrategias para fortalecer los procesos pedagógicos y de gestión educativa, así como las metas a lograr y el sistema para evaluar resultados. En su entrevista, Zubiría dejó la siguiente consigna "La educación de hoy está frente al reto de poner la ciencia al servicio de la vida".

A pesar de que Colombia, entre el 2012 y el 2015, aumentó el puntaje de las pruebas PISA en lenguaje, matemáticas y ciencias, los resultados para el año 2018 evidencian un retroceso del país en el puntaje obtenido para lectura y ciencias en comparación con los resultados del año 2015. Asi mismo, el país presenta una brecha importante frente al promedio de países de la OCDE en los tres componentes de evaluación: 98 puntos en matemáticas, 75 puntos en lectura y 76 puntos en ciencias (Gráfica 1).

Gráfica 1. Puntaje de pruebas PISA (2015-2018)

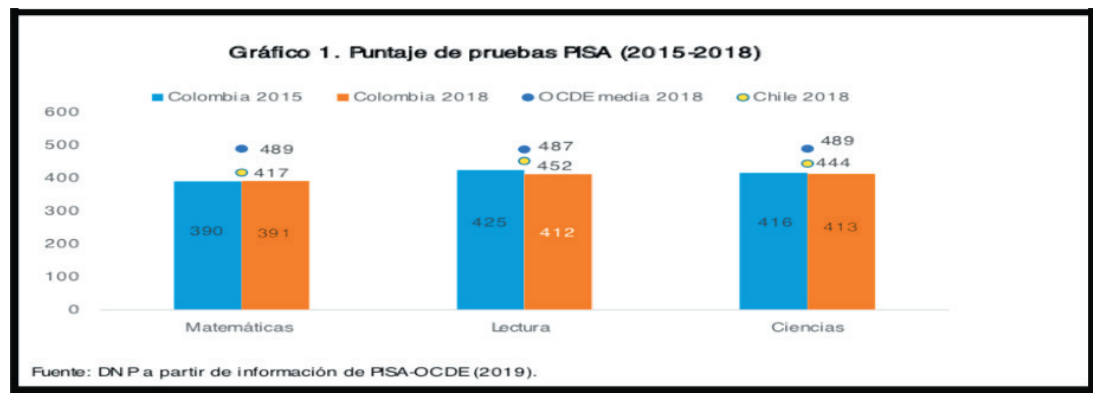

Fuente: Universidad de los Andes. "La Educación Superior en Colombia: 2017

Para lograr mejores estándares de calidad en la educación, es vital tener presente los valores, el sentido de la vida y la realidad social que vivimos para ejercer en los educandos una mentalidad con sentido de pertenencia, formando al hombre con sentido social que contribuya al desarrollo de la sociedad y de su cultura desde una perspectiva crítica y reflexiva que aporte a las 
dificultades o problemas que se presentan en su entorno mediante posibles soluciones. Por consiguiente, es fundamental la búsqueda y aplicación de los mejores métodos y estrategias educativas que permitan formar a niños y jóvenes con los más altos niveles académicos, puesto que si se tiene una sociedad bien educada se tendrán personas con altos niveles intelectuales y una sociedad bien organizada y progresista.

Desde la mirada de otros gremios se plantea el siguiente interrogante “¿La calidad de la educación para cuándo? esta pregunta que el gobierno nacional, la Federación Colombiana de Trabajadores de la Educación (Fecode) y, en general la sociedad, no han discutido a fondo, nos compromete a todos, si aceptamos que la educación es un proceso integral donde participan escuela, gobierno, padres de familia y sociedad". En este sentido la Federación Colombiana de Trabajadores de la Educación (Fecode) plantea que "para empezar a discutir sobre la calidad de la educación deberíamos reconocer que tenemos un pésimo sistema educativo, las pruebas PISA señalan que nuestros mejores estudiantes, quienes pertenecen a los colegios privados (donde estudian los hijos de las élites del país), no alcanzan a los escolares con más bajos resultados de otros países..."

Según Harri Skog, "La educación es la llave para el desarrollo de un país", pues ésta va mucho más allá de una colección de conocimientos; por eso una nación que tiene como política de Estado priorizar la educación de su pueblo, es un país que alcanza excelentes niveles de calidad de vida y altos estándares competitivos en todas las ramas como la ciencia, educación, economía y tecnología a nivel nacional e internacional; precisamente Japón y Finlandia son países cuya inversión en educación es prioridad de Estado lo que hace que sus niveles educativos sean muy altos.

Andreas Schleicher, Director de Educación de la Organización para la Cooperación y el Desarrollo Económicos (OCDE), en entrevista exclusiva con la Revista Semana Educación el 19 de 
julio de 2018, afirma que el sistema educativo en Colombia "está muy fragmentado, muy atomizado y muy localizado para tener la calidad suficiente". Respecto de los retos que tiene el país sobre la educación rural plantea que todo empieza con la financiación y el modelo del Sistema General de Participaciones (SGP), que al momento tiene la intención de apoyar a las comunidades rurales, pero no lo está haciendo en realidad. De hecho, las inversiones son demasiado pequeñas para cerrar la brecha entre regiones, pero más importante que esto, se trata de cómo atraer al mejor talento, maestros líderes que puedan enseñar las mejores prácticas para desarrollar el mejor talento y que fortalezcan los lazos con la comunidad. También advierte Schleicher que, más que un currículo, Colombia necesita un marco de referencia educativo que sea muy claro sobre cuáles son las buenas prácticas docentes y de qué se trata una buena experiencia de aprendizaje, pues cuando se observan los resultados de PISA, una de las razones por las que Colombia y sus estudiantes están teniendo dificultades es porque el sistema educativo ha privilegiado una educación de "reproducción de contenido".

Los estudiantes no son muy buenos cuando tienen que crear conocimiento, extrapolar desde lo que saben o usar su conocimiento creativamente. Concluye la entrevista diciendo que se debe tener claridad entre los recursos que se invierten en la educación y las necesidades de los estudiantes, pues las bases son lo que más importa, si se da a las personas una excelente educación básica pueden tener excelentes resultados en la vida universitaria y profesional.

Para Juan Manuel Lopera, del CEO de Aulas AMIGAS la innovación es la base del desarrollo de un país, donde las escuelas, colegios y líderes gubernamentales están llamados a desempeñar el papel más importante en la base de la pirámide: acompañar a los docentes para que puedan brindar una educación de calidad. Esto se requiere para mantenerse a la vanguardia en materia de aprendizaje y sostener una sociedad más competitiva. Es claro 
que, para lograr la excelencia en la educación, todos los actores: maestros, instituciones, gobierno y empresa privada están llamados a trabajar juntos, para que esta sea justa, asequible y de calidad. En Colombia, el ranking de las instituciones educativas más reconocidas genera un impacto importante en la deserción escolar, por tanto, es vital trabajar en desarrollos tecnológicos que involucre a los colegios y sus docentes a la hora de ubicarse a un mismo nivel académico. La posibilidad de ampliar el acceso a recursos pedagógicos que cualquier docente pueda usar y adaptar, en particular en contextos donde son escasos, constituye una gran oportunidad para hacer realidad una educación competitiva y en crecimiento. Se trabaja en la estructuración de un Plan Nacional de Educación Rural cuyo objetivo es cerrar la brecha con la educación urbana. En este marco, es esencial garantizar la adecuada implementación y adopción de herramientas tecnológicas capaces de llevar conectividad a zonas donde no hay internet, instrumentos pedagógicos innovadores y metodologías de aprendizaje de calidad internacional.

Para hablar de la educación también es importante analizar reflexiones de personajes de reconocimiento mundial como Nelson Mandela, quien dijo una vez "La educación es el arma más poderosa para cambiar el mundo", lo cual deja enseñanzas importantes: la primera es que todo empieza siempre con la educación, es decir, que si Colombia desea cambiar en términos económicos, culturales, sociales y políticos tiene que ofrecer una educación de calidad, con todo lo necesario para que su población sea de las que cambia el mundo y no de las que ayuda a empeorarlo. La segunda enseñanza es aquel país que no se esfuerce porque su población más joven se eduque significa que quiere seguir teniendo a su gente sumida en la ignorancia y la decadencia. De estudios recientes se deduce que muchos jóvenes bachilleres y egresados de universidades opinan que en Colombia se tienen universidades muy buenas, en calidad educativa $y$ avances tecnológicos, pero todos coinciden en que es muy complicado entrar a una universidad ya sea pública o privada, debido a que no 
cuentan con el dinero o porque no lograron pasar el examen de admisión. Esto debe llevar a reflexionar, no solo sobre las políticas que rigen el sistema de admisiones, sino también las variables que intervienen en el proceso educativo y los métodos pedagógicos que se aplican en las Instituciones de Educación Superior

Por todo lo anterior, considero que los resultados que se observan en la calidad de la educación, de acuerdo con los diferentes estudios y opiniones, responden entre otras cosas, a fallas en el ciclo propedéutico que empieza desde la educación en la primera infancia, pasando por la media, básica y luego la formación universitaria, lo cual puede estar determinado por una o varias de las siguientes causas como por ejemplo los métodos de educación, las condiciones socioeconómicas de las familias, las capacidades y competencias de los docentes, los recursos financieros como los provenientes del Sistema General de Participaciones (SGP) que no son invertidos eficientemente en los entes territoriales, la infraestructura, recursos didácticos y pedagógicos de las escuelas y colegios que son inadecuados, las vías de acceso, los servicios públicos, la conectividad, entre otros factores.

\section{3 Marco normativo de la educación en Colombia}

En el ámbito de la formación se ha establecido el marco normativo del Sistema de educación formal y no formal en Colombia regido por leyes fundamentales que definen los principios constitucionales sobre el derecho a la educación que tiene toda persona. Las leyes que se destacan son: Ley 115 de 1994 (Ley general de educación), que de conformidad con los artículos 27, 54 y 67 de la Constitución Política de Colombia define y desarrolla la organización y la prestación de la educación formal en los niveles de preescolar, educación básica (primaria y secundaria) y media, no formal e informal. La Ley 30 de 1992 y el decreto reglamentario 1403 de 1993 establece los lineamientos de la educación superior y define el carácter y la autonomía 
de las instituciones de educación superior (IES), el objeto de los programas académicos y los procedimientos de fomento, inspección y vigilancia de la enseñanza.

Así mismo, cabe mencionar la Ley 749 de 2002 que organiza el servicio público de la educación superior en las modalidades de formación técnica profesional y tecnológica, amplía la definición de las instituciones técnicas y tecnológicas, hace énfasis en los ciclos propedéuticos de formación y establece la posibilidad de transferencia de los estudiantes y de articulación con la media técnica. En ese ámbito, las condiciones de calidad que debe tener la educación se definen mediante el Decreto 2566 de 2003 y la Ley 1188 de 2008, así como en el Decreto 1295 de 2010, por el cual se reglamenta el registro calificado de la Ley 1188 de 2008 y la oferta y desarrollo de programas académicos de educación superior. En el marco de la investigación se encuentra la Ley 29 de 1990 "Por la cual se dictan disposiciones para el fomento de la investigación científica y el desarrollo tecnológico" (pág 1) y la Ley 1286 de 2009 "Por la cual se modifica la ley 29 de 1990, se transforma a Colciencias en Departamento Administrativo, se fortalece el Sistema Nacional de Ciencia, Tecnología e Innovación en Colombia y se dictan otras disposiciones" (pág 1). Recientemente se creó el Ministerio de Ciencia Tecnología e Innovación, mediante la ley $\mathrm{N}^{\circ} 1951$ del 24 enero de 2019, para fortalecer el Sistema Nacional de Ciencia Tecnología e Innovación. En el campo de la formación para el trabajo cabe mencionar la Ley 1064 de 2006 y su decreto reglamentario 4904 de 2009 por los cuales se dictan normas para el apoyo y fortalecimiento de la educación para el trabajo y el desarrollo humano. Además, el Decreto 2020 de 2006 organiza el sistema de calidad en la formación para el trabajo y la Ley 1429 de 2010 determina la formalización y generación de empleo a partir del diseño y la promoción de programas de formación, capacitación, asistencia técnica y asesoría especializada que conduzcan a la formalización y generación empresarial del empleo y el teletrabajo. 
También es importante resaltar la Ley 1014 de 2006 o la Ley de fomento a la cultura del emprendimiento, la cual establece la promoción de los jóvenes emprendedores y sus organizaciones en Colombia. Como referentes internacionales, el tema de la formación para el trabajo está contemplada en la recomendación 195 de 2004 de la OIT, ya que este insta a los Estados miembros a reconocer que la educación y la formación "contribuyen de manera significativa a promover los intereses de las personas, las empresas, la economía y la sociedad en su conjunto, por la importancia que reviste alcanzar el pleno empleo, la erradicación de la pobreza, la inclusión social y el crecimiento económico sostenido en una economía mundializada" (pág 50). En este mismo sentido y en procura de la mejora de la educación, el Ministerio de Educación estableció el Sistema colombiano de formación de educadores (2013) donde se definen lineamientos y políticas sobre las rutas que hacen posibles las dinámicas de cada uno de los subsistemas de educación y la articulación entre estos; además presenta las líneas de acción y hace visible la corresponsabilidad de los actores del sistema de formación de educadores.

En este contexto, también es de resaltar el CONPES 3988, que define la política nacional para impulsar la innovación en las prácticas educativas a través de las TIC, el cual se desarrollará en el siguiente apartado.

\section{4 Marco referencial de las TIC en el campo de la educación}

En el marco de las normas y políticas que orientan la educación superior en Colombia, con el transcurrir del tiempo se ha incursionado en la aplicación de las TIC en la formación y en diferentes procesos institucionales que buscan mejorar la calidad de la educación y la gestión administrativa, en procura de hacer uso eficiente y eficaz de los recursos disponibles. En este ámbito, el Ministerio de las TIC planteó como iniciativa la propuesta "Educación y TIC incluyendo software para interacción", cuyo objetivo es fomentar y promocionar las TIC en la comunidad 
académica mediante el uso y apropiación de una plataforma de interacción y comunicación que beneficie a toda la comunidad educativa (padres, alumnos, docentes y directivos).

Por consiguiente, y para adaptarse a las necesidades de la sociedad actual, las instituciones de educación superior, así como las instituciones públicas y las empresas del sector privado, se han flexibilizado y han desarrollado vías de integración de las tecnologías de la información y la comunicación en los diferentes procesos de formación. Además, han trabajado en la aplicación de una nueva concepción de los usuarios y en los cambios de rol en los educadores y administradores en relación con los sistemas de comunicación, el diseño y la distribución de la enseñanza. No obstante, para estar en línea con los avances tecnológicos, se requiere incursionar en procesos de innovación, como lo plantea Jesús Salinas en su escrito Innovación docente y uso de TIC en la enseñanza universitaria.

En este ámbito, para impulsar el uso y apropiación de las TIC en los procesos de enseñanza aprendizaje se expidió el CONPES 3988 del 31 de marzo de $2020^{7}$, mediante el cual se plantea que "el desarrollo de las tecnologías digitales ha transformado la manera como las personas se comunican, interactúan, acceden a la información y generan conocimiento, lo cual plantea desafíos en materia de educación. En este contexto, Colombia tiene el reto de mejorar la calidad educativa para desarrollar las competencias que les permitan a los estudiantes aprovechar los beneficios de la sociedad digital". Por tanto, las tecnologías digitales plantean la oportunidad de habilitar la innovación educativa con el fin de contribuir a la calidad en la educación, al desarrollo de competencias en los estudiantes y al cierre de brechas educativas.

“...La presente política establece las acciones para transformar y complementar el enfoque del programa Computadores

7 CONPES 3988 del 31 de marzo de 2020, pág 8-63. Política Nacional para impulsar la innovación en las prácticas educativas a través de las tecnologías digitales 
para Educar (CPE) a fin de estructurar, articular y ejecutar las apuestas institucionales necesarias para impulsar la innovación en las prácticas educativas a partir de las tecnologías digitales. Lo anterior para el desarrollo de competencias en estudiantes de educación preescolar, básica y media del sector oficial. Para lograr este objetivo, las acciones de esta política se enmarcan en cuatro pilares:

(i) aumentar el acceso a las tecnologías digitales para la creación de espacios de aprendizaje innovadores,

(ii) mejorar la conectividad a Internet de las instituciones educativas oficiales,

(iii) promover la apropiación de las tecnologías digitales en la comunidad educativa, $y$

(iv) fortalecer el monitoreo y la evaluación del uso, acceso e impacto de las tecnologías digitales en la educación.

Estos cuatro pilares, implementados de forma integral, permitirán enfrentar las principales barreras que han impedido que las tecnologías digitales hayan impulsado de manera sistemática la innovación en las prácticas educativas..."

El Ministerio de las Tecnologías de la Información y las Comunicaciones, de manera articulada con el Ministerio de Educación Nacional y el Servicio Nacional de Aprendizaje (SENA), lideraran la implementación de esta política en un horizonte de cinco años. El Conpes parte de unos antecedentes y justificación sobre la calidad de la educación, con énfasis especialmente en los resultados de las pruebas PISA, de lo cual se precisan algunos aspectos tales como: insuficiencia en acceso a las tecnologías digitales en las sedes educativas, deficiencia de conectividad a internet en sedes educativas, baja eficiencia en la adquisición de servicios de conectividad, baja apropiación de las tecnologías digitales para la innovación en prácticas educativas, 
debilidad en la formación y acompañamiento a los docentes y debilidad en el monitoreo y evaluación de acceso, uso e impacto de las tecnologías digitales en la educación.

El objetivo de esta política es "Impulsar la innovación en las prácticas educativas a través de las tecnologías digitales, para el desarrollo de competencias en los estudiantes de educación preescolar, básica y media del sector oficial, que les permita consolidar su proyecto de vida, asi como enfrentar los retos y aprovechar las oportunidades de la sociedad digital", los objetivos específicos están orientados a cerrar las brechas identificadas en el diagnóstico. Respecto del plan de acción, la implementación de las acciones de esta política permitirá ampliar el enfoque del programa Computadores para Educar (CPE) y orientar los esfuerzos de diferentes entidades públicas para fomentar la innovación en las prácticas educativas a partir de las tecnologías digitales. Esta política se sustenta en cuatro líneas estratégicas, para las cuales se proyecta invertir \$231.188 millones del 2020 al 2024, las cuales son: a) Aumentar el acceso a tecnologías digitales en las sedes educativas oficiales para la creación de espacios de aprendizaje innovadores, b) Mejorar la conectividad a Internet en las sedes educativas oficiales con el fin de potenciar el uso de las tecnologías digitales, c) Promover la apropiación de las tecnologías digitales en la comunidad educativa para la innovación en las prácticas educativas y d) Fortalecimiento del monitoreo y evaluación del uso, acceso e impacto de las tecnologías digitales en la educación .

Las entidades encargas de la financiación son El Ministerios de Tecnologías de la Información y las Comunicaciones (86,7\%), Ministerio de Educación Nacional (27,5\%), Instituto Colombiano para la evaluación de la Educación (0,2\%), Servicio Nacional de Aprendizaje (SENA) (10,3\%), Colombia Compra Eficiente Agencia Nacional de Contratación pública (0,097\%)

El uso de las TIC en el ámbito educativo en algunas instituciones ha generado gran impacto en la formación, 
capacitación y construcción del conocimiento en los espacios laborales, principalmente en los modelos de b-learning que favorecen la formación orientada por la práctica y el trabajo colaborativo dirigido a la solución de problemas complejos, pues se trata de combinar medios y modalidades que permitan una mayor flexibilidad en la gestión del proceso de interacción entre los participantes y el facilitador en pro de la generación de oportunidades en todos los ámbitos.

Dado que los docentes tienen un rol determinante en la transformación de las prácticas educativas, se proyecta que todos los años de implementación de la política, al menos el $60 \%$ de los docentes que han tenido formación y acompañamiento por parte del programa Computadores para Educar transiten a un nivel superior de apropiación de tecnologías digitales. Por otra parte, dado que esta política incorpora acciones para impulsar de manera integral el acceso tecnológico, la conectividad a Internet de las sedes educativas, y el fomento a la apropiación de tecnologías digitales, se espera que, al año siguiente del inicio de la política, al menos el $60 \%$ de las sedes educativas transiten de un nivel superior de madurez digital superior. Por último, dado que el objetivo de la política es aumentar la innovación educativa, se espera que los entes territoriales fortalezcan sus capacidades para el fomento de la innovación educativa. Se espera que para el 2021, el $60 \%$ de los entes territoriales mejoren estas capacidades a partir de la implementación de las acciones acompañamiento por parte del programa Computadores para Educar transiten a un nivel superior de apropiación de tecnologías digitales.

En este campo, el ingeniero Juan Cadillo León, en su documento Educación, sistemas, redes y TIC fundamentado en la tutoría de la realidad aumentada con Scratch Spot, explica la importancia de las ideas para generar proyectos desde un enfoque sistemático que promueva el uso de las TIC y sistemas de información, permitiendo la solución de problemas o satisfacción de necesidades en entornos organizacionales, sobre la base de 
que las herramientas tecnológicas son un medio facilitador dentro del proceso de enseñanza y aprendizaje posibilitando el enriquecimiento de este proceso y posibilitando escenarios que apoyen el desarrollo de un grupo de competencias clave para nuestros tiempos (OCDE): El uso interactivo de las herramientas, la interacción entre grupos heterogéneos y actuar en forma autónoma. (2014, p.ág 11). Cabe reconocer las consideraciones sobre el uso de espacios virtuales en la formación de investigadores como Darío Rodríguez, Rodolfo Bertone y Ramón García Martínez, del Programa de Maestría en Tecnología Informática aplicada a la educación en la Universidad Nacional de la Plata, Facultad de Informática con el Instituto de Investigaciones de Informática (LIDI).

Por su parte, el equipo de trabajo de la oficina de planeación de la Universidad Nacional de Colombia, sede Medellín, elaboró la guía para la formulación de proyectos con base en la metodología del banco de proyectos de la Universidad Nacional de Colombia (BPUN).

Todos estos referentes fueron muy útiles como aportes para recrear el estado del arte de este estudio, especialmente, para conocer de las lecciones aprendidas y que han sido convertidas en buenas prácticas en cada una de estas instituciones para la implementación de nuevos modelos educativos y administrativos aprovechando los beneficios de las TIC.

\section{Desarrollo y Fundamentación de la Monografía}

En este capítulo se hará un despliegue sobre el impacto de las TIC en la educación, uso y apropiación de las TIC, situación actual y retos de la educación superior y evaluación de la educación mediada por TIC en tiempos de COVID-19. 


\section{1 Ámbito de las Tecnologías de Información y las}

Comunicaciones (TIC) en la Educación Superior

LasTIC son herramientasorientadas a fortalecer competencias necesarias para la solución de problemas y contribución al desarrollo social, económico y ambiental del país. Las Tecnologías de Información y las Comunicaciones (TIC) privilegian, entre otros aspectos, la flexibilización en la educación, cuyo propósito es la articulación del conocimiento y la acción, que da al estudiante mayores oportunidades para la selección de rutas de formación en diferentes ámbitos y direcciones. En este sentido, la flexibilización busca una formación menos rígida, con mayor vinculación e impacto en el conjunto de habilidades que orientan el desempeño profesional, de acuerdo con las exigencias de un mundo cada vez más competitivo, inestable y cambiante. Las herramientas tecnológicas también contribuyen al cambio organizacional con el aporte a las competencias para el análisis, comprensión y solución de problemas, ya que propician el, trabajo autónomo, colaborativo e interdisciplinar, con la participación de actores que de manera presencial y virtual promueven el aprendizaje significativo y el desarrollo cognitivo utilizando estrategias didácticas que motivan la revisión y el análisis de recursos y materiales como libros, documentos bibliográficos, videos, desarrollo de foros, talleres prácticos, ensayos, videoconferencias, encuentros sincrónicos, estudio de casos y exámenes en línea; todo ello, mediado por las Tecnologías de la Información y las Comunicaciones (TIC) en ambientes virtuales.

En la virtualidad se destacan conceptos como b-learning, porque aporta a la enseñanza la flexibilidad en los tiempos y espacios educativos, el acceso a multiplicidad de recursos más allá de los ofrecidos por el docente, los nuevos modos de interacción entre alumno-docente y entre los mismos alumnos, el incremento de la autonomía y la responsabilidad del estudiante en su propio proceso (Adell y Area, 2009), elementos que permiten mejorar la educación y facilitar el desarrollo de las competencias digitales. La 
modalidadb-Learning o también conocida como Blended Learning (aprendizaje semipresencial o mixto) es una combinación de lo virtual con lo presencial y se pretende seleccionar lo mejor de las dos, de lo presencial el trabajo directo de actitudes y habilidades, la interacción cara a cara, y de la modalidad a distancia la rapidez, economía. "Esta mezcla de canales de aprendizaje enriquece el método formativo y permite individualizar la formación a cada uno de los destinatarios y cubrir más objetivos del aprendizaje, el alumno se ve obligado a participar de forma muy activa para poder seguir las enseñanzas, razón por la que aprovechará mejor el aprendizaje." (Rodrigo, 2011). Se utilizan materiales basados en la tecnología y sesiones presenciales, y se persigue que juntos logren una enseñanza eficaz, algunas herramientas son el internet para la parte en línea, y herramientas comunes para sus clases presenciales.

Bartolomé define el b-Learning como "modelo que trata de recoger las ventajas del modelo virtual tratando de evitar sus inconvenientes, aprovecha la importancia del grupo, el ritmo de aprendizaje y el contacto directo con el profesor de la enseñanza presencial, pero trata de desarrollar en los alumnos la capacidad de auto organizarse, habilidades para la comunicación escrita, y estilos de aprendizaje autónomo. Y hace énfasis en la importancia en el desarrollo de habilidades en la búsqueda y trabajo con información en las actuales fuentes de documentación en Internet." (Bartolomé, 2002). Las ventajas del b-Learning según (Bello, 2007) son la flexibilidad, movilidad, ampliación de cobertura, eficacia, ahorro en costos, diversidad de presentación de contenidos, actualización e interacción. Otros estudios también han demostrado que los modelos b-learning permiten calidad de la educación, el incremento al acceso de esta y la flexibilidad y la mejora de la relación costo-eficacia (Graham, 2013).

En estas metodologías para el uso de las TIC surge e-learning que tiene como objetivo llevar la formación fuera de las aulas, permitiendo al alumno aprender también fuera de las mismas. 
Esta modalidad cambió las tradicionales ataduras 'físicas' por otras como la necesidad de disponer de un ordenador, conexión a la Red, ancho de banda y velocidad suficiente para que el proceso sea ágil, y finalmente, que todo ello funcione correctamente.

Luego aparece el mobile learning o m-learning (aprendizaje móvil), aprendizaje a través de dispositivos móviles (smartphone, PDA, computadora portátil, tablets) concebido como un acceso a programas formativos desde dispositivos móviles sin cables (wireless), o aprendizaje en contextos, en donde el centro de atención es la movilidad de los aprendices, interactuando con tecnología portátil o fija (Conde, 2007). Es una forma de aprendizaje que facilita la construcción del conocimiento, la resolución de problemas y el desarrollo de destrezas y habilidades diversas de manera autónoma y ubicua, gracias a la mediación de dispositivos móviles. Las soluciones de m-Learning ofrecen la libertad de capturar pensamientos e ideas de manera espontánea, justo cuando la inspiración llega, y permiten acceder a las tecnologías de la información cuando y donde el usuario lo necesite, facilitando la posibilidad de implementar innovadores modos de dar clase y aprender (Hellers, 2004).

El m-learning es una derivada de e-learning, pero la diferencia fundamental radica en la modalidad que ofrece el mobile learning - el e-learning puede realizarse desde un dispositivo fijo, lo cual influye en los contenidos, mientras que los del m-learning son más ligeros mini sesiones educativas con imágenes, videos y listas de chequeo sencillas de recordar, los del e-learning ofrecen información más ampliada y detallada. En consecuencia, las sesiones de m-learning están diseñadas para durar pocos minutos, mientras que las de e-learning pueden durar hasta una hora.

La posición de la UNESCO al respecto de éste método es clara "si al uso del móvil en el aula si se trata de un uso apropiado", por tanto, esta organización definió directrices y políticas de aprendizaje móvil para la adaptación del espacio escolar al 
m-learning. En este sentido se sugiere que para introducir este método conviene apoyarse en el uso de aplicaciones adecuadas que permitan crear lista de alumnos y de tareas, crear la agenda de clases, tomar notas, crear contenidos, presentaciones, fotografías y podcasts, entre otros.

El m-Learning ha ido ganando en importancia y en usabilidad, no obstante, se deben señalar cuáles son sus ventajas y desventajas así:

Como ventajas se destacan: acceso en cualquier lugar y momento, contenidos actualizados, estimula la creatividad en los estudiantes, engancha y motiva al estudiante a acceder a los cursos online, fomenta la metodología del aprendizaje basado en problemas (ABP), facilita la adquisición de determinadas habilidades, fomenta la interacción y la comunicación, fomenta el trabajo cooperativo y colaborativo, mediante la distribución de tareas, permite un mejor acceso a avisos y recordatorios, fomenta la comunicación sincrónica (intercambio de información por internet en tiempo real) y asincrónica (comunicación entre personas cuando no existe una coincidencia temporal), permite la publicación inmediata de contenidos, permite la creación de nuevas comunidades de aprendizaje Como desventajas se pueden mencionar: Cobertura de la red puede inhibir los acceso a los cursos, los estudiantes pueden quejarse de utilizar sus datos para uso de la empresa o la universidad, consumo de espacio de disco en el teléfono o tableta, profesores no formados y con competencias para gestionar a sus alumnos (en el caso de educación formal), los anchos de banda pueden limitar el acceso a los contenidos, los diferentes tamaños de pantalla suelen ser un reto de diseño, qué pasa con los estudiantes que no están siempre conectados, y, las repetitivas notificaciones suelen ser elementos de distracción para el estudiante.

Respecto de sus características se pueden destacar las siguientes: 
- Los contenidos deben ser precisos, concisos y adaptados al medio

- Los contenidos deben ser motivantes

- Contenidos basados en Micro-learning

- Evaluaciones justas y adaptadas al medio

- Fuerte carga de diseño de tal manera que estimule al estudiante

- Retador y que desafíe al estudiante

- Algunos tipos de contenidos podrían ser: videos cortos, juegos cortos, lecturas muy reducidas en tamaño, $\mathrm{FAQ}$, infografías, etc.

Por sus características, se recomienda tener especial cuidado en su diseño instruccional por lo que se deben definir objetivos claros a alcanzar antes de comenzar a diseñar cursos bajo esta tecnología. Si bien, esta modalidad del aprendizaje electrónico aún no ha despegado en toda su magnitud, si tiene un gran potencial a futuro El m-Learning se debe entender como una parte del e-Learning y por consecuencia del aprendizaje a distancia (d-Learning). "El punto en el que la computación móvil y el eLearning se cruzan para producir la experiencia de aprendizaje en cualquier momento y lugar" (Kambourakis, Kontoni, \& Sapounas, 2004).

En este contexto, se encuentra el U-learning que tiene como objetivo crear un ambiente de aprendizaje donde el estudiante esté totalmente inmerso, y donde no solo adquiere conocimiento, sino que también lo comparte con sus compañeros y/o su organización. Por ello, el U-learning es el conjunto de actividades formativas apoyadas en la tecnología móvil, que permite acceder al aprendizaje desde cualquier lugar y en cualquier momento, no limitando la formación a la recibida a través del ordenador (Carmona \& Francisco, 2012). 
Mark Weiser (Weiser, 1991) fue uno de los pioneros en hablar del uso de una tecnología flexible en espacio y tiempo, así como de la integración de la informática como parte esencial en la vida de las personas dando forma al concepto de "ubiquitous computing". En 2007 esta idea de ubicuidad se trasladó al mundo de la formación, evolucionando el concepto de e-Learning, aprendizaje a través de Internet, a U-Learning, aprendizaje apoyado en la tecnología no limitando la formación a la recibida a través de una computadora y accesible a través del Internet en todo momento y lugar que admite la incorporación de cualquier medio tecnológico que nos permita recibir y asimilar información para convertirla en aprendizaje como las computadoras tradicionales, portátiles y móviles.

El aprendizaje ubicuo tiene como objetivo crear un ambiente de aprendizaje o contexto educativo generalizado u omnipresente en el cual se realiza un ambiente de aprendizaje y que el alumno esté totalmente inmerso en Ubiquitous learning enviroment, y dónde no solo adquiera conocimiento, sino que también lo comparta con sus compañeros y con su entorno, no solo van a poder tener acceso al conocimiento sino también lo van a poder compartir y divulgar. Su significado es la capacidad de aprender desde diversos contextos y situaciones, en diferentes momentos temporales y a través de dispositivos o medios varios. El concepto adquiere hoy en día una mayor relevancia teniendo en cuenta la proliferación de plataformas y dispositivos de lo más diverso como la televisión interactiva, smartphones, tabletas, libros electrónicos o digitales, consolas de videojuegos, etc., que tienen todos ellos la capacidad de transmitir contenidos multimedia interactivos (Carmona \& Francisco, 2012). De aquí, se desprende el término "omnipresencia", esto quiere decir la posibilidad de estar presentes en varios lugares al mismo tiempo, desafiando las limitaciones impuestas por el entorno físico, supone una especial capacidad para la flexibilidad y la adaptación a contextos diversos y en constante movimiento. 
En esta modalidad la actividad de aprender se convierte en algo natural donde la interacción con la tecnología es casi trasparente e invisible para el alumno, por esto, se considera el U-learning como una evolución del e-learning y que toma la movilidad del aprendizaje m-learning para que se dé el aprendizaje omnipresente, es decir, en todo momento y lugar. Por tanto, el paradigma ya ha cambiado, como dice Eric Schmidt, director de Google, "La nueva regla hoy, lo primero es el móvil".

Algunas de las características de esta metodología son:

- Accesibilidad: Todos los contenidos formativos están virtual izados y accesibles en todo momento y desde cualquier dispositivo pudiendo revisar documentos, datos o videos desde cualquier sitio.

- Permanencia: Todas las actividades formativas en las que participan los alumnos quedan acumuladas y almacenadas para futuras consultas en su proceso de aprendizaje.

- Colaborativo: Los alumnos pueden comunicarse, relacionarse y aprender con compañeros, profesores de forma sincrónica y asincrónica.

- Continuado: La actividad de aprender forma parte de la vida del individuo creándose un hábito de aprendizaje

- Natural: La interacción diaria con la tecnología ha generado una manera natural de aprender siendo casi trasparente e invisible para el alumno.

Inmediatez: en cualquier momento, pueden tener cualquier información en el instante.

- Interactividad: interactúan de un modo inconsciente con computadoras y dispositivos, además, interactúan con expertos, profesores, compañeros, etc. 
- Adaptabilidad: se basa en la idea de adaptar los métodos de enseñanza a los estilos de aprendizaje de los alumnos; un método individualizado de enseñanza ayudará a aprender más rápido, de un modo mucho más eficaz y con un grado de comprensión elevado (Jones \& Jo, 2004).

- Actividades Educativas Situadas: el aprendizaje se integra en la vida diaria; los problemas encontrados y el conocimiento requerido están presentes de forma natural y auténtica (Rodríguez, 2009).

Pese a las bondades de estos modelos, en las instituciones de educación superior, los métodos tradicionales para la formación no han permitido una verdadera apropiación de las TIC, no garantizan aprendizajes significativos (Díaz, 2006) (Sacristán, 2008) (Ortega \& Flores, s.f.) ni el afianzamiento de competencias interpretativas, argumentativas y propositivas.

En el mismo sentido, estudios de expertos como Gabriel Misas Arango (2004) en su libro la Educación superior en Colombia. Análisis y estrategias para su desarrollo, la actual formación universitaria no responde ni cualitativa ni cuantitativamente a las necesidades de la sociedad colombiana. Es por esto por lo que el autor propone instituciones que construyan una visión de futuro que oriente al sistema de educación superior en el desarrollo y consolidación de los programas de formación e investigación que se consideren estratégicos para contribuir al desarrollo económico y social del país. La educación superior cumple un papel estratégico en el proyecto de desarrollo económico, social, ambiental y político del país, por lo que se necesitan instituciones que estén en la capacidad de formar a las nuevas generaciones de manera competente y responsable, para asumir los compromisos que demanda la construcción de la sociedad y para ello, es necesario romper los paradigmas y creencias que se tienen sobre la educación medida por las TIC, aquí radica el gran desafío para el cambio del modelo de educación. 
2.2 Uso y apropiación de las Tecnologías de Información y las Comunicaciones (TIC) en Colombia

Según estudios realizados por el Ministerio de las TIC y Vive Digital en el año $2015^{8}$, sobre el uso y apropiación de las TIC en Colombia donde se encuestaron 3.730 personas de 30 municipios mayores de 150.000 habitantes se obtuvieron los siguientes resultados.

La percepción ciudadana evidencia que el uso de las TIC contribuye al mejoramiento de la calidad de vida de los colombianos, ya que disminuye la inequidad, empodera a los ciudadanos, permite ahorro de tiempo y beneficia a los empresarios y emprendedores (Gráfica 2).

Gráfica 2. Beneficios del uso de las TIC

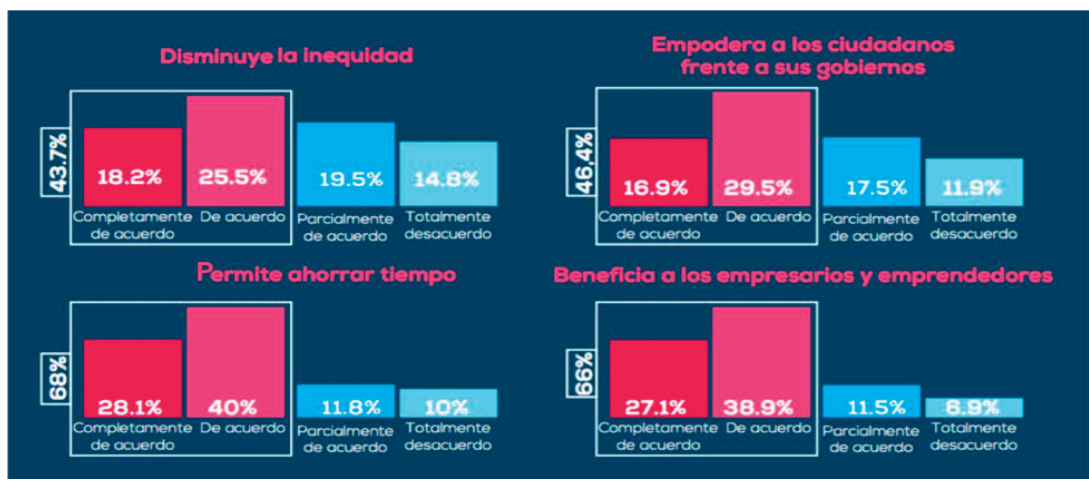

Fuente: Min TIC y Vive Digital

De otra parte, los colombianos ven en la internet una herramienta para generar nuevas oportunidades y dinámicas productivas de trabajo (Gráfica 3)

8 Ministerio de las TIC y Vive Fdigital en el año 2015, pág. 5-48. Uso y apropiación de las TIC en Colombia 
Gráfica 3. Las TIC y el trabajo colaborativo

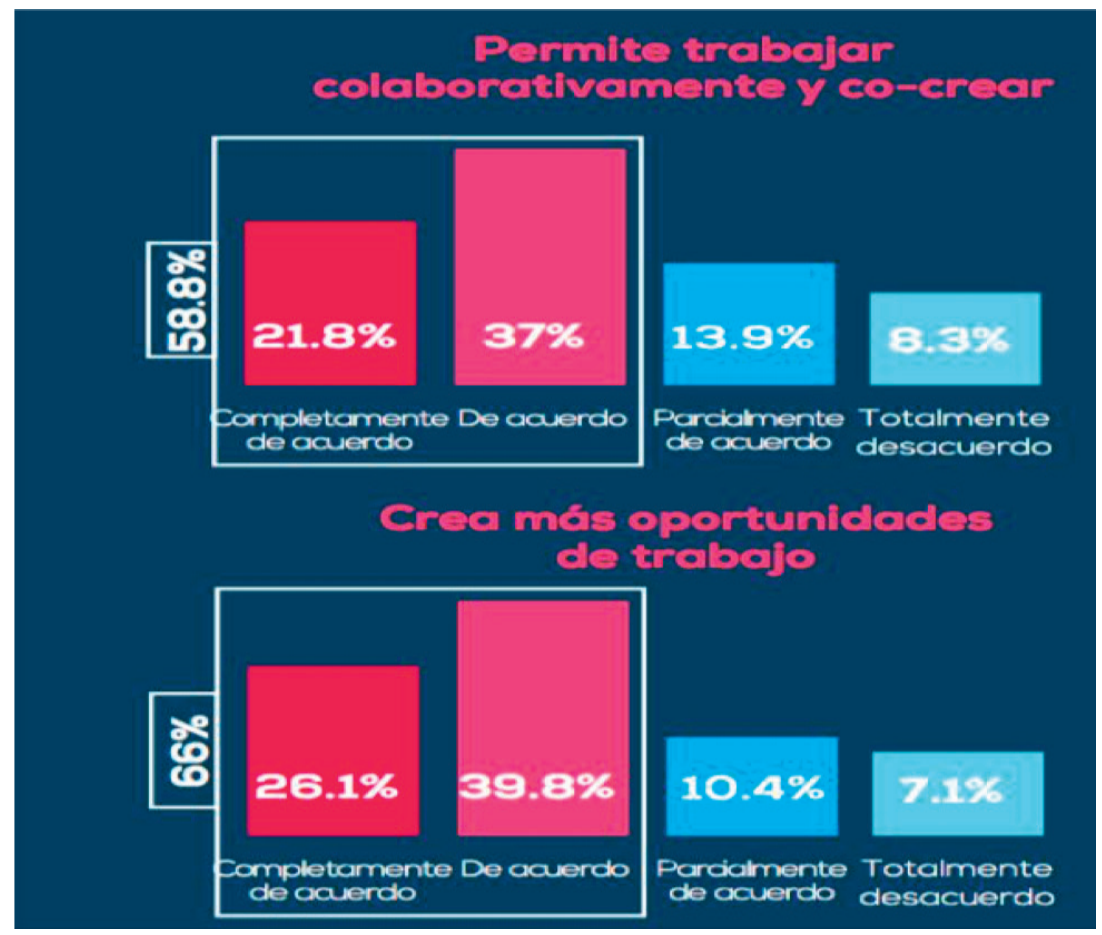

Fuente: Min TIC y Vive Digital

Las principales actividades que realizan los colombianos en internet son enviar y recibir mensajes instantáneos, correos electrónicos, fotos y videos. Para enviar y recibir archivos solo utilizan el internet el 33,4\% (Gráfica 4)

Gráfica 4. Actividades realizadas en Internet

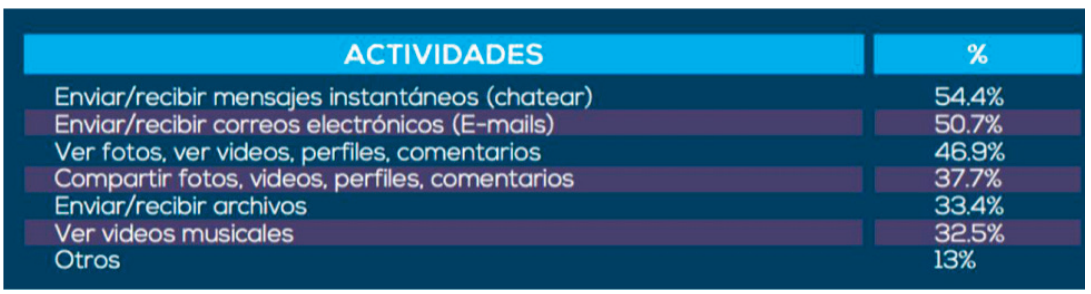

Fuente: Min TIC y Vive Digital 
Según el estudio, las aplicaciones que se descargan de internet con mayor frecuencia son redes sociales, música, juegos y entretenimiento. Para temas de educación descargan el $52 \%$ de los usuarios (Gráfica 5).

Gráfica 5. Aplicaciones descargadas de Internet

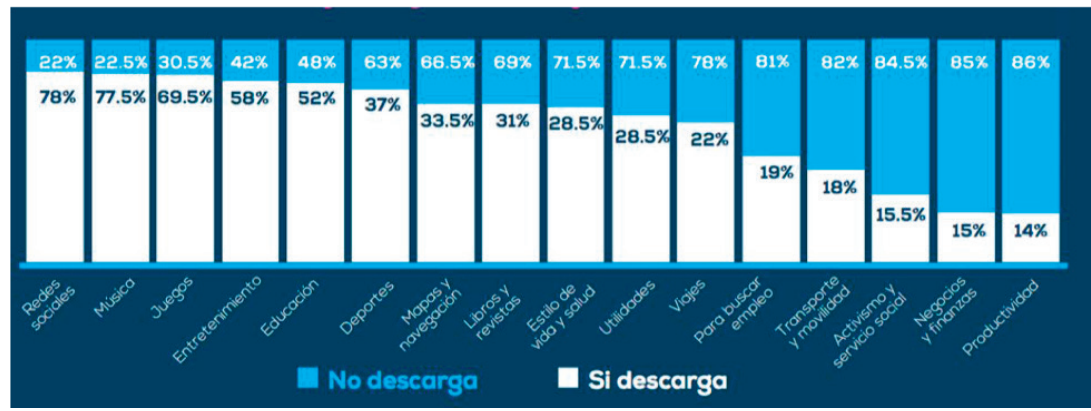

Fuente: Min TIC y Vive Digital

Sobre la frecuencia de acceso a redes sociales, se encontró que el el 59\% de los colombianos accede a redes sociales al menos diez veces al día (Gráfica 6).

Gráfica 6. Frecuencia de acceso a redes sociales

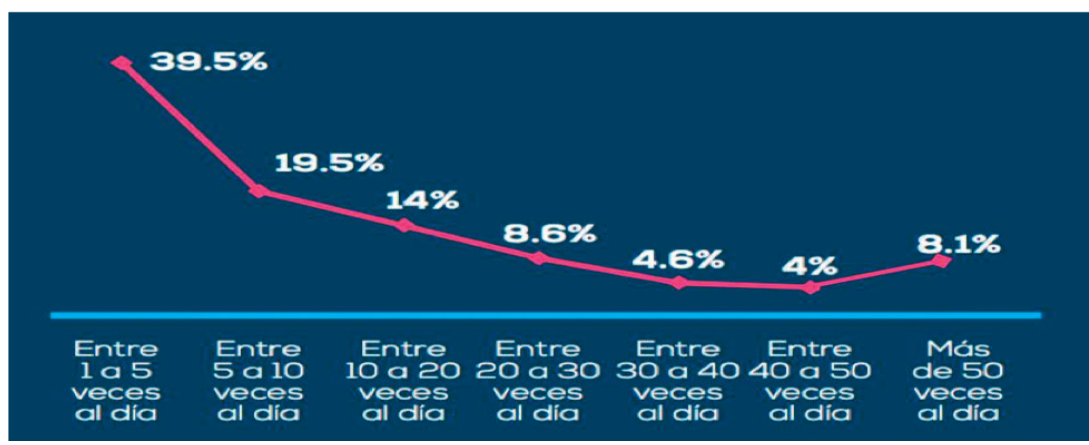

Fuente: Min TIC y Vive Digital

Las plataformas utilizadas por los colombianos con mayor frecuencia son facebook, WhatsApp y YouTube (Gráfica 7). 
Gráfica 7. Uso de plataformas más frecuentes

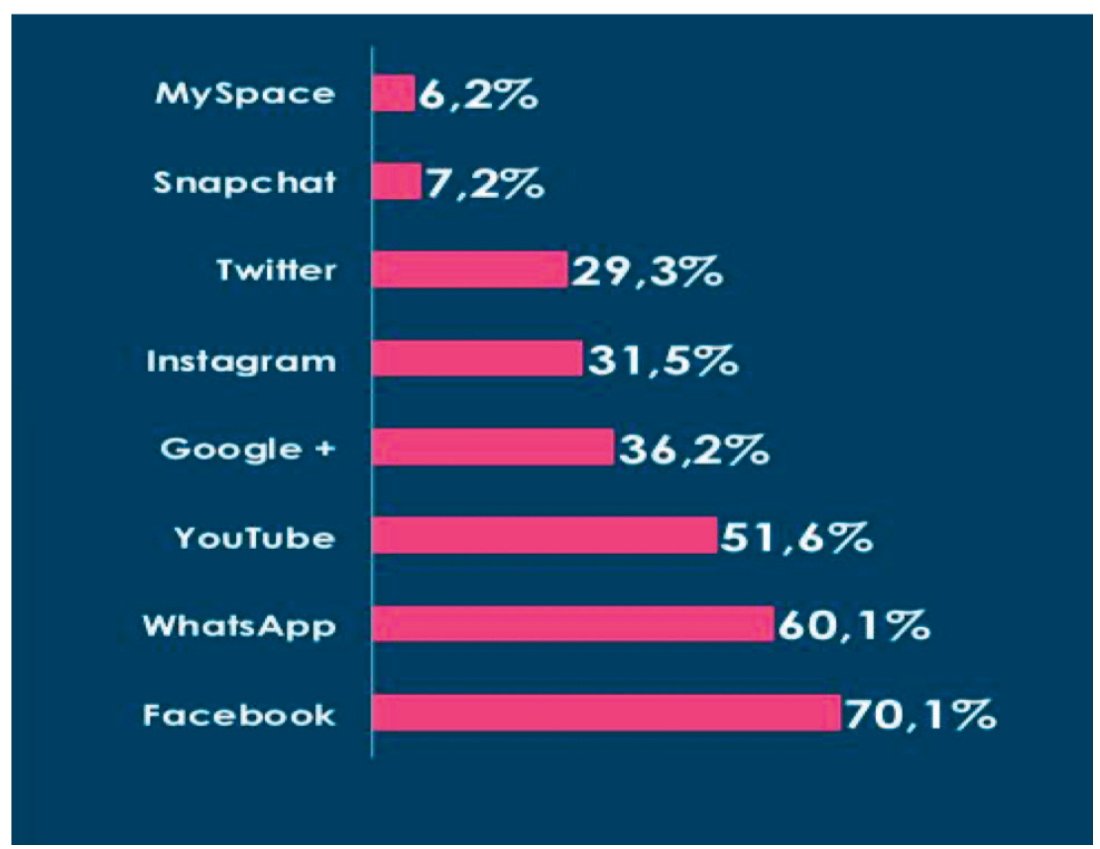

Fuente: Min TIC y Vive Digital

El estudio también arrojó que el $42 \%$ de los colombianos aprendió internet de manera autodidacta, el 19,5\% por enseñanza de profesores, mientras que el 38,5\% aprendió por un conocido o familiar (Gráfica 8)

Gráfica 8. Adquisición del conocimiento para uso de internet

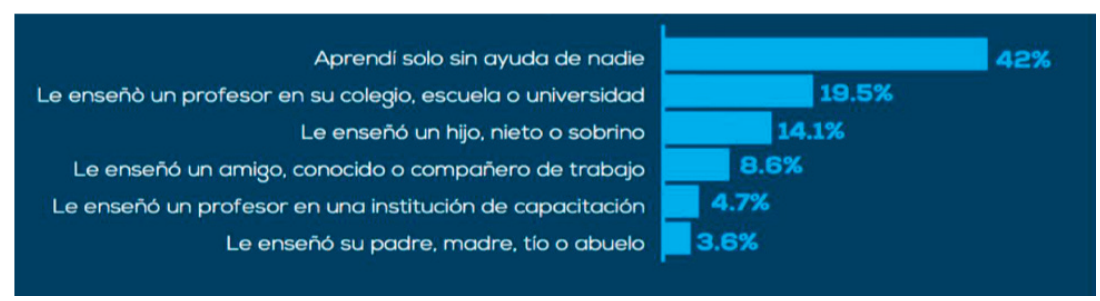

Fuente: Min TIC y Vive Digital

Por otra parte, el $49 \%$ de los colombianos considera que la incersión de nuevas tecnologías ayuda a preservar la cultura de las comunidades (Gráfica 9) 
Gráfica 9. Inserción de nuevas tecnologías como aporte a la cultura

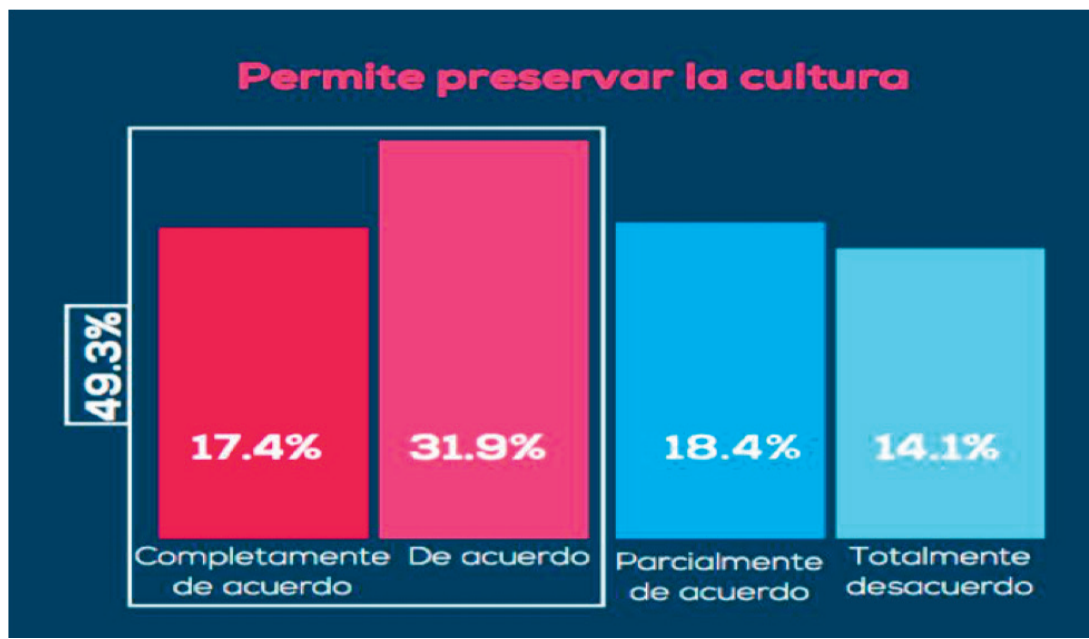

Fuente: Min TIC y Vive Digital

El 76\% de los jóvenes entre los 12 y 17 años tiene teléfono móvil propio con voz y datos, el 91,6\% corresponde a jóvenes entre 18 y 24 años y el 89,4\% corresponde a personas entre 25 y 34 años. Lo anterior significa que un alto porcentaje entre jóvenes y adultos tienen telefono móvil con voz y datos (Gráfica 10)

Gráfica 10. Teléfono móvil propio

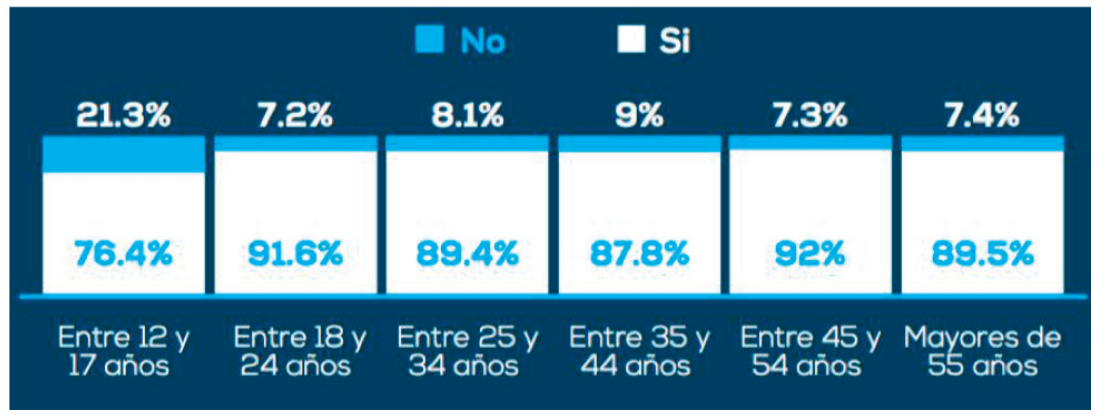

Fuente: Min TIC y Vive Digital 
De este estudio se concluye que la mayor parte de los colombianos y especialmente los jovenes tienen un alto uso de las TIC parala interacción en redes sociales y temas deentretenimiento, sin embargo, se evidencia un bajo uso y apropiación para trabajar en contenidos y temas educativos. De otra parte, el hecho de que un alto porcentaje de jovenes y adultos sean propietarios de teléfonos móviles con datos, abre una gran oportunidad para implementar modelos educativos fundamentados en m-learning y u-learning.

En Colombia en el ámbito educativo, según diagnóstico contenido en el Conpes 3988 de marzo 31 de 2020 las estrategias de apropiación TIC del programa Computadores para Educar (CPE) ha estado focalizada principalmente hacia los docentes, pero no ha logrado incidir de manera significativa en los niveles de apropiación de los estudiantes. Aunque el $60 \%$ de los docentes formados por este programa participaron del componente de formación para la Innovación a partir de las TIC, menos de la mitad de las instituciones educativas que cuentan con docentes formados reportan alguna experiencia significativa de innovación en el aula de clase a través del uso de las TIC (Universidad Nacional de Colombia, 2018). Por consiguiente, la debilidad en el componente formativo está relacionada con su reducido impacto sobre la innovación de las prácticas educativas.

Así mismo, el programa carece de estrategias que acompañen el acceso de las TIC en el ámbito educativo, como la conectividad a Internet (Unesco, 2016b), el monitoreo y seguimiento de las TIC en la educación y una estrategia de apropiación fortalecida que esté orientada a la innovación en la educación.

En relación con la dotación de contenidos digitales, el Ministerio de Educación Nacional en el año 2004 creó el portal Colombia Aprende, el cual, junto con los contenidos desarrollados por el programa (CPE), ha sido el eje central de la gestión TIC implementada, este portal dispone de oferta de contenidos y cursos virtuales para los niveles de educación primaria, básica, 
media y superior. El propósito de Colombia Aprende es difundir conocimiento para toda la comunidad educativa para mejorar la enseñanza de docentes y el aprendizaje de los estudiantes. Por otra parte, la Oficina de Innovación Educativa del Ministerio de Educación Nacional ha consolidado una amplia oferta de contenidos educativos para todas las áreas y grados. Actualmente, se cuenta con una oferta de 40.000 contenidos, los cuales se han distribuido y circulado en distintos canales en línea como el Portal Colombia Aprende y canales fuera de línea.

A pesar de lo anterior, la entrega de contenidos educativos no ha contado con instrumentos o mecanismos de medición frente a su uso y apropiación, lo cual ha dificultado evaluar su uso y pertinencia. Así mismo, no existen estadísticas relacionadas con la circulación de los contenidos distribuidos a través de los terminales entregados por Computadores para Educar (CPE) durante los últimos años. Una falencia que se ha identificado es la falta de promoción de estas herramientas entre los docentes de distintos grados y áreas. En materia de conectividad, con el fin de disminuir las brechas de acceso universal a Internet y uso de las TIC en las sedes educativas rurales y urbanas, el Ministerio de Educación Nacional y el Ministerio de las Tecnologías de la Información y las Comunicaciones han implementado programas como Conexión Total y Acceso Comunitario a Internet. En el año 2011, a través del artículo 149 del Plan Nacional de Desarrollo (PND) 2010-2014 Prosperidad para Todos, el Gobierno nacional, en cabeza del Ministerio de Tecnologías de la Información y las Comunicaciones y el Ministerio de Educación Nacional, creó el programa Conexión Total con el objetivo de aumentar las competencias de los estudiantes en el uso de TIC a partir de la ampliación de la conectividad en los establecimientos educativos.

Por su parte, en el marco del Plan Vive Digital 2010-2018, el Ministerio de Tecnologías de la Información y las Comunicaciones implementó en el año 2013 los Kioscos Vive Digital, que fueron puntos de acceso comunitario a Internet instalados en lugares 
comunes y de fácil acceso como casas de familia, salones comunales y colegios. En la fase II del programa, el Gobierno nacional adjudicó 5.648 Kioscos Vive Digital exclusivamente en establecimientos educativos de las zonas rurales del país. Los esfuerzos del Gobierno durante los últimos años han permitido ampliar la cobertura de conectividad en el ámbito educativo. Sin embargo, otra de las limitaciones que se identifica es que las estrategias en materia de conectividad no han estado articuladas con las estrategias de acceso y dotación de terminales. Por ejemplo, entre el año 2015 al año 2018, Computadores para Educar entregó terminales en 32.952 sedes educativas de las cuales 17.634 no tienen conectividad a Internet, lo equivalente al 53,5 \%. Esto es relevante porque a pesar de que la mayor parte de contenidos no necesitan de Internet, los docentes y directivos formados enfrentan dificultades para integrar las tecnologías digitales en la educación a causa de la falta de conectividad a Internet (Universidad Nacional de Colombia, 2018).

Respecto de la innovación, en el año 2016, a partir del Plan Decenal de Educación (2016-2026), se planteó el uso pedagógico de las tecnologías digitales para impulsar la innovación y la promoción del desarrollo de competencias para el siglo XXI. Así mismo, se consideró que las tecnologías son esenciales para la transformación del sistema educativo, con el fin de quela educación responda a los contextos y las necesidades de las regiones que conforman al país. En el plan se identificó como principal desafío el uso pertinente de las nuevas tecnologías para apoyar la enseñanza y la innovación educativa. Para abordar este desafío se plantearon estrategias orientadas a (i) fomentar en la comunidad educativa el uso de las TIC en el aprendizaje continuo, (ii) incentivar el uso pedagógico de las TIC en las prácticas docentes y (iii) fomentar los aprendizajes de tecnología que respondan a contextos y retos de la sociedad digital (Ministerio de Educación Nacional, 2016).

En el año 2019, el Ministerio de Educación Nacional implementó el programa Aprender Digital, en donde se reconoce 
que la transformación digital implica un cambio de aprendizaje en los estudiantes y exige la transformación de la enseñanza por parte de docentes y directivos. Para ello, se fomenta la innovación educativa y la transformación de los ambientes de aprendizaje a partir de las herramientas digitales. Sin embargo, al ser un programa reciente, requiere del apoyo y promoción de diferentes acciones que impulsen la estrategia y que permitan lograr una mayor cobertura en las escuelas públicas a nivel nacional. En octubre del año 2019, se aprobó el Documento CONPES $3975^{9}$ "Política Nacional para la Transformación Digital e Inteligencia Artificial”. A través de esta política se identificó la necesidad de preparar al talento humano del país para adquirir las nuevas habilidades digitales en el marco de la cuarta revolución industrial e implementar acciones para fortalecer los ecosistemas de innovación educativa y los espacios de aprendizaje para la creatividad, la cultura de innovación y el emprendimiento

La incorporación de las tecnologías digitales en la vida cotidiana genera nuevas oportunidades y grandes retos relacionados con el cierre de brechas sociales, el aumento de la productividad y el crecimiento económico de un país. Así mismo, el capital humano es un factor fundamental para enfrentar las transformaciones sociales y económicas asociadas a las tecnologías digitales. Frente a lo anterior, el sector educativo tiene el reto de garantizar una educación de calidad que se caracteriza por la promoción de las competencias necesarias para participar en las diferentes áreas de la vida humana, desarrollar el proyecto de vida y afrontar los desafíos de la sociedad actual (Unesco, 2007, p. 9) que se ha transformado por las tecnologías digitales.

Con relación al acceso a tecnologías digitales en escuelas y colegios del país se encuentra que estamos lejos de llegar a una relación 1:1, esto es, estudiantes por terminales, como se puede

9 CONPES 3975, octubre 2019, pág 8-58. "Política Nacional para la Transformación Digital e Inteligencia Artificial". 
observar en (Gráfica 11), la brecha entre departamentos es significativa, mientras en San Andrés la relación es prácticamente un terminal por estudiante, en la Guajira esta relación es de siete estudiantes por computador.

Gráfica 11. Relación de estudiantes por terminales por departamento

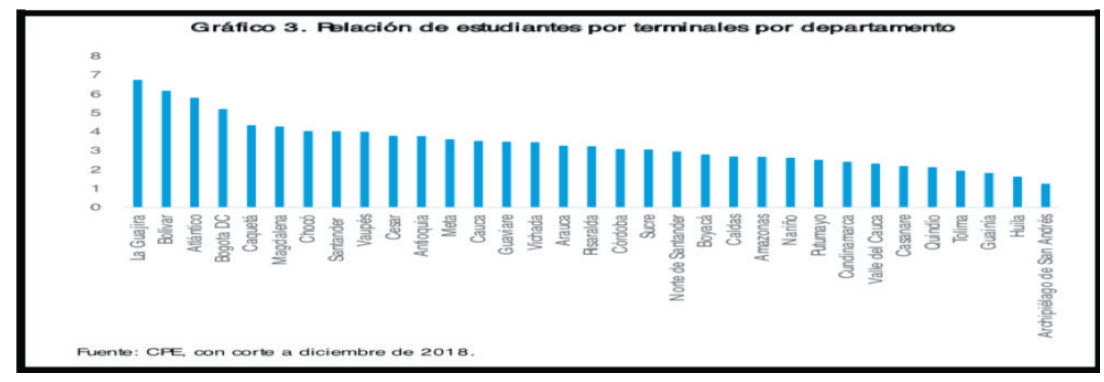

Universidad de los Andes. La Educación Superior en Colombia, 2018

De igual manera, la calidad en la educación desde la primera infancia hasta la educación pos media es un factor determinante en la competitividad de un país (Consejo Privado de Competitividad, 2017) y en la capacidad que tiene para lograr sendas de crecimiento sostenido en el largo plazo. De acuerdo con el Índice Global de Competitividad (IGC) ${ }^{10}$, que mide la utilización de los recursos que dispone un país para proveer a sus habitantes un alto nivel de prosperidad, Colombia obtuvo en el año 2019, el puesto 57 de 141 países y se ubicó 24 puestos por debajo de Chile, el país con el mejor puesto de América Latina. En el pilar de habilidades, Colombia se ubicó en el puesto 80 de 141 países y perdió puntaje con respecto al 2018 en los indicadores relacionados con competencias para el siglo XXI, tales como habilidades digitales o pensamiento crítico en la enseñanza (Gráfica 12). 
Gráfica 12. Índice Global de Competitividad

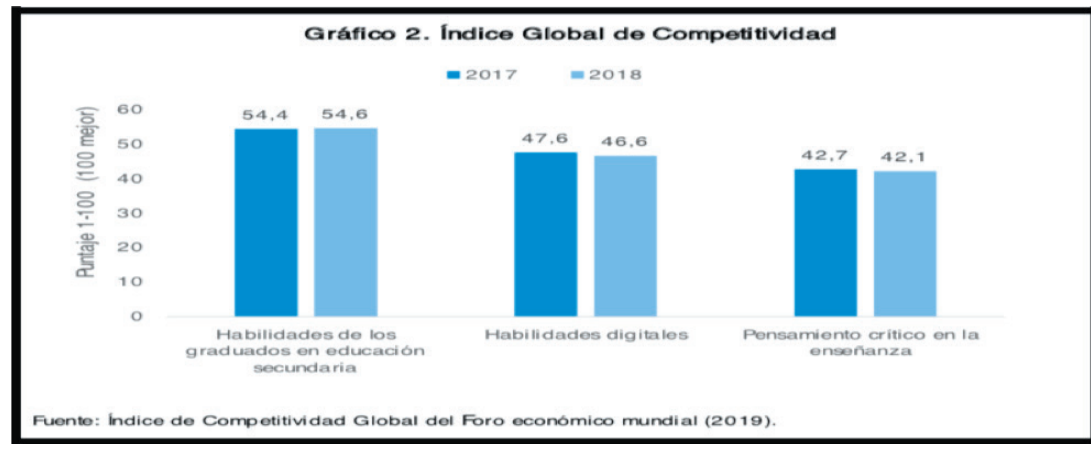

Fuente: Índice Global de Competitividad (IGC). Consejo Privado de Competitividad, 2017

Ahora bien, con respecto al uso y apropiación de las TIC en las pymes colombianas, se consultó el estudio realizado por J. Ricardo Puentes G (2017) ${ }^{11}$, cuyas principales conclusiones fueron las siguientes:

- Los estudios realizados en el país demuestran que, efectivamente, no hay un avance significativo en la adopción de las tecnologías de la información y las comunicaciones (TIC) por parte de las pymes (Mayorga, 2012; DANE, 2012; Vive Digital, 2012) y que los programas desarrollados por los diferentes gobiernos no han hecho mella en esta problemática. Por consiguiente, el rezago que presenta el país en las TIC se ve reflejado en las pymes en todos los nivele, $y$, en forma reiterada, confirmado por las encuestas y los estudios

- El $45 \%$ de las pymes no están lista para TLC, es una de las conclusiones a la que llegó el último estudio del Politécnico Grancolombiano después de revisar los da- tos de 9200 microempresarios de todo el país. (El Espectador, 6 de mayo de 2012; Vega et al., 2011)

11 J. Ricardo Puentes G (2017), p. 20-38. Análisis de la apropiación y uso de las TIC por parte de las pymes colombianas 
- En el informe del Foro Económico Mundial se muestra que en 2011 el país ocupaba el lugar 58 entre las 138 naciones objeto de estudio en TIC

- El uso que se les da a las TIC es superficial y hay desaprovechamiento y desconocimiento de las capacidades de los sistemas computacionales y de los diferentes productos para usos empresariales.

- Se necesita una gran inversión en capacitación masiva en diferentes temas empresariales, pero, ante todo, en el uso de las TIC.

Este apartado se complementa con los hallazgos de la Tesis Doctoral denominada "Modelo de formación en proyectos trazado por las tecnologías de la información y las comunicaciones (TIC) $(2018)^{12}$, que indagó sobre el uso y apropiación de las TIC en los procesos de enseñanza y aprendizaje por parte de estudiantes y docentes, así como, también, la opinión sobre las potencialidades de la educación mediada por TIC desde la mirada de docentes y profesionales. Para esta investigación se realizaron 507 encuestas, distribuidas de la siguiente manera: 162 estudiantes, 204 profesionales y 141 docentes; del total de la muestra el 57,4\% (291) fueron del género masculino y el 42,6\% (216) del género femenino. Las encuestas se aplicaron de manera virtual y presencial a personas de diferentes carreras y asignaturas, pero todas afines a la formulación y evaluación de proyectos en 21 universidades del país, tanto públicas como privadas. A continuación, se muestran los resultados del estudio.

Sobre el uso y apropiación de TIC, los entornos utilizados por estudiantes son los siguientes: el 63,3\% utilizan Gmail, el $32,1 \%$ Facebook y solo el 19,8\% manejan contenidos educativos mediante aulas virtuales en el proceso de enseñanza y aprendizaje (Gráfica 13). Lo anterior confirma que la mayoría de los estudiantes

12 Modelo de formación en proyectos trazado por las tecnologías de la información y las comunicaciones (TIC) (2018) 
usan las TIC para la interacción en redes sociales y temas de entretenimiento, pero hay bajo uso y apropiación para trabajar en contenidos y temas educativos.

Gráfica 13. Entornos virtuales utilizados por estudiantes en la educación

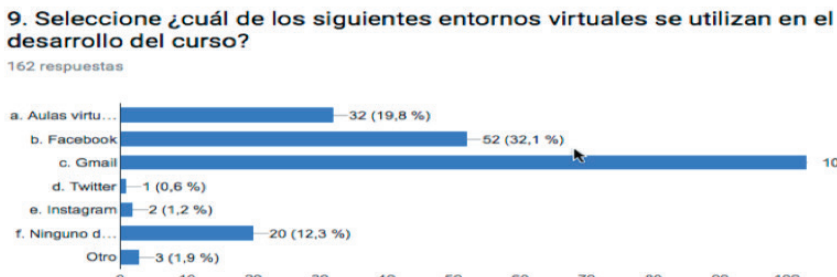

Fuente: "Modelo de Formación en Proyectos trazado por las TIC" (2018). Torres Moreno Jairo Ordilio. Atlantic International University (AIU)

En el caso de los docentes, el 55,8\% utilizan las aulas virtuales en sus procesos de enseñanza, el 44,2\% usan Gmail y en menor proporción 17,4\% utilizan Facebook (Gráfica 14). Lo anterior indica que los docentes aprovechan de mejor manera los entornos digitales para trabajar contenidos educativos

Haciendo un cruce de variables entre estudiantes y docentes encontramos que mientras el $55,8 \%$ de los docentes utilizan las TIC para efectos académicos a través de las aulas virtuales, solo el 19,8\% de los estudiantes las utilizan en prácticas académicas. En contraste, el 95\% de los estudiantes son más activos en redes sociales comparado con los docentes cuya participación es del $59,2 \%$. 
Gráfica 14. Entornos virtuales utilizados por docentes en la educación:

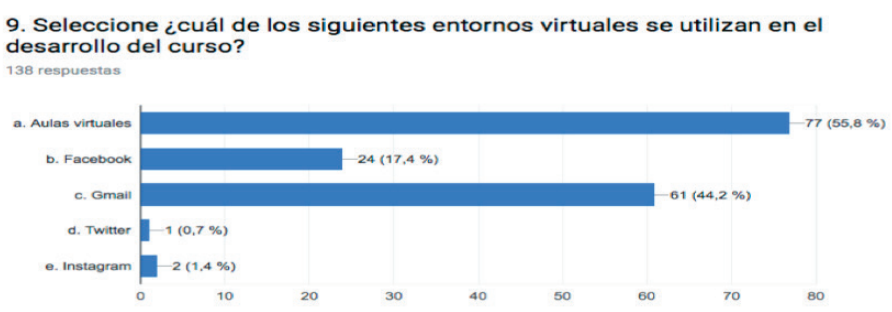

Fuente: "Modelo de Formación en Proyectos trazado por las TIC" (2018). Torres Moreno Jairo Ordilio. Atlantic International University (AIU)

Respecto de la opinión sobre el uso de las TIC en la educación se encontró que el 97,9\% de los docentes están de acuerdo que un modelo de formación mediado por entornos virtuales puede contribuir a mejorar los procesos de enseñanza y aprendizaje, en contraste un porcentaje muy pequeño del $2,1 \%$ están poco de acuerdo con un modelo de este tipo (Gráfica 15)

Gráfica 15. Opinión de docentes sobre el uso de las TIC en la educación

10. ¿Considera que el uso de las Tecnologías de Información y Comunicaciones (TIC) y los entornos ... métodos de formación en proyectos? 140 respuestas
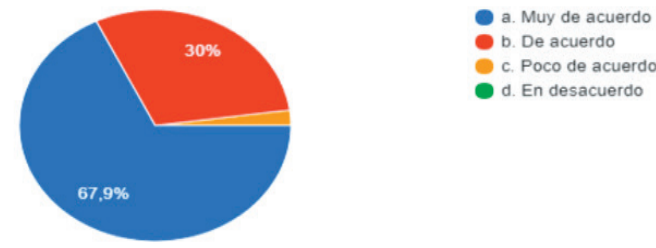

Fuente: "Modelo de Formación en Proyectos trazado por las TIC"(2018). Torres Moreno Jairo Ordilio. Atlantic International University (AIU). 
Por su parte, el 98\% de profesionales están de acuerdo que un modelo de formación mediado por TIC puede contribuir a mejorar los procesos de enseñanza y aprendizaje, en contraste solo el 2,1\% están poco de acuerdo (Gráfica 16). Como se puede observar en los resultados de las gráficas 15 y 16, tanto docentes como profesionales tienen la misma opinión sobre las bondades que pueden tener los entornos virtuales para la formación de calidad

Gráfica 16. Opinión de profesionales sobre el uso de las TIC en la educación

11. ¿Considera que el uso de las tecnologías de información y comunicación (TIC) y los entornos vi...s métodos de formación en proyectos? 205 respuestas
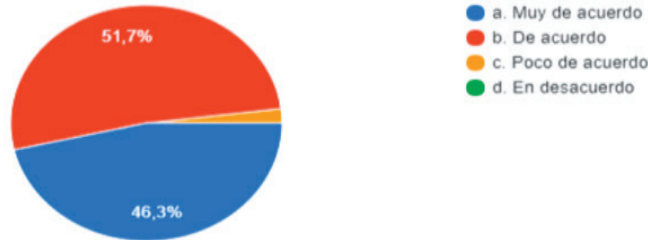

Fuente: Tesis Doctoral "Modelo de Formación en Proyectos trazado por las TIC”(2018). Torres Moreno Jairo Ordilio. Atlantic International University (AIU)

Respecto de las estrategias aplicadas para la enseñanza que motivaría en los estudiantes el mayor aprendizaje se encontró que el $46 \%$ preferirían una combinación entre educación presencial y educación virtual, es decir, metodología b-learning, mientras que el otro 54\% participarían de todas las estrategias y métodos incluyendo ambientes virtuales (Gráfica 17) 
Gráfica 17. Estrategias aplicadas para la enseñanza según opinión de Estudiantes

11. Seleccione cuál de las siguientes estrategias aplicadas para la enseñanza motivaría su mayor aprendizaje

161 respuestas

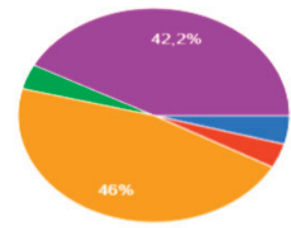

Fuente: "Modelo de Formación en Proyectos trazado por las TIC"(2018). Torres Moreno Jairo Ordilio. Atlantic International University (AIU)

Sobre los métodos tradicionales utilizados para la formación en proyectos el $77,7 \%$ de estudiantes afirmó que son inadecuados o poco adecuados, mientras que el $22,4 \%$ respondieron que los métodos son adecuados (Gráfica 18). Lo anterior, indica que es necesario revisar y adecuar los métodos de formación a las necesidades de los estudiantes del siglo XXI.

Gráfica 18. Métodos utilizados para la formación en proyectos según opinión de Estudiantes

7. Considera que los métodos utilizados para la formación en proyectos son:

161 respuestas

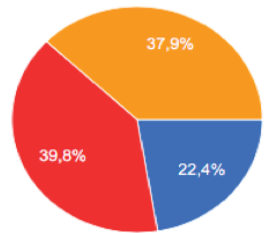

a. Adecuados

b. Poco adecuados

c. Inadecuados

Fuente: "Modelo de Formación en Proyectos trazado por las TIC"(2018). Torres Moreno Jairo Ordilio. Atlantic International University (AIU) 
Respecto del aprendizaje significativo para el análisis, comprensión y solución de problemas el 72,1\% de estudiantes consideran que el método de enseñanza no permite aprendizajes significativos, solo el 27,9\% están de acuerdo con los métodos tradicionales (Gráfica 19). Esta respuesta es coherente con el resultado de la Gráfica 18, donde solo el 22,4\% de los estudiantes respondieron que los métodos de enseñanza son adecuados

Gráfica 19. Métodos con aprendizajes significativos según opinión de Estudiantes

6. ¿Considera que el método de enseñanza aplicado en el curso le ha permitido lograr aprendizajes significativos para el análisis, comprensión y solución de problemas?

161 respuestas

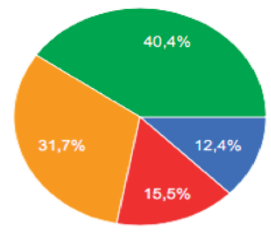

$$
\begin{aligned}
& \text { a. Muy de acuerdo } \\
& \text { b. De acuerdo } \\
& \text { c. Poco de acuerdo } \\
& \text { d. En desacuerdo }
\end{aligned}
$$

Fuente: "Modelo de Formación en Proyectos trazado por las TIC" (2018). Torres Moreno Jairo Ordilio. Atlantic International University (AIU)

\subsection{Situación actual y Retos de la Educación Superior mediada por las TIC}

\subsubsection{Situación actual de las Instituciones de Educación Superior en Colombia}

Para examinar la situación de la educación superior en el país, se retomaron estudios realizados por universidades, instituciones y gremios de la educación, así como, opiniones de expertos en la materia. Para iniciar, abordamos el estudio realizado por la Universidad de los Andes ${ }^{13}$, donde se describe el comportamiento

13 Universidad de los Andes. "La Educación Superior en Colombia: Situación actual y análisis de eficiencia” 2018, pág. 60-103 
de los principales indicadores del sector, como son el de cobertura y número de matriculados, número de instituciones y programas, nivel de formación de los docentes, las tasas de deserción, la financiación de las instituciones educativas públicas y los resultados de logro académico, así mismo, se analizan la eficiencia en el desempeño académico de un conjunto de instituciones de educación superior utilizando técnicas de frontera estocástica.

\section{Cobertura:}

Durante los últimos 25 años, el acceso a la educación superior aumentó a un mayor ritmo, lo que se tradujo en una tasa de cobertura bruta que pasó del 24,0\% en el año 2000 al 49,0\% al final del 2015. Durante este período, la población matriculada a nivel de pregrado ascendió de 487.448 estudiantes en 1990 a 873.079 en el año 2000 y a 2.142.443 en el 2014. Gran parte del aumento reciente del número de matriculados tiene origen en la expansión de cupos para educación técnica y tecnológica, que pasaron de 152.324 en el 2000 a 713.500 en el 2014. Se destaca que, mientras la tasa de cobertura en educación técnica y tecnológica ascendió del 4,0\% en el 2000 al 16,3\% en el 2015, en el nivel profesional esta tasa aumentó del $18,7 \%$ en el primer año al 32,7\% en el último (Tabla 1)

Tabla 1. Matrícula y tasa bruta de cobertura educación superior a nivel de pregrado

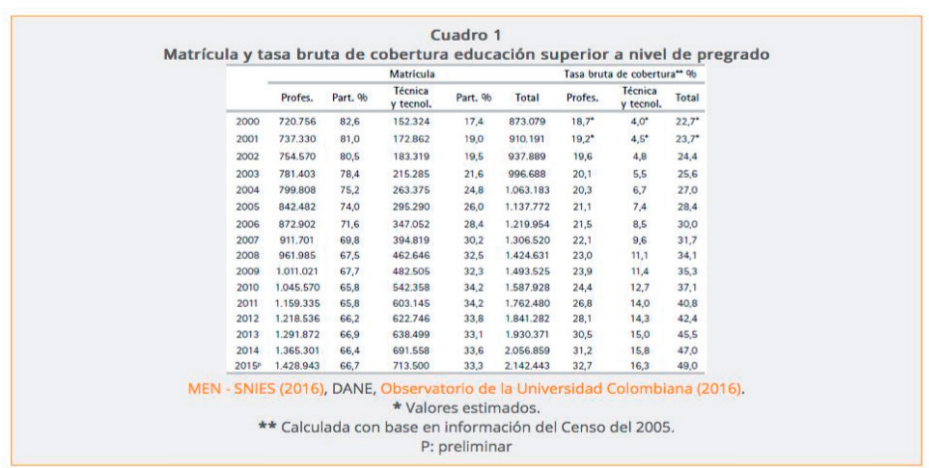

Fuente: Universidad de los Andes. La educación superior en Colombia, 2018 
Cuando se examinan las tasas de cobertura por regiones se observa una gran heterogeneidad. Por ejemplo, para el año 2014, mientras la tasa de cobertura de Bogotá fue del 97,6\% y la de Quindío del 53,4\%, departamentos como Amazonas, Arauca y Putumayo registraron tasas inferiores al 12\% (Gráfica 20)

Gráfica 20. Tasa bruta de cobertura de la educación superior (20092014)

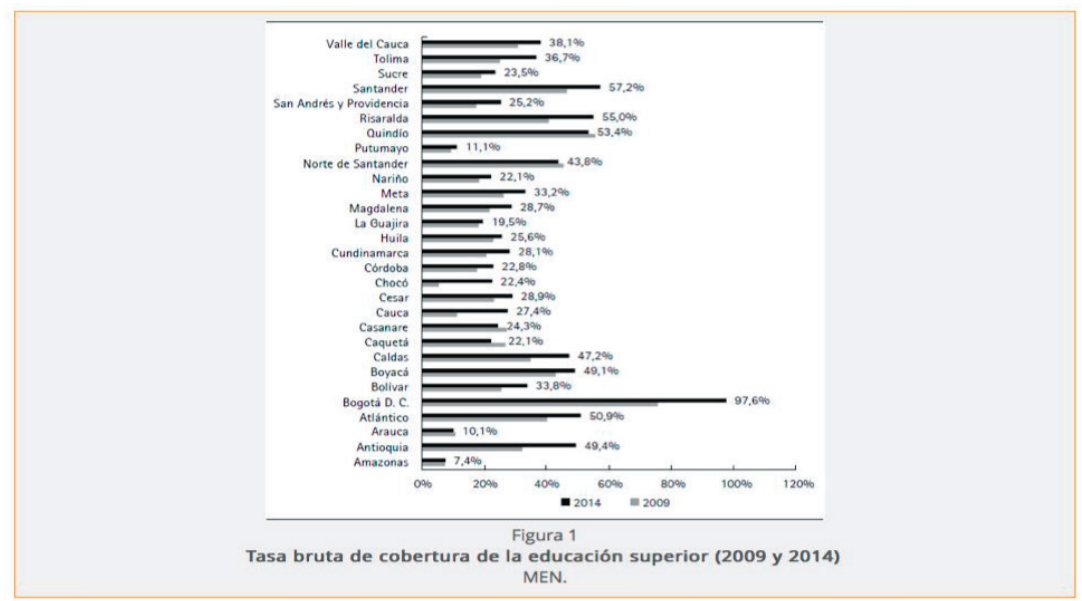

Fuente: Universidad de los Andes. La educación superior en Colombia, 2018

Durante la última década la cobertura en el tercer nivel de enseñanza registra un avance importante, especialmente por los esfuerzos realizados en educación técnica y tecnológica. No obstante, desde una perspectiva internacional, la tasa de cobertura de Colombia es relativamente baja cuando se compara con países desarrollados como Estados Unidos, Finlandia, España, Nueva Zelandia, Australia, Noruega y con países latinoamericanos como Argentina y Chile, cuyas tasas de cobertura superan el 80\% (Tabla 2). 
Tabla 2. Tasa bruta de cobertura de la educación superior

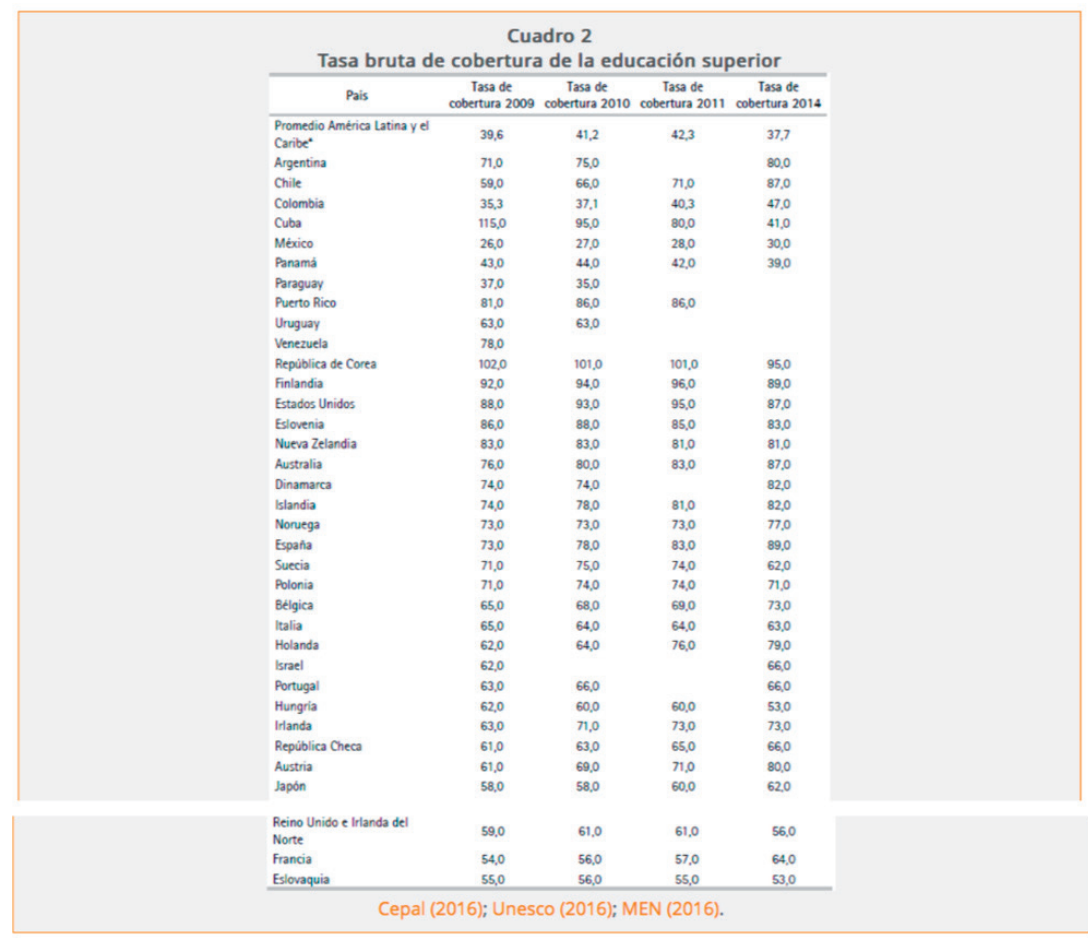

Fuente: Universidad de los Andes. La educación superior en Colombia, 2018

\section{Instituciones:}

Para atender la demanda por servicios de educación superior, en el año 2015 el país contaba con 290 instituciones, de las cuales 83 corresponden a universidades, 120 a instituciones universitarias, 51 a instituciones tecnológicas y 37 a instituciones técnicas. Del total de entidades, 62 son oficiales, 207 privadas y 19 de régimen especial durante los últimos años, el número de instituciones universitarias ascendió de 82 en el año 2000 a 119 en el 2015. En este mismo período, el número de universidades aumentó en $10 \mathrm{y}$ el de las instituciones tecnológicas en 4 . El número de instituciones técnicas, por el contrario, disminuyó en 7 (Tabla 3). 
Tabla 3. Instituciones de educación superior

\begin{tabular}{|c|c|c|c|c|c|}
\hline \multicolumn{6}{|c|}{$\begin{array}{l}\text { Cuadro } 3 \\
\text { Instituciones de educación superior }\end{array}$} \\
\hline Aก๊̃o & $\begin{array}{l}\text { Instituciones } \\
\text { técnicas }\end{array}$ & $\begin{array}{l}\text { Inssituciones } \\
\text { tecrologicas }\end{array}$ & $\begin{array}{l}\text { Instituciones } \\
\text { universitarias }\end{array}$ & Universidades & Total \\
\hline 2000 & 44 & 47 & 82 & 73 & 246 \\
\hline 2001 & 44 & 49 & 94 & 73 & 260 \\
\hline 2002 & 43 & 47 & 104 & 73 & 267 \\
\hline 2003 & 42 & 49 & 110 & 80 & 281 \\
\hline 2004 & 42 & 48 & 106 & 80 & 276 \\
\hline 2005 & 41 & so & 106 & 80 & 277 \\
\hline 2006 & 41 & 49 & 105 & 80 & 275 \\
\hline 2007 & 42 & 51 & 106 & 80 & 279 \\
\hline 2008 & 42 & 53 & 109 & 80 & 284 \\
\hline 2009 & 42 & 55 & 113 & 80 & 290 \\
\hline 2010 & 42 & 55 & 115 & 80 & 292 \\
\hline 2011 & 39 & 54 & 115 & 80 & 288 \\
\hline 2012 & 37 & 50 & 120 & 81 & 288 \\
\hline 2013 & 37 & 50 & 120 & 82 & 289 \\
\hline 2014 & 37 & 51 & 120 & 82 & 290 \\
\hline 2015 & 37 & 51 & 119 & 83 & 290 \\
\hline \multicolumn{6}{|c|}{ MEN - SNIES (2016). } \\
\hline
\end{tabular}

Fuente: Universidad de los Andes. La educación superior en Colombia, 2018

Para el año 2015, de acuerdo con las Estadísticas de Educación Superior del Ministerio de Educación Nacional (2016), con información de SACES y CNA, la oferta de programas académicos con registro calificado de las instituciones de educación superior incluía 6.341 programas de pregrado, de los cuales 1.066 son técnicos profesionales, 1.519 son tecnológicos y 3.756 son profesionales universitarios. También se ofrecieron 4.872 programas de posgrado, de los cuales 3.171 corresponden a especializaciones, 1.465 a maestrías y 236 doctorados. Vale la pena resaltar que del total de programas académicos (11.213 programas con registro calificado en pregrado y posgrado), solo $956(8,5 \%)$ están acreditados con alto nivel de alta calidad, de estos programas acreditados, 856 corresponden a programas de pregrado $(89,5 \%)$ y 100 a programas de posgrado (7,5\%). De los programas de pregrado, 18 corresponden al nivel técnico profesional, 66 al tecnológico, y 772 al universitario. Por su parte, de los programas de posgrado, 8 corresponden a especialización, 66 a maestría y 14 a doctorado. Por áreas de conocimiento, el 31,8\% de los programas acreditados con alto nivel de calidad corresponden a ingeniería, arquitectura y urbanismo, el $18,8 \%$ a ciencias sociales y humanas, el 16,3\% a economía, administración, contaduría y carreras afines, 
el 10,3\% a ciencias de la salud, el $9,1 \%$ a ciencias de la educación, el 6,5\% a matemáticas y ciencias naturales, el 4,2\% a bellas artes, y el restante $3 \%$ a programas de agronomía, veterinaria y afines.

Los diferentes programas de educación superior registraron 1.954.201 estudiantes en el año 2015, de los cuales 1.806 .400 estaban matriculados en programa técnico, tecnológico o de pregrado y 147.800 en programas de posgrado. Por nivel de formación académica, 89.842 estudiantes (4,6\%) pertenecían al nivel técnico profesional, 623.658 (31,9\%) al tecnológico, $1.092 .900(55,9 \%)$ al universitario, $88.427(4,5 \%)$ a especialización, 54.106 a maestría $(2,8 \%)$ y 5.268 a doctorado $(0,3)$, (Gráfica 21$)$. Es importante señalar que del total de estudiantes para el 2015, el $50,7 \%$ asisten a instituciones públicas y el $49,3 \%$ a instituciones privadas. En el año 2002, el 41,7\% de los estudiantes estaban matriculados en instituciones oficiales y el 58,3\% en privadas. El aumento de la participación pública en el total de la matrícula obedece principalmente al aumento de cupos del SENA, que pasó de 48.123 en el 2003 a 428.318 en el 2015.

Gráfica 21. Matrícula en instituciones de educación superior según nivel de formación (2015)

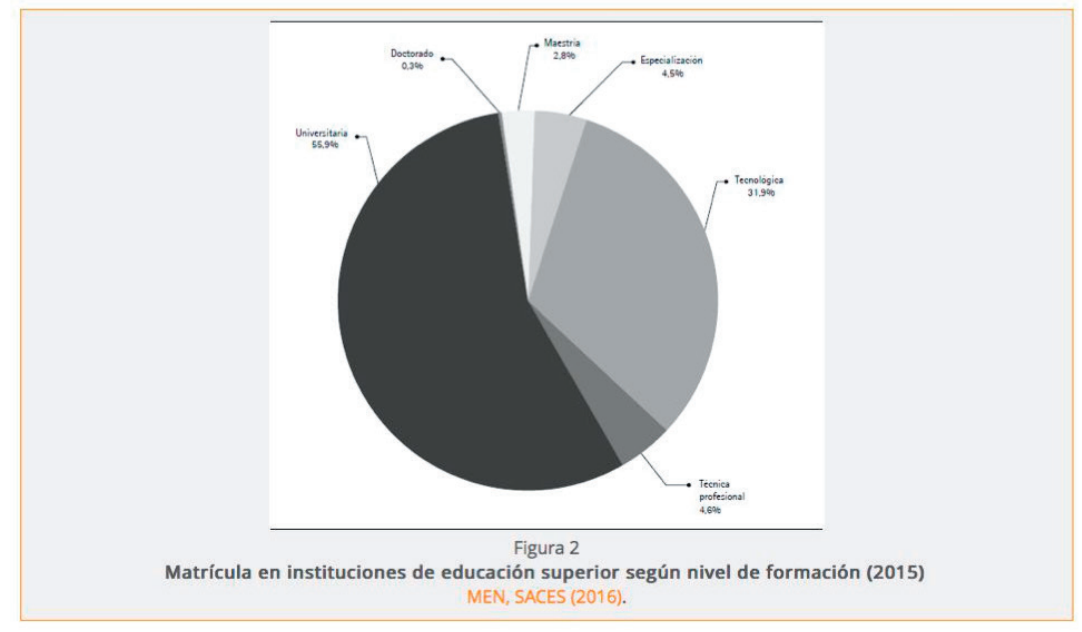

Fuente: Universidad de los Andes. La educación superior en Colombia, 2018 
En cuanto a la matrícula universitaria a nivel de pregrado se puede destacar que el número de estudiantes registrados ascendió de 582.672 en el 2000 a 1.092 .900 en el año 2015. En cuanto a las universidades públicas, la matrícula aumentó de 234.210 estudiantes en el año 2000 a 553.197 estudiantes en el 2015. En este período se puede destacar el aumento de 53.754 estudiantes matriculados en la Universidad Nacional Abierta y a Distancia. Además, las instituciones con mayor número de estudiantes matriculados en el 2015 fueron la Universidad Nacional Abierta y a Distancia con 61.411 estudiantes, la Universidad Nacional de Colombia con 43.300 estudiantes, la Universidad de Antioquia con 32.523 estudiantes y la Universidad Pedagógica y Tecnológica de Colombia con 26.263 estudiantes (Tabla 4)

Tabla 4. Matrículas universidades públicas a nivel de pregrado profesional

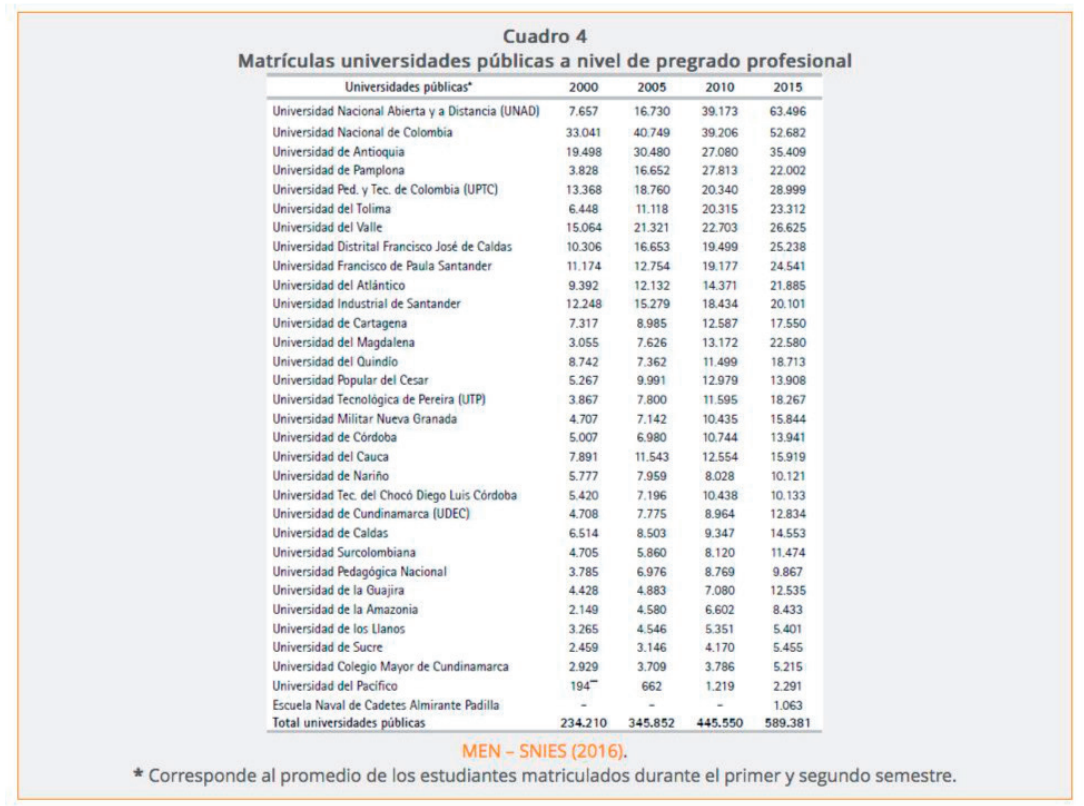

Fuente: Universidad de los Andes. La educación superior en Colombia, 2018 
Por su parte, las universidades privadas aumentaron su matrícula de 348.462 estudiantes en el 2000 a 539.704 estudiantes en el 2015. Para este último año se destaca la matrícula de la Universidad Cooperativa de Colombia con 48.144 estudiantes, la de la Universidad Libre con 29.082 estudiantes, la de la Universidad Santo Tomás con 28.109 estudiantes, y la de la Pontificia Universidad Javeriana con 25.309 estudiantes (Tabla 5).

Tabla 5. Matrículas en las universidades privadas a nivel de pregrado profesional

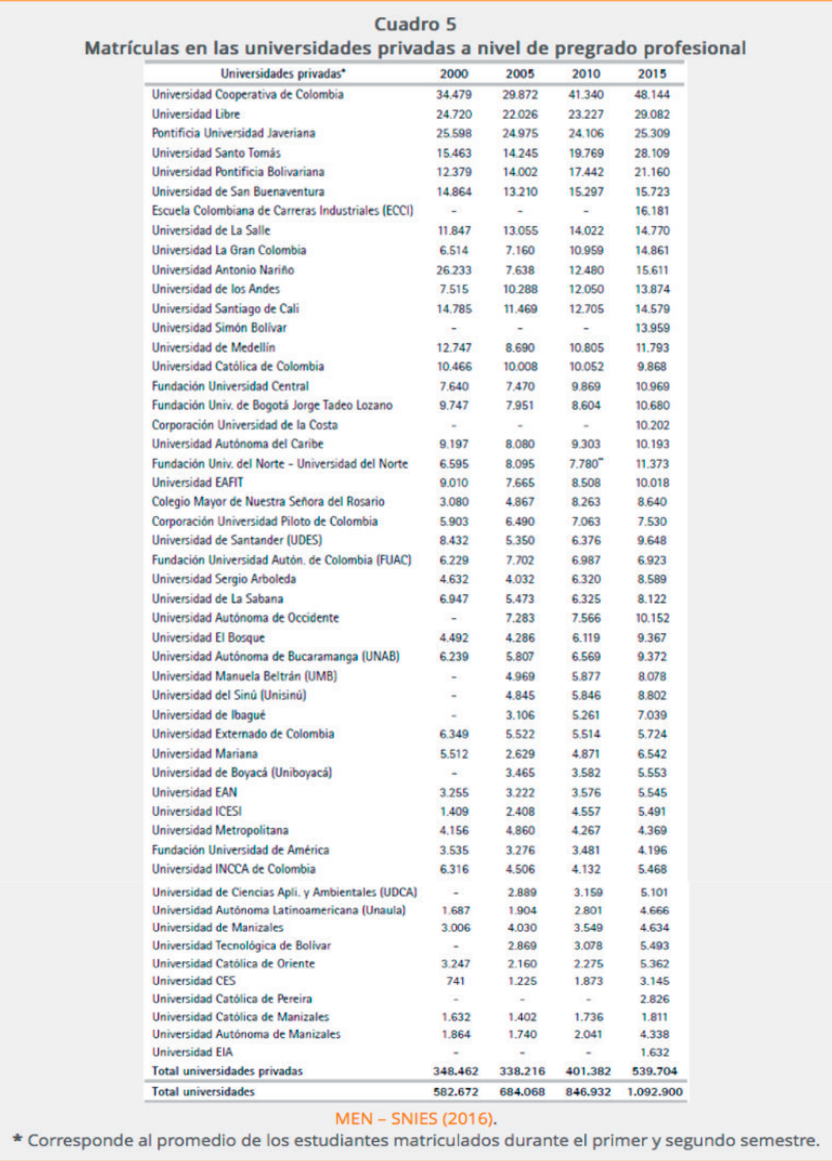

Fuente: Universidad de los Andes. La educación superior en Colombia, 2018 
Dentro de las instituciones universitarias públicas sobresale la Escuela Superior de Administración Pública (ESAP) con 10.319 estudiantes, el Politécnico Colombiano Jaime Isaza Cadavid con 14.811 estudiantes y el Instituto Tecnológico Metropolitano con 22.765 estudiantes. Dentro de las instituciones universitarias privadas se destacan la Corporación Universitaria Minuto de Dios con 93.658 estudiantes, el Politécnico Gran colombiano con 30.748 estudiantes, la Fundación Universitaria del Área Andina con 18.850 estudiantes, la Corporación Universitaria Remington con 18.281 estudiantes y la Fundación Universitaria Luis Amigó (FUNLAM) con 15.035 estudiantes.

A nivel de posgrado, las matrículas aumentaron de 62.259 estudiantes en el año 2002 a 122.514 estudiantes en el 2015 . Para este último año, dentro de las universidades públicas se pueden destacar la Universidad Nacional con 9.383 estudiantes, la Universidad del Valle con 3.218 estudiantes, la Universidad de Antioquia con 2.886 estudiantes, la Universidad Militar Nueva Granada con 1.858 estudiantes y la Universidad Pedagógica y Tecnológica de Colombia (UPTC) con 2.737 estudiantes. En el ámbito privado, se destacan la Universidad de Santander con 9.885 estudiantes, la Universidad Externado de Colombia con 7.502 estudiantes, la Pontificia Universidad Javeriana con 5.488 estudiantes, la Universidad de los Andes con 4.419 estudiantes y la Universidad Libre con 5.119 estudiantes.

\section{Deserción:}

En cuanto a las tasas de deserción, los indicadores revelan una situación preocupante. En efecto, del seguimiento a las tasas de deserción por período y por cohortes se concluye que en promedio uno de cada dos estudiantes no culmina sus estudios superiores (MEN, 2009) . Por nivel de formación, para el año 2015, la tasa de deserción por período fue del 32,6\% para el nivel técnico, 18,0\% para el nivel tecnológico, y 9,3\% para el nivel universitario; por su parte, la tasa de deserción por cohorte representó un $56,9 \%$ 
para el nivel técnico, un 52,1\% para el nivel tecnológico y $46,1 \%$ para el nivel universitario. Cuando se evalúa la permanencia de los estudiantes por áreas del conocimiento (cuadro 6), las mayores tasas de deserción por período al nivel universitario se observan en matemáticas y ciencias naturales $(11,1 \%)$, en agronomía, veterinaria y afines (10,2\%), y en economía, administración, contaduría y afines $(10,1 \%)$, (Tabla 6 )

Tabla 6. Deserción anual por área de conocimiento y nivel de formación (2015)

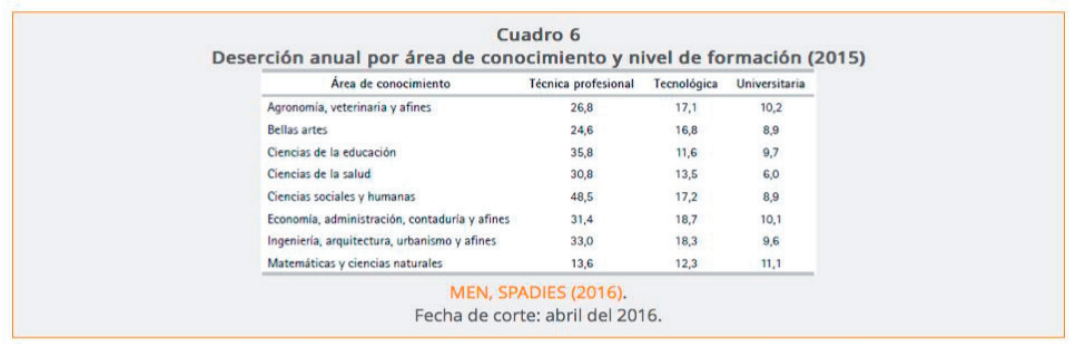

Fuente: Universidad de los Andes. La educación superior en Colombia, 2018

En el nivel técnico, la tasa de deserción por cohorte (o acumulada) alcanza $28,8 \%$ en el primer semestre y $57,0 \%$ en el sexto. Por su parte, el nivel tecnológico acumula tasas de deserción del $24,9 \%$ en el primer semestre y $52,1 \%$ en el sexto. Asimismo, en el nivel universitario la tasa de deserción asciende del 18,0\% en el primer semestre al 46,1\% en el décimo (Gráfica 22). 
Gráfica 22. Deserción por nivel de formación académica (2015)

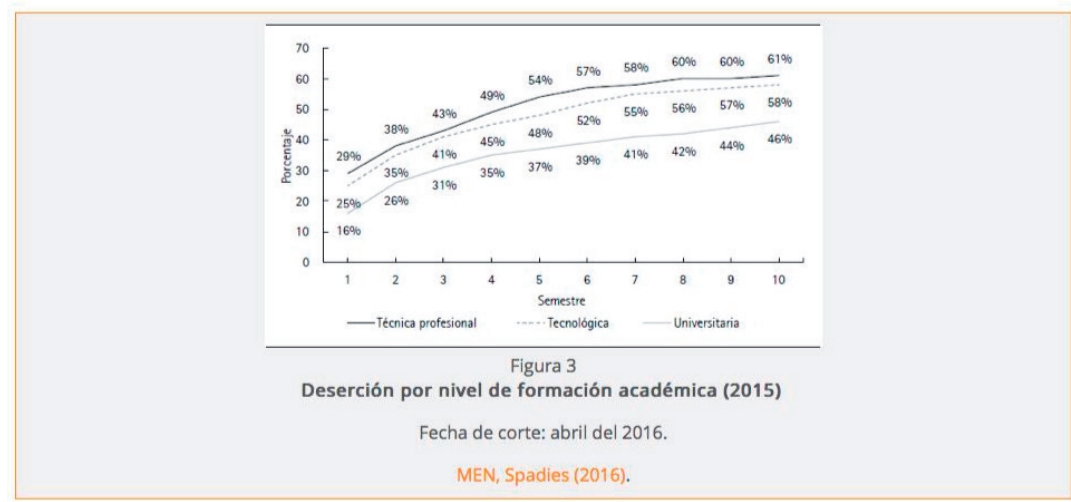

Fuente: Universidad de los Andes. La educación superior en Colombia, 2018

Por áreas del conocimiento, las tasas de deserción por cohorte muestran que las áreas de conocimiento con mayores tasas acumuladas (al décimo semestre) resultan ser ingeniería, arquitectura, urbanismo y afines $(55,0 \%)$, bellas artes $(52,8 \%)$, economía, administración, contaduría y afines (51,6\%) y matemáticas y ciencias naturales $(51,0 \%)$ (Tabla 7$)$.

Tabla 7. Deserción por cohorte por área del conocimiento (2015)

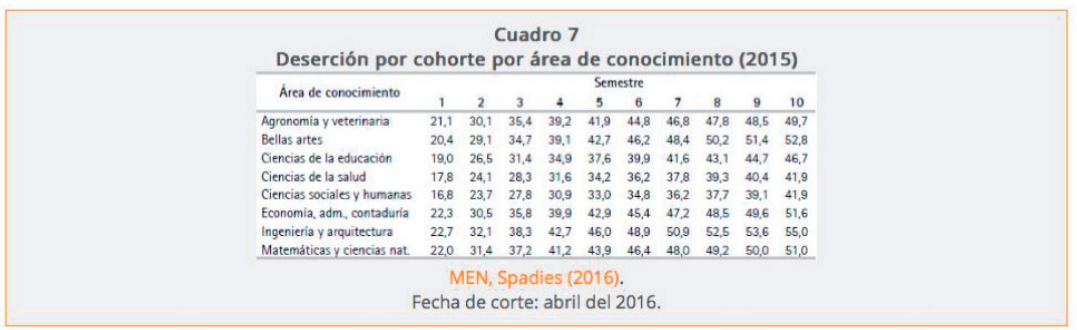

Fuente: Universidad de los Andes. La educación superior en Colombia, 2018 
Por último, debe señalarse que en general, las razones por las cuales los estudiantes abandonan sus estudios obedecen a una combinación de factores sociales, económicos, familiares e individuales que afectan el entorno de los jóvenes (MEN, 2016). Específicamente, de acuerdo con el estudio del MEN (2009), son principalmente razones de índole personal (edad, género, situación laboral), académicas (repitencia, área de conocimiento y puntaje del ICFES), socioeconómicas (nivel de ingresos, educación de la madre, tasa de desempleo de la región, número y posición entre los hermanos) e institucionales (facilidad de apoyo financiero).

\section{Docentes:}

Respecto a los docentes, de acuerdo con el MEN, en el 2015 el sistema de educación superior contaba con 148.689 profesores, en promedio para ambos semestres, de los cuales $45.362(30,5 \%)$ laboraban con un contrato de tiempo completo, $14.048(9,4 \%)$ en la modalidad de medio tiempo y $90.763(61,0 \%)$ con un esquema parcial o de hora cátedra (Tabla 8). Por nivel de formación, para los 144.270 profesores que indicaron máximo nivel de formación, el 2,1\% de estos docentes tenía título de técnico o tecnólogo, el $29,9 \%$ tenían título de pregrado, el 30,6\% de especialización, el $30,7 \%$ de magíster y el 6,7\% de doctorado o posdoctorado. Llama la atención la alta proporción de profesores catedráticos (61\%) y el bajo porcentaje de docentes con doctorado $(6,7 \%)$, que además están concentrados en pocas universidades (Tabla 8). Esta situación puede estar afectando las actividades de investigación, la formación académica de los estudiantes y, en general, los resultados del sistema educativo. 
Tabla 8. Docentes e educación superior

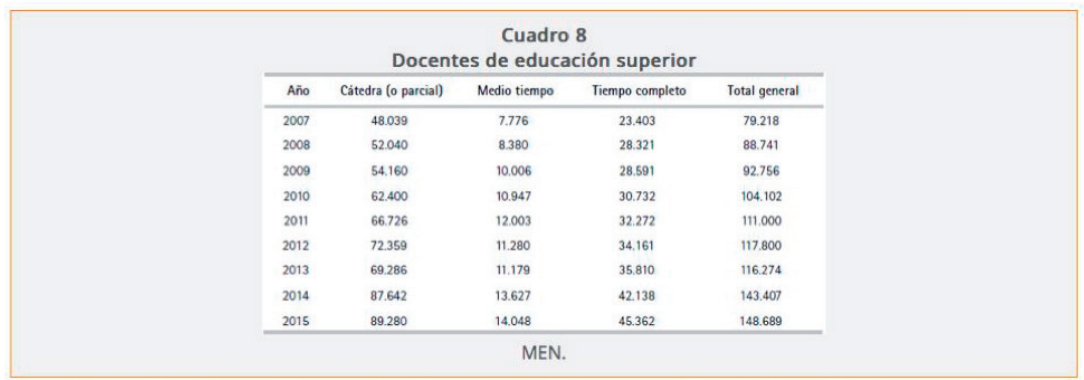

Fuente: Universidad de los Andes. La educación superior en Colombia, 2018

\section{Financiación:}

Sobre la financiación de las instituciones de educación superior, es necesario señalar que mientras los recursos de las entidades privadas provienen esencialmente del cobro de derechos de matrícula, los de las instituciones de carácter público se originan en gran parte en transferencias del gobierno central y/o de los gobiernos subnacionales, a través del Sistema General de Participaciones (SGP). En el período 2000-2015, el gasto estatal en este nivel de enseñanza representó en promedio $0,94 \%$ del PIB, del cual un poco más de la mitad corresponde a aportes de la nación y el resto a recursos territoriales y a rentas (Tabla 9). Los aportes de la nación están asignados principalmente al financiamiento de las universidades Nacional, de Antioquia y del Valle, que reciben alrededor del 30\%, el 10\% y el $9 \%$ de los recursos, respectivamente, el $51 \%$ restante, se distribuye entre las otras 29 universidades públicas. Durante la última década, los recursos estatales para educación superior no han mostrado cambios significativos respecto al PIB, lo cual sugiere que el Estado no ha respondido de forma paralela al crecimiento de la demanda por cupos de educación superior, aunque en los últimos años se observó un leve crecimiento en la participación de los aportes de la nación a las IES públicas. 
Tabla 9. Gasto del Estado en educación superior (porcentaje del PIB)

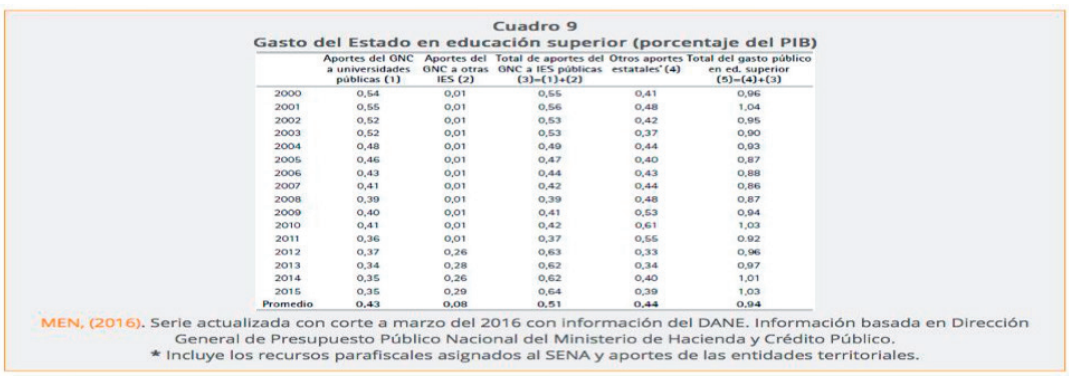

Fuente: Universidad de los Andes. La educación superior en Colombia, 2018

\section{Calidad:}

En particular, los resultados del 2012, que se presentan en la tabla 10, indican que los programas de medicina y economía obtienen en general los mejores puntajes en razonamiento cuantitativo, lectura crítica, escritura e inglés. Por su parte, los programas de humanidades se destacan en escritura, lectura crítica e inglés y los de ingeniería en razonamiento cuantitativo.

Tabla 10. Resultados de las pruebas genéricas Saber Pro (2012)

\begin{tabular}{|c|c|c|c|c|}
\hline \multicolumn{5}{|c|}{$\begin{array}{l}\text { Cuadro 10 } \\
\text { Resultados de las pruebas genéricas Saber Pro (2012) }\end{array}$} \\
\hline Grupo de referencia & Razonamiento cuantitativo & Lectura critica & Escritura & Ingles \\
\hline Administración y afines & 9,9 & 9.9 & 10,2 & 10,2 \\
\hline Arquitectura y urbanismo & 10.1 & 10,1 & 10.1 & 10.6 \\
\hline Bellas artes y disefio & 10,0 & 10,3 & 10,2 & 11,3 \\
\hline Ciencias agropecuarias & 10,1 & 9,9 & 10,0 & 10,1 \\
\hline Ciencias militares $y$ navales & 10,1 & 9,7 & 10,1 & 10,4 \\
\hline Ciencias naturales $y$ yexactas & 10,6 & 10,4 & 10,4 & 10,9 \\
\hline Ciencias sociales & 9.8 & 10.2 & 10,7 & 10.5 \\
\hline Com, period. y publicidad & 9,8 & 10,2 & 10,5 & 10,8 \\
\hline Contaduria y afines & 9,9 & 9,8 & 10,0 & 9,7 \\
\hline Derecho & 9,8 & 10.1 & 10.5 & 10.1 \\
\hline Economia & 10,7 & 10,5 & 10,7 & 11,0 \\
\hline Educación - Todas & 9,5 & 0.7 & 10,1 & 9,9 \\
\hline Enfermeria & 9.7 & 9.8 & 10.1 & 9.8 \\
\hline Humanidades & 9,9 & 10,5 & 10,9 & 11,0 \\
\hline Ingenieria & 10,6 & 10,2 & 10,2 & 10,6 \\
\hline Medicina & 10.5 & 10,6 & 10,4 & 11.1 \\
\hline Psicologia & 9,6 & 10,1 & 10,4 & 10,1 \\
\hline Salud & 0,7 & 0.8 & 10,0 & 9,9 \\
\hline \multicolumn{5}{|c|}{ ICFES. } \\
\hline
\end{tabular}

Fuente: Universidad de los Andes. La educación superior en Colombia, 2018 


\section{Eficiencia:}

En la tabla 11, se presentan el promedio y la desviación estándar de las medidas de eficiencia estimadas por medio de los modelos base y alternativo. Para el total de la muestra, la eficiencia técnica promedio, utilizando el modelo base, es de 0,789 , con un máximo de 0,958 y un mínimo de 0,259 . Con el modelo alternativo, el promedio es de 0,607 , con un máximo de 0,973 y un mínimo de 0,228 . Estos resultados sugieren que existe un margen para que las instituciones de educación superior mejoren su eficiencia, especialmente, si se tiene en cuenta que mientras para algunos esta medida supera el 0,90, para otros es inferior al 0,30.

Tabla 11. Eficiencia técnica

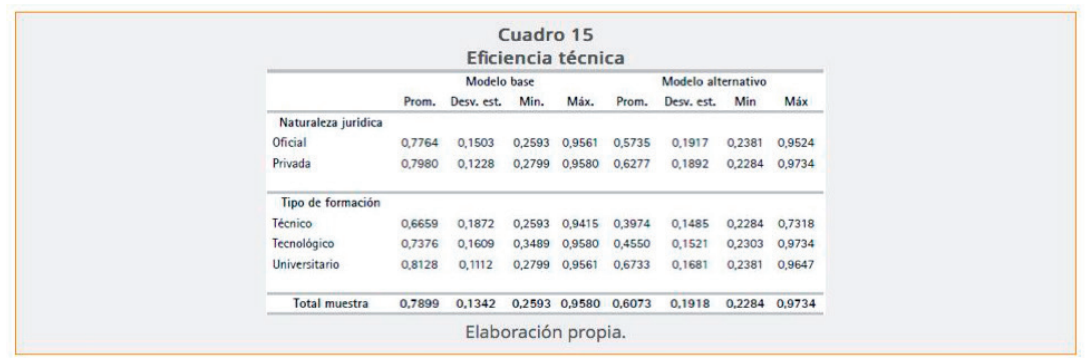

Fuente: Universidad de los Andes. La educación superior en Colombia, 2018

Estos resultados son consistentes con estudios que han mostrado que las condiciones socioeconómicas de los estudiantes y sus familias tienen un impacto significativo sobre el rendimiento de los estudiantes (Escobar y Orduz, 2013). Vale la pena resaltar que estas variables no dependen directamente de la gestión de las instituciones de educación superior la eficiencia en los dos casos es mayor para las instituciones privadas, y, cuando se evalúan los resultados por tipo de formación, los mayores niveles de eficiencia se registran en el nivel universitario con 0,81 en el modelo base y con 0,67 en el alternativo 
Como conclusiones del estudio de la Universidad de los Andes se destacan ${ }^{14}$ :

A pesar de los avances institucionales y del aumento en la matrícula estudiantil, aún se observa gran heterogeneidad en la calidad de los programas ofrecidos, inequidad en el acceso y una oferta insuficiente de cupos. En efecto, aunque durante las dos últimas décadas la cobertura registra adelantos importantes, especialmente en la formación técnica y tecnológica, desde una perspectiva internacional la tasa de cobertura del país continúa siendo relativamente baja cuando se compara con países desarrollados y con países de América Latina como Argentina, Chile, Cuba, Uruguay y Puerto Rico

Con respecto a las pruebas de logro académico para educación superior, con la Ley 1324 del 2009, adquirieron el carácter de obligatorias y empezaron a evaluar competencias genéricas comunes para todos los programas. En general, los resultados indican variaciones importantes entre los programas académicos y las instituciones académicas del país.

Los resultados del ejercicio, que estima la eficiencia en el desempeño de 1.020 grupos de referencia asociados a diferentes programas académicos de 155 instituciones de educación superior, indican que las variables de infraestructura y aquellas asociadas al personal docente tienen un impacto positivo en los resultados de las pruebas de logro de los estudiantes de las diferentes instituciones. En cuanto a las medidas de eficiencia, se encuentra que estas varían entre 0,228 y 0,973 , lo que indica que existe un margen amplio para obtener ganancias de eficiencia por parte de varias instituciones del país.

Por otro lado, los resultados destacan la importancia de las condiciones socioeconómicas de los estudiantes y de sus 
familias, así como de otros factores de entorno, para explicar las diferencias en el desempeño académico de los estudiantes de los diferentes programas académicos ofrecidos por las instituciones de educación superior del país

Aunque muchas instituciones educativas tienen margen para mejorar sus niveles de eficiencia, están restringidas por la influencia de los factores de entorno de sus estudiantes. Así, para lograr un mejoramiento de los resultados académicos, las medidas de política del Estado y las estrategias de las instituciones deben tomar en cuenta, además de los criterios en la contratación de docentes, la definición de incentivos para la investigación y los aspectos administrativos y financieros, los mecanismos que permitan ayudar a contrarrestar el impacto negativo derivado de las condiciones socioeconómicas de los estudiantes y de otros factores ambientales.

En este mismo sentido, vale mencionar otros estudios realizados sobre la calidad de la educación en Colombia recopilados en documento del ICFES (2012), que entre otros aspectos resalta: "En general, es común encontrar la conclusión de que los factores socioeconómicos son el principal determinante del logro educativo (Caro, 2000; Gaviria y Barrientos, 2001b, 2001c; Banco Mundial, 2009),

incluso el nivel socioeconómico medio de los planteles, ya que dentro de estos las condiciones socioeconómicas son homogéneas (Casas et al., 2002; Gamboa et al., 2003), evidenciando que el sistema educativo colombiano posee un gran sesgo clasista que “... además de que es injusto e inequitativo, no contribuye a cualificar el capital humano" (Sarmiento et al., 2000, p 58). Algunos factores asociados al desempeño desde lo institucional son: el gasto en educación a nivel municipal, asociado positivamente con el logro; la pobreza y la desigualdad, que en los municipios se asocian negativamente con los resultados escolares (Mina, 2004)”. El estudio de la calidad en la educación superior colombiana ha 
sido escaso, pero hay nociones de que los factores asociados al logro en este nivel educativo son diferentes a los encontrados en la educación básica. Sarmiento et al. (2000) encuentran una mayor proporción de egresados de colegios privados dentro de los inscritos y admitidos en la Universidad Nacional de Colombia en 1998, lo cual sugiere que estos son "mejores" que los oficiales, y resaltan la relación existente entre el nivel socioeconómico de los alumnos y la incidencia del plantel en el logro educativo.

Respecto de la brecha educativa es un problema de eficacia escolar, que está definida por la incapacidad del sistema educativo para lograr que individuos de menores condiciones socioeconómicas incorporen efectivamente los conocimientos y competencias que necesitan para participar en la sociedad. Estudios nacionales han cuantificado la brecha educativa desde tres perspectivas metodológicas: (i) diferencia entre el puntaje obtenido y el puntaje potencial, (ii) dispersión en los puntajes obtenidos dentro de un grupo y (iii) comparación entre los promedios del puntaje obtenido por el grupo estudiado y un grupo de referencia.

Ahorabien, sobrelo que está pasando en el mundo con respecto a la educación en las circunstancias actuales del COVID-19, según el estudio realizado por el Instituto Internacional para la Educación Superior en América Latina y el Caribe (IESALAC) y la Organización de las Naciones Unidas para la Educación, la Ciencia y la Cultura (UNESCO) ${ }^{15}$, los cierres temporales de instituciones de educación superior (IES) por causa de la pandemia del COVID-19, son significativos. A continuación, se presentan los resultados. Las estimaciones de la UNESCO IESALC, muestran que el cierre temporal afecta aproximadamente a unos 23,4 millones de estudiantes de educación superior (CINE 5, 6, 7

15 Estudio del Instituto Internacional para la Educación Superior en América Latina y el Caribe (IESALAC) y la Organización de las Naciones Unidas para la Educación, la Ciencia y la Cultura (UNESCO), 2020, p. 5-15 https://www.universidad.edu.co/wp-content/uploads/2020/04/ Covid_19_Unesco.pdf 
y 8) y a 1,4 millones de docentes en América Latina y el Caribe; esto representa, aproximadamente, más del $98 \%$ de la población de estudiantes y profesores de educación superior de la región (Gráfica 23). De hecho, se podría decir que la pandemia añade un grado más de complejidad crítica a una educación superior que, prácticamente en todo el mundo, pero en particular en la región, ya se enfrentaba a retos no resueltos como un crecimiento sin calidad, inequidades en el acceso y la pérdida progresiva de financiamiento público

Gráfica 23. Estudiantes y docentes afecados en el mundo por cuenta del COVID-19

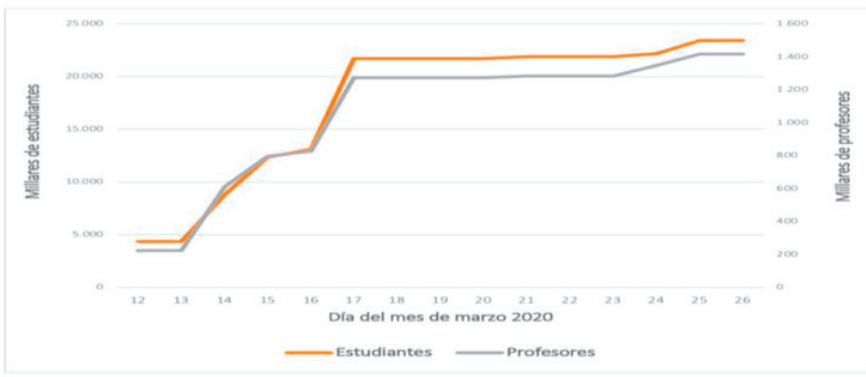

Fuente: Tomado de Documento: Oportunidad Estratégica. ¿A qué se enfrenta la educación superior en el 2020? Jorge Hernán Cárdenas S.

21 de abril de 2020

Con respecto a la conectividad, se observa en primer lugar, el porcentaje de hogares con conexión a internet y refleja la baja conectividad en África y en América Latina y el Caribe que, apenas alcanza el $17 \%$ y el $45 \%$ respectivamente. En el caso de América Latina y el Caribe la conectividad alcanza aproximadamente el $48 \%$, esto es tanto como decir que solo uno de cada dos hogares está conectado (Gráfica 24). 
Gráfica 24. Estado de la conectividad por regiones del mundo

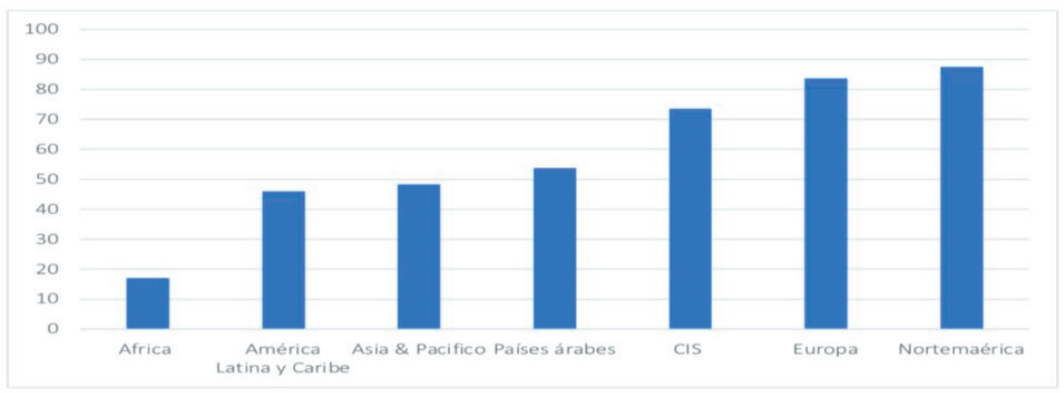

Fuente: Tomado de Documento: Oportunidad Estratégica. ¿A qué se enfrenta la educación superior en el 2020? Jorge Hernán Cárdenas S.

21 de abril de 2020, pág 2-27

En este sentido, parece claro que en todo el mundo el cese temporal de las actividades presenciales de las Instituciones de Educación Superior (IES) ha operado como un enorme disruptor sobre su funcionamiento. El impacto de esta disrupción es muy variable y depende, en primer lugar, de su capacidad para mantenerse activas en sus actividades académicas y, en segundo lugar, de su sostenibilidad financiera. (IESALAC y UNESCO, 2007)

Por lo anterior, en términos de respuestas políticas en el tema de la educación, los países han tenido que limitarse a tres cosas: a) implementar medidas administrativas para la salvaguarda del funcionamiento del sistema; b) gestionar recursos financieros y la puesta a disposición de recursos para dar continuidad a las actividades formativas, por medio de la educación a distancia; c) el apoyo con recursos bibliográficos y tecnológicos y, también socioemocional a la comunidad universitaria (IESALAC y UNESCO, 2020).

Según estos estudios, la educación a distancia lleva años experimentando un gran crecimiento en la región. Concretamente, la cobertura de esta modalidad ha crecido un $73 \%$ desde 2010 , 
mientras que la presencial lo hizo solo un 27\%. En 2010, casi 2 millones y medio de los 21 millones de estudiantes universitarios de primer título en la región estudiaban a distancia, representando un $11,7 \%$ del total. El incremento de la educación virtual se veía en América Latina desde hace algunos años. Ahora va a tomar más fuerza ${ }^{16}$.

Para el caso de Colombia, según artículo del Espectador titulado "Educación superior en cuidados intensivos por coronavirus" escrito por Camila Taborda - @Camilaztabor ${ }^{17}$, se experimenta un decrecimiento dramático en las matrículas tanto de las universidades públicas como privadas.

Según este artículo, desde el 2016, viene descendiendo la matricula en las instituciones de educación superior y para el primer semestre de 2018 el descenso ya era del 18\% para las universidades públicas y el $8 \%$ para las universidades privadas (Gráfica 25).

Grafica 25. Matrícula primer curso en pregrado en IES

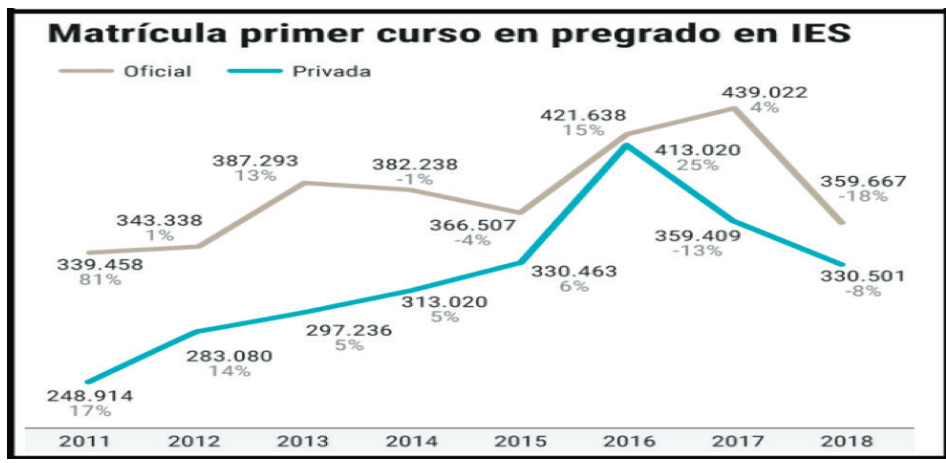

Fuente: Tomado de Periódico el Espectador: "Educación superior en cuidados intensivos por coronavirus", Educación, 24 Abr 2020 - 9:00 PM.

16 Documento: Oportunidad Estratégica. ¿A qué se enfrenta la educación superior en el 2020? Jorge Hernán Cárdenas S. 21 de abril de 2020, p. 2-27

17 Periódico el Espectador: Artículo "Educación superior en cuidados intensivos por coronavirus", Educación, 24 Abr 2020,pág . 1-6. Camila Taborda - @Camilaztabor. http://elespectador.com/ coronavirus/educacion-superior-en-cuidados-intensivos-por-coronavirus-articulo-916419 
Antes de la llegada del COVID-19, venía registrándose una gradual reducción en la demanda de programas que dieron origen a la reducción de la matrícula, atribuida en parte a temas demográficos y en parte por la ampliación en la oferta de programas, nuevas Instituciones de Educación Superior (IES) y proveedores alternativos de propuestas educativas formales y no formales de menor duración y en línea y, muchas otras opciones, nacionales e internacionales ${ }^{22}$.

Con respecto a la matricula en programas presenciales que había venido creciendo hasta el año 2015 a 1.965 .890 estudiantes, a partir del 2016 empezó a descender situándose en el 2018 en 1.882.749 estudiantes, disminución equivalente al 4,2\% para el primer semestre (Gráfica 26)

Grafica 26. Matrícula en programas académicos presenciales en IE

\section{Matrícula en programas académicos presenciales}

Primer semestre

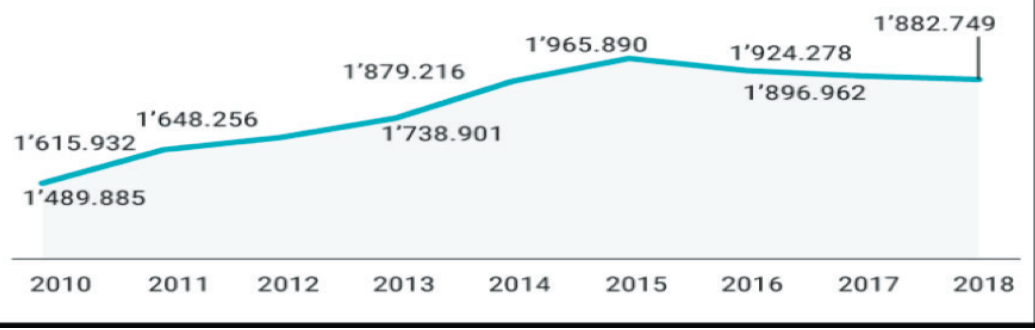

Fuente: Tomado de Periódico el Espectador: "Educación superior en cuidados intensivos por coronavirus”, Educación, 24 Abr 2020 - 9:00 PM

Para el caso de los programas virtuales, el panorama es diferente, la matricula académica registra un crecimiento importante del 191\%\% entre el 2015 y 2018 primer semestre, según reportes de ASCUN Y ESNIES (Gráfica 27) 
Grafica 27. Matrícula en programas académicos virtuales en IES

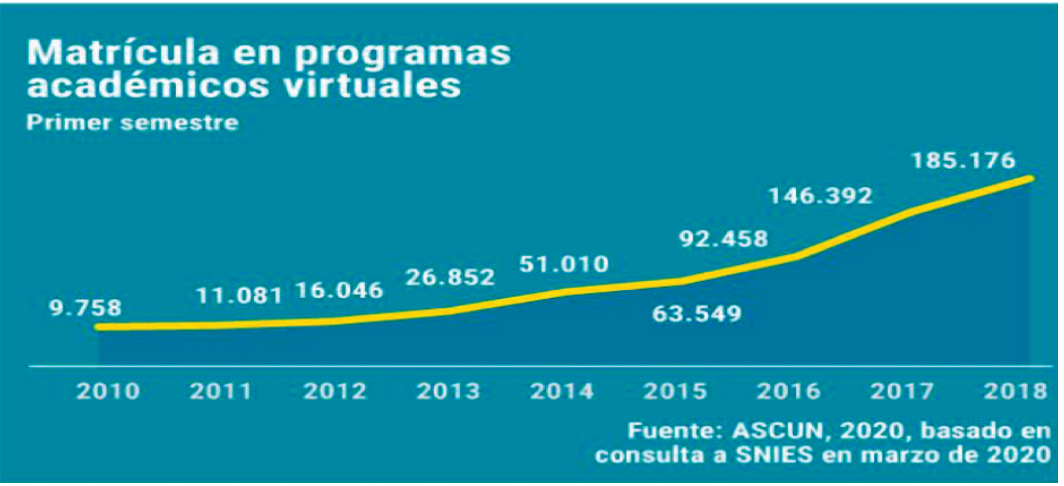

Fuente: Tomado Periódico el Espectador: “ Educación superior en cuidados intensivos por coronavirus”, Educación, 24 Abr 2020 - 9:00 PM

A la caída de matrículas universitarias que venía registrándose, se sumó la emergencia del COVID-19, y la crisis económica que podrían quebrar para el segundo semestre a varias instituciones del país. En estas circunstancias, no es un secreto que la educación superior del país es una de las mayores víctimas del coronavirus. Aunque la crisis de las Instituciones de Educación Superior (IES), en principio, no es novedad, pues desde hace cuatro años cada vez son menos las personas que empiezan a estudiar un pregrado en Colombia. La prueba de ello es que las admisiones en universidades privadas, cuyos ingresos dependen esencialmente del cobro de matrícula, cayeron un $13 \%$ entre 2016 y 2017. En el caso de las públicas, que se sostienen por transferencias del Gobierno, la baja de matrículas fue del $18 \%$ hace tres años, según análisis del Laboratorio de Economía de la Educación de la Universidad Javeriana ${ }^{23}$.

Lo anterior se debe a que "la mayoría de las instituciones ha actuado con lentitud en aprovechar el potencial de las nuevas tecnologías", afirma una docena de líderes latinoamericanos en

23. Periódico el Espectador: "Educación superior en cuidados intensivos por coronavirus", Educación, 24 Abr 2020, pág . 1-6. Camila Taborda - @Camilaztabor. http://elespectador.com/ coronavirus/educacion-superior-en-cuidados-intensivos-por-coronavirus-articulo-916419 
educación superior a través de un manifiesto frente al COVID-19. La emergencia es una angustia que supera la región. En Estados Unidos, por ejemplo, más de 2.000 IES estiman que sus déficits aumentarán $5 \%$ o más para final de este año, de acuerdo con un informe hecho por la consultora Mckinsey.

De otra parte, según Carlos Mario Lopera, quien lleva más de una década pensado el sector desde el Observatorio de la Universidad Colombiana, no más del $20 \%$ de las 302 IES tenían experiencia en virtualidad. Así que, "mientras más se extienda la suspensión de clases presenciales, la probabilidad de que se quiebren va a aumentar fuertemente, específicamente, las privadas. Solo un grupo de universidades grandes puede sobrevivir este año". Para ello tendrán que bajar sus costos de matrícula, otorgar becas, descuentos, generar mecanismos de cooperación entre ellas, ser por fin un sistema de educación nacional y ofrecer facilidades de pago como algunas lo han anunciado hasta ahora.

El problema es que esa transición es costosa y toma tiempo, asegura José Leonardo Valencia, rector de la Fundación Universitaria del Área Andina, una de las IES líderes en educación virtual del país con 14 mil estudiantes a nivel nacional y otros 6 mil inscritos en Costa Rica y Panamá. Según lo afirma el rector, para atender la crisis del COVID-19 "Lo que ha hecho la mayoría de las IES es migrar de un modelo presencial a uno remoto en el que utilizan herramientas de conectividad como Zoom o Microsoft Teams, donde acceden a momentos sincrónicos, en los que hay interacción, pero esa no es la virtualidad completa. Para ello necesitas una apropiación de tecnologías y una inversión en infraestructura, no edificios sino una plataforma pedagógica, simuladores, creadores de contenido, diseñadores, animadores, un estudio de televisión. A un equipo como ese, en Área Andina, le tarda tres meses desarrollar el modelo de una clase. 
Un curso nos cuesta US $\$ 5.000$ y un programa de educación tiene 60 cursos, eso equivale a \$1.200 millones más lo que vale la licencia", cuenta el rector quien ha apadrinado, por petición del Ministerio de Educación, a cuatro IES del país en medio de la coyuntura $^{24}$.

En este sentido, la Ministra de Educación Nacional en entrevista con la Revista Semana ${ }^{25}$ reconoce que, claramente, la transformación digital y el trabajo colaborativo son una de las principales lecciones que tiene el sector en esta coyuntura. En este proceso se ha logrado convocar a todos los actores que desde diferentes escenarios tienen intereses, avances, desarrollos y experiencias en educación y destaca la gran solidaridad de diferentes Instituciones de Educación Superior, que se han unido para liderar junto con el Ministerio la estrategia llamada "Plan Padrino IES", cuyo objetivo es unir esfuerzos para compartir capacidades, experiencias y conocimientos en el desarrollo de actividades académicas asistidas por las herramientas que ofrecen las Tecnologías de la Información y las Comunicaciones - TIC.

En cualquier caso, según el artículo de Oportunidad Estratégica “...La educación superior no volverá a ser la misma y más allá de las dificultades tecnológicas, la limitación de conocimiento y las reservas paradigmáticas sobre la virtualidad, la enseñanza - aprendizaje se modificará en sus formas y obligatoriamente incorporará de forma definitiva a la tecnología"26

Si bien es cierto que, varias universidades del país han venido avanzando en el proceso de virtualización de algunos programas, las circunstancias actuales demuestran que las instituciones de

24 Revista Semana. EDUCACIÓN |3/30/2020, pág 1-8. 'Hoy debemos ser flexibles, innovar y trabajar en equipo': Ministra de Educación. https://www.semana.com/educacion/articulo/coronavirusministra-de-educacion-habla-del-impacto-en-las-clases/660324

25 Documento: Oportunidad Estratégica. ¿A qué se enfrenta la educación superior en el 2020? Jorge Hernán Cárdenas S. 21 de abril de 2020, pág 2-27

26 Documento: Oportunidad Estratégica. ¿A qué se enfrenta la educación superior en el 2020 ? Jorge Hernán Cárdenas S. 21 de abril de 2020, pág. 2-27 
educación superior deben ir migrando progresivamente hacia la virtualización de sus programas para estar a la vanguardia de los retos de la globalización y las exigencias de la población, especialmente los jóvenes que demandan cada vez más el uso de las tecnologías para la solución rápida de los problemas. Esto implica realizar grandes inversiones para tener capacidad instalada con la integración de nuevas tecnologías.

El desafío es cada vez mayor para las instituciones de educación superior, si se tiene en cuenta que un buen número de universidades a nivel mundial han venido ofreciendo cursos en línea, masivos y gratuitos de corta duración, orientados a adquirir y fortalecer competencias específicas aplicadas al trabajo, estos son los denominados Massive Online Open Courses "Mooc"; en este sentido, cada vez los jóvenes están prefiriendo realizar este tipo de cursos antes que matricularse en una carrera formal cuya duración es de 5 o más años, pues las empresas están requiriendo preferencialmente, personas con competencias laborales a cambio de profesionales con títulos.

Precisamente, la universidad de Harvard acaba de lanzar cursos virtuales gratuitos en áreas como humanidades, ciencias sociales, ciencias exactas, prevención de la salud y atención de emergencias, con duración entre 3 y 15 semanas. Esta es una gran oportunidad para estudiantes, docentes y profesionales que nunca podrían ir a estudiar a esa universidad, dado el alto costo de sus programas.

Pese a los esfuerzos realizados por el gobierno y algunas universidades de manera autónoma, en la coyuntura actual que vive el mundo por la pandemia del COVID 19, ha quedado al descubierto que las instituciones de educación superior, particularmente en Colombia, no se encuentran preparadas para asumir el reto de la educación medida por las TIC, por lo tanto, este es un gran desafío que tienen por delante todas las instituciones, tanto públicas como privadas para avanzar rápidamente en este 
propósito a fin de ser competitivas ante las nuevas demandas y expectativas de sus clientes. Es claro que las circunstancias, durante este período de emergencia sanitaria, han traído dificultades de todo tipo, pero también, se han abierto oportunidades para asumir nuevos retos que constituyen cambios profundos y aprendizajes nuevos para hacerle frente a las realidades de éste nuevo siglo, en particular, lo relacionado con el uso y apropiación de las TIC.

En concordancia con lo anterior, el Estado de Emergencia Económica, Social y Ecológica decretado por el Gobierno Nacional a través del Decreto con fuerza de Ley 417 del 17 de marzo de 2020, Decreto de Legislativo 491 del 28 de marzo del 2020 y todas las directrices derivadas del mismo, la Resolución 385 del 12 de marzo de 2020 del Ministerio de Salud y Protección Social, que decreta la emergencia sanitaria en todo el país; así como, las Directiva Presidencial No. 2 del 12 de marzo de 2020 y la Directiva No. 04 del 22 de marzo de 2020 del Ministerio de Educación, han obligado a todas las instituciones de educación superior a establecer estrategias para darle continuidad a los planes de estudio y programas académicos con registros calificados en modalidad presencial, utilizando todas las herramientas disponibles en materia de TIC, denominado por el Ministerio de Educación como Presencialidad Asistida por Tecnologías (PAT). Por lo tanto, en Colombia, para salirle al paso a la emergencia del COVID-19 y garantizar el cumplimiento de los programas y planes de estudio, muchas universidades han recurrido al uso de diferentes plataformas para educación asistida tales como Moodle, Teams, Classroom, así como la plataforma Zoom y Meet, para encuentros sincrónicos, entre otras. De igual manera, se han capacitado los docentes para el uso adecuado de estas herramientas $\mathrm{y}$, algunas universidades han hecho entrega de equipos como tabletas, computadores y sim card a estudiantes, de acuerdo con la caracterización de sus necesidades.

En síntesis, esta es una situación que vino para quedarse, es decir, que así superemos la pandemia, todas las Instituciones de Educación Superior tendrán que reinventarse en la manera de 
realizar sus procesos, tanto académicos como administrativos para cumplir con la misión y sostenerse en el mercado ofreciendo sus programas.

\subsubsection{Evaluación Educación Mediada por TIC en tiempos de COVID-19 Universidad Libre de Pereira y Escuela Superior de Administración Pública ESAP - Quindío Risaralda}

En concordancia con la situación de las Instituciones de Educación Superior planteada anteriormente, se realizó un trabajo orientado a indagar sobre la percepción que tienen los estudiantes frente al desarrollo de las clases asistidas por Tecnologías de Información y Comunicaciones -TIC- mediante la plataforma Teams, en la Universidad Libre de Pereira y la Escuela Superior de Administración Pública ESAP Territorial Quindío Risaralda, en el marco de la emergencia del COVID-19, que obligó a todas las instituciones de educación superior a reinventar sus modelos y métodos de formación, procurando la integración de los entornos virtuales a partir del uso y apropiación de las TIC. La evaluación comprende el análisis sobre el uso y apropiación de las herramientas tecnológicas para la mediación del proceso de enseñanza y aprendizaje, así mismo, aspectos sobrela conectividad, accesibilidad y dispositivos utilizados. También, se evaluó de manera integral logros obtenidos en el desarrollo de los módulos, verificando el cumplimiento de los objetivos, coherencia de los contenidos, actividades, recursos, transferencia de conocimientos, trabajo colaborativo, participación del estudiante y evaluación del aprendizaje, entre otros aspectos. De otra parte, se indagó sobre el nivel de satisfacción de los estudiantes bajo esta modalidad, así como también sus expectativas sobre un modelo de virtualización de la educación.

Para el caso de la Universidad Libre de Pereira se tomó VII semestre de la carrera Ingeniería Civil con 55 estudiantes matriculados en los grupos G-01 y G-03 jornada diurna de la 
asignatura Formulación y Evaluación de Proyectos, para lo cual se aplicó un cuestionario de 31 preguntas a través de la plataforma Google Forms entre el 17 de junio y el 23 de junio del 2020. En la Escuela Superior de Administración Pública ESAP Territorial Quindío Risaralda, se evaluaron los módulos Gerencia de Recursos Físicos y Financieros y Planeación del Desarrollo en VII y VIII semestre de la Carrera Administración Pública, encuestando 40 estudiantes con un cuestionario de 31 preguntas aplicado a través de la plataforma Google Forms entre el 11 de julio y el 14 de julio del 2020. Los criterios de evaluación definidos para calificar los resultados de las variables fueron: Excelente cuando el resultado es mayor del $80 \%$ (> $80 \%$ ), Bueno entre $70 \%$ y hasta $80 \%$ (> 70 $\%$ - $80 \%)$ y Aceptable menor del 70\% (<70\%)

Los resultados de este estudio demuestran que hay cambios positivos con la implementación de la educación mediada por TIC (Prespecialidad Asistida), si se tiene en cuenta que según el estudio realizado en el 2017 un 77,7\% de estudiantes afirmaron que los métodos de formación tradicionales son inadecuados, del mismo modo, el $72 \%$ consideran que el método de enseñanza no permite aprendizajes significativos para el análisis, comprensión y solución de problemas. A continuación, los resultados del muestreo realizado

\subsubsection{Evaluación educación mediada por TIC - Universidad Libre de Pereira}

Se evaluó la asignatura Formulación y Evaluación de Proyectos en dos cursos de VII semestre de la carrera Ingeniería Civil. A continuación, se presentan los resultados:

\section{A. Información general:}

En este punto se tuvo en cuenta aspectos como la edad y el género, obteniendo que la edad promedio de los estudiantes oscila entre los 16 y 27 años, esto es, el 93\% (Gráfica 28) 
Gráfica 28. Rango de edad estudiantes

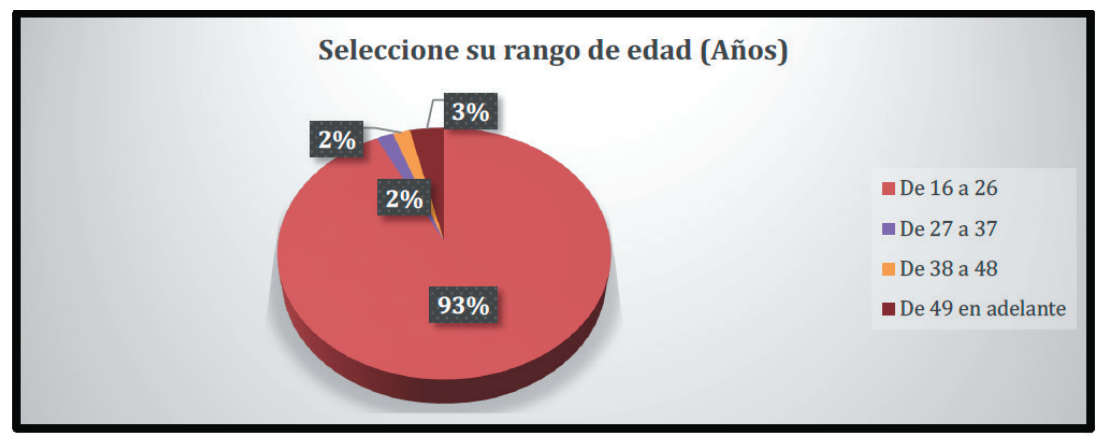

Fuente: Elaboración propia

De otra parte, el $67 \%$ de los estudiantes son de género masculino y el 33\% de género femenino (Gráfica 29)

Gráfica 29. Género de estudiantes

\section{Seleccione su género}

$33 \%$

$67 \%$
Masculino

aremenino

Gráfica 30. Dispositivos electrónicos usados

El dispositivo electrónico usado para recibir clases es

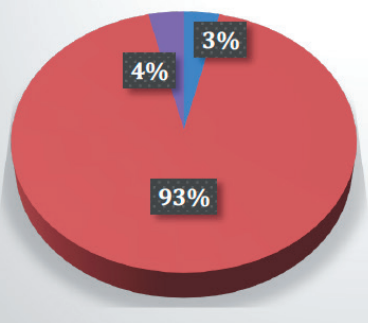

- Computador de mesa o escritorio - Computador Portátil

- Tableta o Ipad

- Celular o Smartphone

Fuente: Elaboración propia 


\section{B. Uso y apropiación de las tecnologías TIC}

En este componente se evalúa el uso y apropiación de las herramientas tecnológicas para la mediación

del proceso de enseñanza y aprendizaje, así como, dispositivos utilizados, la conectividad y accesibilidad

\section{- Dispositivos electrónicos}

Sobre los dispositivos utilizados por los estudiantes para la mediación de la educación se encontró que el 93\% usan computadores portátiles, el $4 \%$ dispositivos como el celular o Smartphone y solo el 3\% computador de mesa, (Gráfica 30)

\section{- Nivel de conectividad}

Sobre la conectividad, el $78 \%$ de los estudiantes tiene buena conectividad, mientras que el $22 \%$ informa tener regular conectividad (Gráfica 31), como se puede observar, el 78\% de los estudiantes tiene muy buena conectividad. Sin embargo, se requiere hacer una caracterización del grupo de estudiantes que presenten dificultades de conectividad para contribuir a la solución.

Gráfica 31. Nivel de conectividad

Su conectividad para las clases asistida es:

$14 \%, 22 \%$

Fuente: Elaboración propia 


\section{- Accesibilidad al entorno virtual}

La accesibilidad de los estudiantes al entorno virtual es alta para el 64\%, mientras que el 31\% afirma que el acceso es aceptable (Gráfica 32). Esto significa que los estudiantes en su gran mayoría (64\%) tienen muy buena accesibilidad a los entornos virtuales; no obstante, se debe investigar la situación del 31\% que su accesibilidad es aceptable o baja.

Gráfica 32. Accesibilidad al entorno virtual

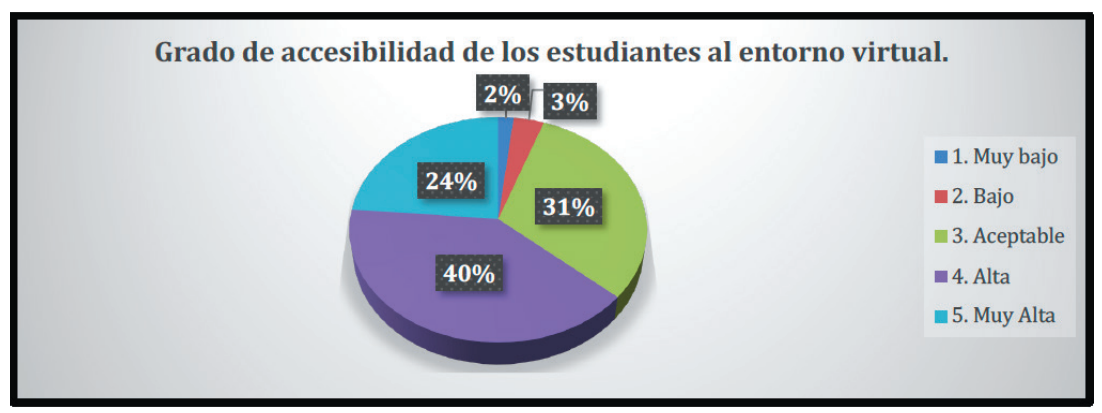

Fuente: Elaboración propia

- Entorno virtual de aprendizaje

El entorno virtual de aprendizaje es altamente estable para el $60 \%$, aceptable y baja para el $40 \%$ Gráfica 33). Esto significa que la mayoría de los estudiantes tiene estabilidad en su entorno virtual para el aprendizaje. Se requiere analizar alternativas para mejorar las condiciones del entorno virtual al otro grupo de estudiantes. 
Gráfica 33. Entorno virtual de aprendizaje

El entorno virtual de aprendizaje funciona de manera estable, gestionando adecuadamente los recursos.

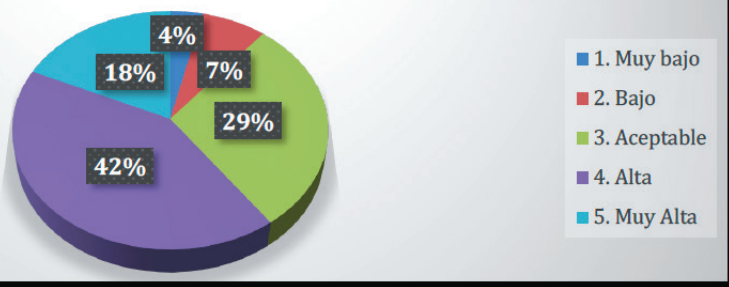

Fuente: Elaboración propia

Herramientas Tecnológicas para la enseñanza y el aprendizaje

Herramientas Tecnológicas (Plataforma Teams)

Sobre las herramientas proporcionadas para el desarrollo del curso, el 69\% afirma que son suficientes en alta proporción, pero aceptable y baja el 31\% (Gráfica 34). Sería conveniente profundizar en la caracterización de los estudiantes que tienen estos requerimientos.

Gráfica 34. Herramientas Tecnológicas (Plataforma Teams)

Las herramientas proporcionadas para el desarrollo del curso son suficientes.

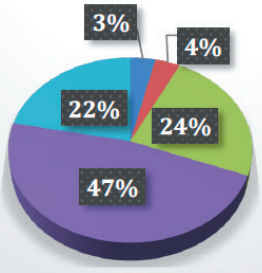

1. Muy bajo

-2. Bajo

3. Aceptable

4. Alta

5. Muy Alta

Fuente: Elaboración propia 
- Nivel de uso y apropiación de las TIC

Según el estudio, el 60,4\% de los estudiantes tiene un nivel alto en el uso y apropiación de las TIC, mientras que para el 39,6\% su nivel es medio alto (Gráfica 35), es necesario profundizar en la identificación de las brechas tecnológicas de este grupo de estudiantes, para tomar las acciones pertinentes. Este resultado coincide con algunos requerimientos de los estudiantes para continuar adecuadamente con el programa, como es la capacitación en el uso de plataformas virtuales.

Gráfica 35. Nivel de uso y apropiación de las TIC

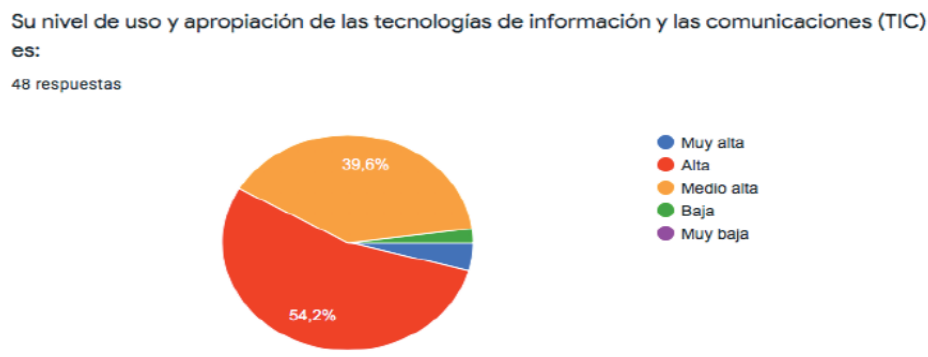

Fuente: Elaboración propia

- Plan de contingencia para atender problemas técnicos

Respecto de los problemas técnicos el $46 \%$ de los estudiantes tiene alta posibilidad de implementar plan de contingencia, el 29\% aceptable probabilidad, mientras que el $25 \%$ no tiene ninguna posibilidad (Gráfica 36). Este resultado amerita caracterizar la problemática para tomar acciones 
Gráfica 36. Plan de contingencia para atender problemas técnicos

Se cuenta con planes de contingencia en caso de problemas técnicos.

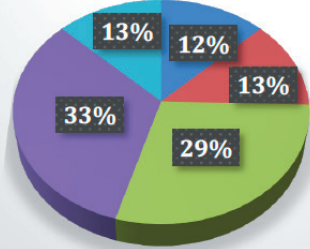

घ1. Muy bajo

- 2. Bajo

3. Aceptable

घ. Alta

5. Muy Alta

Fuente: Elaboración propia

- Habilidades, conocimientos y actitudes de los docentes en la virtualidad

Para el 78\% de los estudiantes los profesores tienen altas habilidades, conocimiento y actitudes para el desempeño optimo en el desarrollo de cursos virtuales, el 18\% dice que son aceptables, mientras que para el $4 \%$ son bajas (Gráfica 37), si bien, la gran mayoría de los docentes tienen competencias para el desempeño optimo en los cursos virtuales, es necesario precisar las brechas tecnológicas para fortalecer sus capacidades.

Gráfica 37. Habilidades, conocimientos y actitudes de docentes en la virtualidad

Los profesores y/o tutores tienen las habilidades, conocimientos y actitudes que les permiten un desempeño óptimo en el desarrollo de cursos virtuales

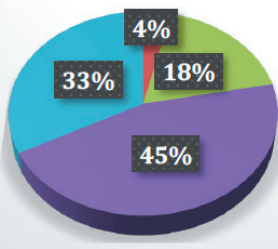

1. Muy bajo

-2. Bajo

3. Aceptable

4. Alta

5. Muy Alta

Fuente: Elaboración propia

- Grado de satisfacción de los estudiantes con clases asistidas mediante plataforma Teams 
Para el 71\% de los estudiantes las clases asistidas por la plataforma Teams fue de alta satisfacción, aceptable para el $22 \%$, mientras que para el $7 \%$ es baja, (Gráfica 38); no obstante, es necesario implementar planes de mejoramiento para lograr mayores niveles de satisfacción de los estudiantes.

Gráfica 38. Grado de satisfacción de estudiantes con plataforma Teams

Grado de satisfacción con el curso bajo la modalidad de clases asistidas por la plataforma Teams

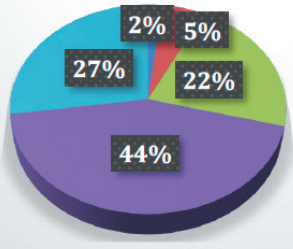

1. Muy bajo

2. Bajo

3. Aceptable

4. Alta

- 5. Muy Alta

Fuente: Elaboración propia

- Aceptación del curso mediante clases asistidas por plataformas virtuales (Temas)

El 64\% de los estudiantes le gustaría desarrollar este tipo cursos bajo la modalidad de clases asistidas en la plataforma Teams, mientras que el 36\% no le gustaría (Gráfica 39). Es conveniente caracterizar estos requerimientos de los estudiantes en procura de atender estas necesidades.

Gráfica 39. Aceptación del curso en plataforma virtual (Temas)

Le gustaría seguir desarrollando éste curso bajo la modalidad de clases asistidas por plataformas virtuales (Teams).

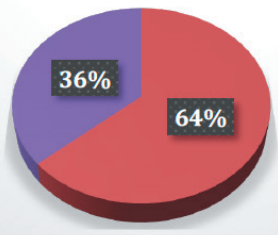

Fuente: Elaboración propia 
- Expectativas de los estudiantes para continuar el programa mediante clases asistidas por plataformas virtuales (Teams)

El 56,2\% de los estudiantes está de acuerdo en continuar desarrollando el programa bajo la modalidad de clases asistidas en plataformas virtuales, el 35,4\% está medianamente de acuerdo, mientras que el $8,4 \%$ se encuentra en desacuerdo (Gráfica 40). Este resultado obliga a profundizar en la identificación de requerimientos de estudiantes para evitar la deserción.

Gráfica 40. Aceptación del programa en plataforma virtual (Temas)

Considera pertinente continuar desarrollando el programa a través de la modalidad de clases mediadas por TIC en plataformas virtuales:

48 respuestas

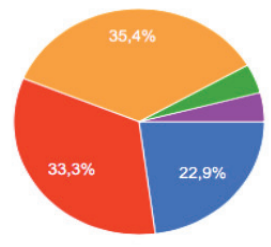

- Totalmente de acuerdo

De acuerdo

Medianamente de acuerdo

- En desacuerdo

Totalmente en desacuerdo

Fuente: Elaboración Propia

- Oportunidades de mejora para el programa con mediación de TIC

Respecto de oportunidades de mejora, el $35,4 \%$ consideran que la conectividad es un factor clave a mejorar, el 25\% capacitando los estudiantes en el uso y apropiación de las TIC, el 20,8 capacitando a los docentes en el uso de TIC y el 18,8\% requieren dotación de equipos tecnológicos (Gráfica 41). La capacitación de estudiantes y docentes en el uso de la plataforma, así como la conectividad y dotación de equipos para los estudiantes son los requerimientos más apremiantes para atender la coyuntura, 
Gráfica 41. Oportunidades de mejora para el programa con mediación de TIC

Que oportunidades de mejora considera que se deben implementar para mejorar la

interacción en la enseñanza y el aprendizaje?

48 respuestas

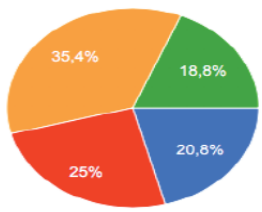

Capacitación a los docentes en el uso

apropiacion de TIC

Capacitación a los estudiantes en el uso

y apropiación de TIC

Mejora de la conectividad

- Dotación de equipos tecnológicos

Fuente: Elaboración propia

- Requerimientos prioritarios de estudiantes para continuar el programa con clases asistidas por TIC

Los requerimientos de los estudiantes son variados, pero los que más prevalecen son: el 39,6\% mejorar conectividad, el $31,3 \%$ capacitación en manejo de la plataforma, el 14,6\% apoyo financiero para la matricula, mientras que el $10,4 \%$ requieren equipos tecnológicos (Gráfica 42). Estas respuestas coinciden con las oportunidades de mejora descritas en la gráfica anterior (Gráfica 41), en este sentido, la universidad podría intervenir para suplir alguna de éstas necesitas de los estudiantes que así lo requieran

Gráfica 42. Requerimientos prioritarios de estudiantes para continuar el programa

¿Cuál de los siguientes requerimientos serian su prioridad para continuar en condiciones adecuadas?:

48 respuestas

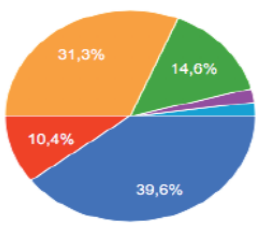

- Conectividad

Equipos tocnológicos

Capacitación en manejo de plataformas y entornos virtuales

Apoyo financiero para la matrícula

Apoyo financiero y capacitación a docentes

Equipos tecnologicos y apoyo financiero matricula

Fuente: Elaboración propia 


\section{- Preferencias sobre modalidad de educación}

Sobre las expectativas en la modalidad de educación, el $81 \%$ de los estudiantes preferiría una combinación de clases presenciales y virtuales (B-learning), el 11\% preferiría clases virtuales y $8 \%$ clases asistidas por plataformas (Gráfica 43 ). Esto indica, que la Universidad debería empezar a prepararse para implementar modalidad de educación bajo cualquiera de estos modelos B-learning, M-learning o U-learning.

Gráfica 43. Preferencias sobre modalidad de educación

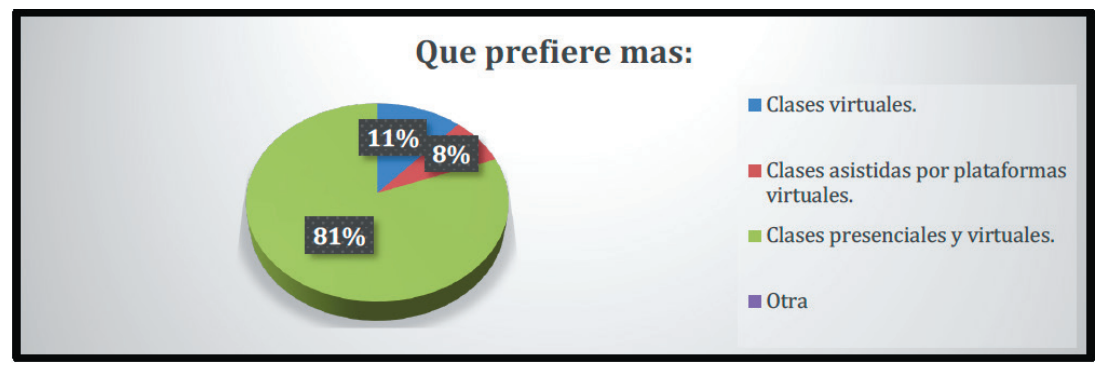

Fuente: Elaboración propia

- Las TIC, los entornos virtuales y su contribución a la calidad de la educación

El 89,6\% de los estudiantes consideran el uso de las TIC y los entornos virtuales contribuyen a mejorar la calidad de la educación, mientras que el 10,4\% están en desacuerdo (Gráfica 44) 
Gráfica 44. Contribución de las TIC a la calidad de la educación

Considera que el uso de las tecnologias de información y las comunicaciones (TIC) y, los entornos virtuales pueden contribuir a mejorar la calidad de la educación:

48 respuestas

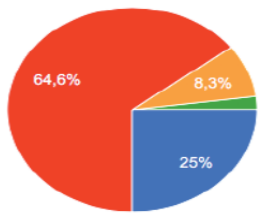

- Muy de acuerdo

De acuerdo

Poco de acuerdo

- En desacuerdo

Fuente: Elaboración propia

C. Evaluación de logros obtenidos en desarrollo de la asignatura

Aquí se evalúan de manera integral los logros obtenidos en el desarrollo de la asignatura, destacándose los objetivos, contenidos, actividades, recursos, transferencia de conocimientos, trabajo colaborativo, participación del estudiante, evaluación del aprendizaje, entre otros aspectos

\section{Objetivos de la asignatura}

Para el 73\% de los estudiantes los objetivos de la asignatura son claros y sencillos de comprender, para el $25 \%$ son aceptables, en tanto que para el $2 \%$ no son claros los objetivos (Gráfica 45 ). En este sentido, es recomendable indagar para este grupo de estudiantes porque no son claros los objetivos de la asignatura, a fin de establecer planes de mejoramiento. 
Gráfico 45. Objetivos de la asignatura

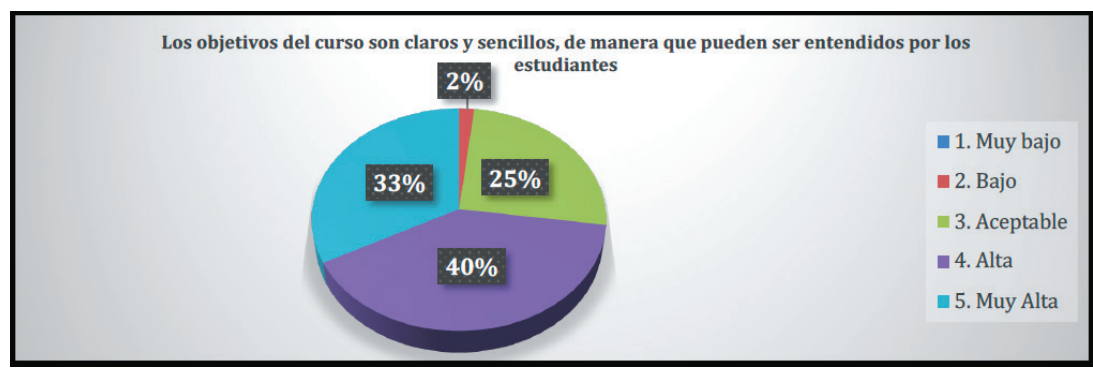

Fuente: Elaboración propia

- Correspondencia de contenidos con objetivos de la asignatura

Según el $78 \%$ de los estudiantes, los contenidos se corresponden altamente con los objetivos de la asignatura, para el $16 \%$ es aceptable, mientras que para el $6 \%$ esta correspondencia es baja (Gráfica 46)

Gráfica 46. Correspondencia de contenidos con objetivos de la asignatura

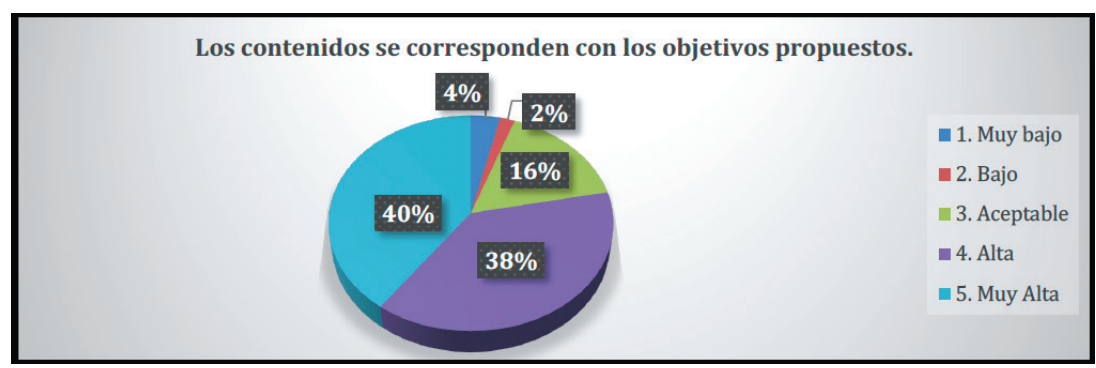

Fuente: Elaboración propia

- Medios de publicación de Contenidos de la asignatura

Según el $62 \%$ de los estudiantes se disponen de medios alternativos para publicación de contenidos y materiales, para el 
$25 \%$ son aceptables los medios, en tanto que para el 13\% no hay medios alternativos (Gráfica 47). Aquí se deberán activar otros medios alternativos donde reposen los contenidos y materiales de la asignatura que sea de fácil acceso, en su defecto, capacitar a los estudiantes en el uso de la plataforma para mayor interacción con los contenidos, materiales, recursos y actividades.

Gráfica 47. Medios de publicación de Contenidos de la asignatura

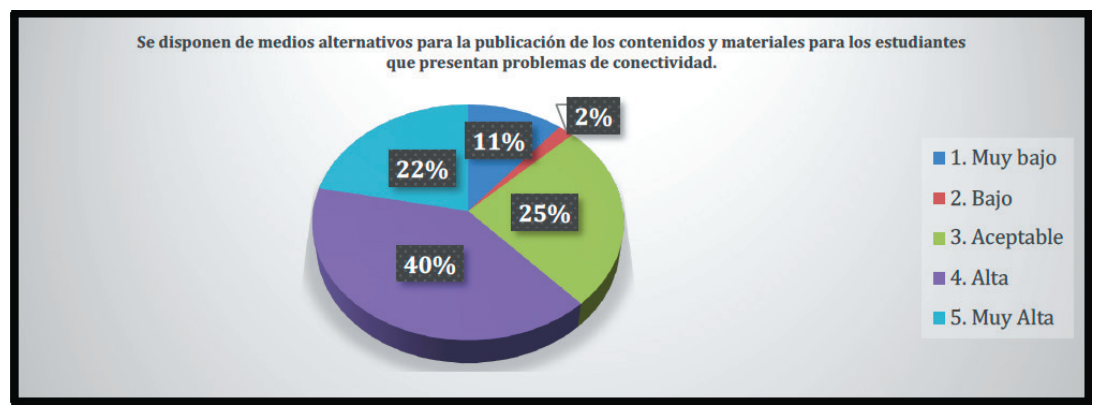

Fuente: Elaboración propia

- Coherencia de las actividades con objetivos de la asignatura

Para el 78\% de los estudiantes las actividades guardan alta coherencia con los objetivos de la asignatura, para el 16\% es aceptable, mientras que el $6 \%$ considera que hay baja coherencia (Gráfica 48). En este sentido, sería interesante caracterizar en este grupo de estudiantes la situación presentada.

Gráfica 48. Coherencia de las actividades con objetivos de la asignatura

Las actividades tienen coherencia con los objetivos del curso.

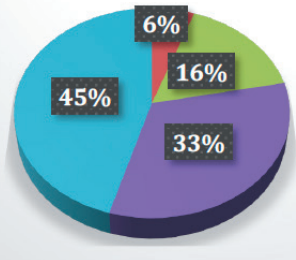

1. Muy bajo

-2. Bajo

3. Aceptable

4. Alta

5. Muy Alta

Fuente: Elaboración propia 
- Motivación de Docentes para participación de estudiantes en actividades

El 78\% de los estudiantes reconocen que los docentes promueven altamente la participación en las actividades propuestas, para el 11\%, es aceptable, mientras que otro $11 \%$ considera que hay baja motivación (Gráfica 49). Si bien, la calificación está en el rango de buena, es necesario revisar este aspecto con los docentes para que se motive más al estudiantado

Gráfica 49. Motivación de Docentes para participación de estudiantes en actividades

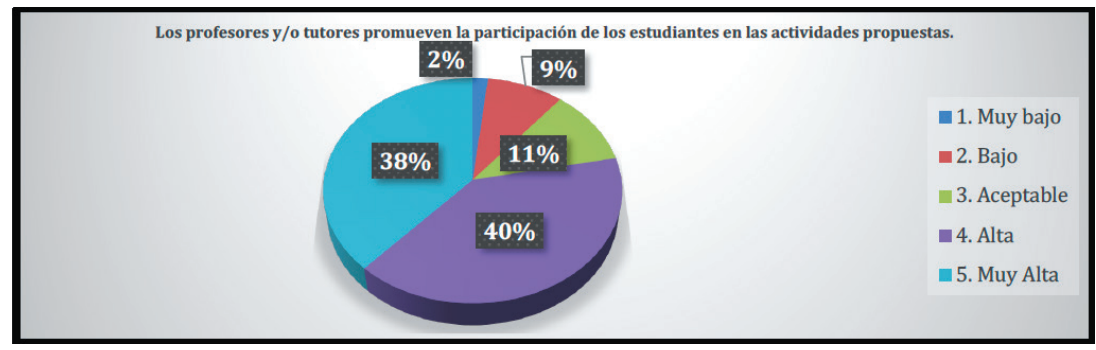

Fuente: Elaboración propia

\section{- Trabajo individual y colaborativo para la enseñanza y} aprendizaje

De otra parte, el 78\% de los estudiantes también confirmaron que las actividades permiten fomentar el trabajo autónomo y colaborativo en el proceso de enseñanza y aprendizaje, para el $20 \%$ es aceptable, mientras que para $2 \%$ no se fomenta el trabajo colaborativo (Gráfica 50). Estos resultados ratifican los de la gráfica anterior, en el sentido de la motivación a los estudiantes a participar de las actividades; es necesario indagar al respecto para tomar medidas correctivas 
Gráfica 50. Fomento del trabajo individual y colaborativo

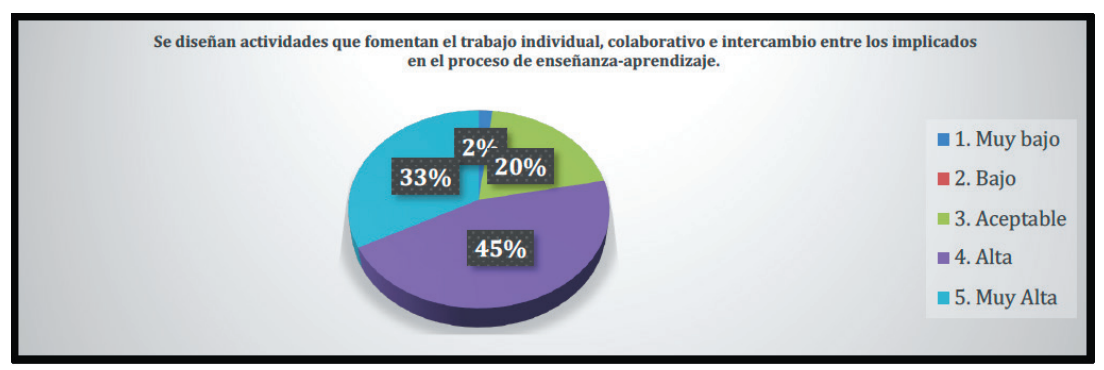

Fuente: Elaboración propia

- Cantidad de actividades con relación al tiempo disponible

En este sentido, el $60 \%$ de los estudiantes considera que la cantidad de actividades guarda alta relación con el tiempo disponible para realizarlas, el 29\% dice que la relación es aceptable, y, por su parte el $2 \%$ no le queda tiempo (Gráfica 51). Lo anterior podría indicar que es necesario replantear la cantidad de actividades que se asignan en el proceso de enseñanza y aprendizaje bajo estas modalidades.

Gráfica 51. Cantidad de actividades con relación al tiempo disponible

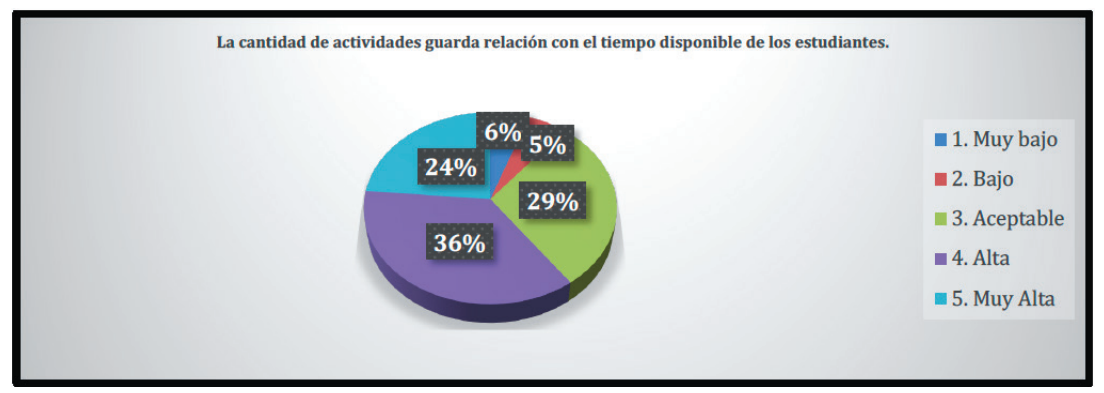

Fuente: Elaboración propia

- Contribución de los conocimientos a la formación integral del profesional 
Sobre los conocimientos adquiridos, el 71\% de los estudiantes consideran que contribuyen altamente a la formación integral del profesional, para el $25 \%$ es aceptable, en tanto que el $4 \%$ considera que es baja la contribución (Gráfica 52). De acuerdo con este resultado, es necesario identificar los requerimientos de este grupo de estudiantes para ajustar si es necesario los métodos, contenidos o los recursos a fin de lograr cumplir con sus expectativas

Gráfica 52. Contribución de los conocimientos a la formación integral del profesional

Contribuyen los conocimientos adquiridos al logro de la formación integral del profesional.

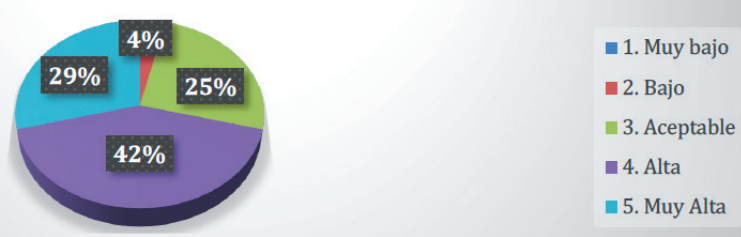

Fuente: Elaboración propia

\section{- Transferencia de conocimientos al ámbito laboral}

En este aspecto también el 69\% de los estudiantes consideran que se logra alta transferencia de los

conocimientos hacia el ámbito laboral, el $27 \%$ estima que es aceptable y para el $4 \%$ hay baja contribución

(Gráfica 53). Esta pregunta guarda estrecha relación con la anterior, y, va en concordancia con los

estudiantes que tienen vinculación laboral y sus funciones están relacionadas con la carrera en general 
Gráfica 53. Transferencia de conocimientos al ámbito laboral

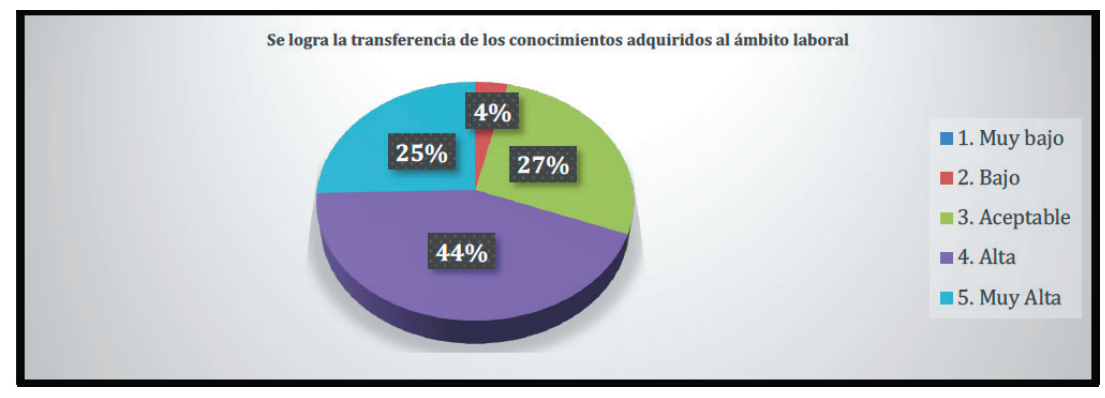

Fuente: Elaboración propia

- Criterios para evaluación de las actividades

Sobre la evaluación del aprendizaje, 76\% de los estudiantes afirman que se definen claramente los criterios de evaluación las actividades, el $20 \%$ consideran que se detallan de manera aceptable, mientras que para el $4 \%$ no hay claridad sobre los criterios de evaluación (Gráfica 54). Aunque el rango de calificación es bueno, es necesario precisar dónde están las fallas para corregir en lo pertinente.

Gráfica 54. Criterios para evaluación de las actividades

Se ofrece información detallada sobre los criterios de evaluación de cada una de las actividades

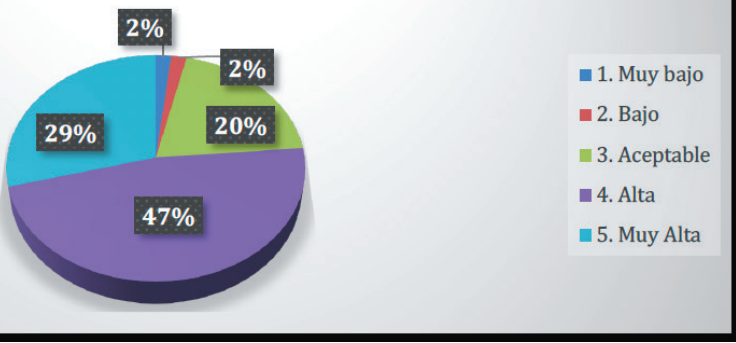

Fuente: Elaboración propia 
-Correspondencia de la evaluación con los objetivos del curso

Para el $84 \%$ de los estudiantes la evaluación responde a los objetivos de la asignatura, el 14\% considera que es aceptable, en contraste el $2 \%$ cree que no corresponde con los objetivos (Gráfica 55)

Gráfica 55. Correspondencia de la evaluación con los objetivos del curso

La evaluación responde a los objetivos del curso.

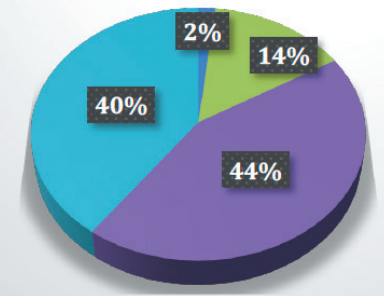

-1. Muy bajo

- 2. Bajo

3. Aceptable

- 4. Alta

n. Muy Alta

Fuente: Elaboración propia

\subsubsection{Evaluación educación mediada por TIC Escuela Superior de Administración Pública -ESAP-}

Se evaluaron las asignaturas Gerencia de los Recursos Físicos y Financieros y, Gestión del Desarrollo, en VII y VIII semestre de la carrera Administración Pública. A continuación, los resultados:

\section{A. Información general:}

En este punto se tuvo en cuenta aspectos como la edad y el género, obteniendo que la edad promedio de los estudiantes oscila entre los 38 y 48 (42,5\%), 27 y 37 años (40\%), 16 y 26 años (10\%) y el 7,5\% mayor de 49 años (Gráfica 56). 
Gráfica 56. Rango de edad estudiantes

Seleccione su rango de edad (Años)

40 respuestas

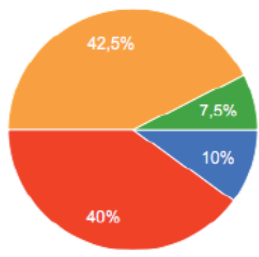

De 16 a 26

De 27 a 37

De 38 a 48

De 49 en adelante

Fuente: Elaboración propia

Respecto del género, el 55\% de los estudiantes son de género femenino y el $45 \%$ son de género masculino (Gráfica 57 )

Gráfica 57. Género de estudiantes

Seleccione su género

40 respuestas

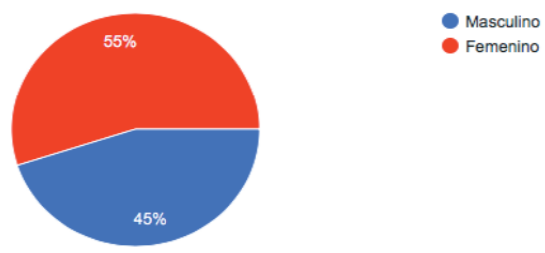

Fuente: Elaboración propia

B. Uso y apropiación de las tecnologías

En este componente se evalúa el uso y apropiación de las herramientas tecnológicas para la mediación del proceso de enseñanza y aprendizaje, así como, aspectos sobre la conectividad, accesibilidad y dispositivos utilizados. 


\section{- Dispositivos electrónicos}

Sobre los dispositivos utilizados por los estudiantes para la mediación de la educación se encuentra que el 45\% usan computadores portátiles, el 30\% celular o Smartphone y el 22\% computador de mesa, sólo un $2 \%$ usa Tablet, (Gráfica 58).

\section{Gráfica 58. Dispositivos electrónicos}

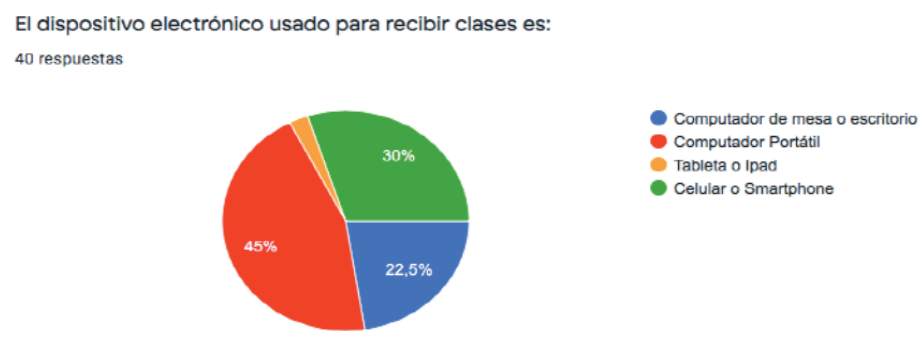

Fuente: Elaboración propia

- Nivel de la conectividad

Sobre la conectividad, el 75\% de los estudiantes tienen buena conectividad, mientras que el 25\% regular conectividad (Gráfica 59). Pese a que los resultados son buenos, se requiere hacer una caracterización del grupo de estudiantes que presenten dificultades de conectividad para contribuir a la solución, ya que este resultado coincide con uno de los requerimientos de los estudiantes para continuar el programa bajo esta modalidad. 
Gráfica 59. Nivel de la conectividad

7. Su conectividad para las clases asistidas es:

40 respuestas

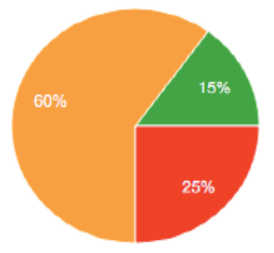

Fuente: Elaboración propia

\section{- Accesibilidad al entorno virtual}

La accesibilidad de los estudiantes al entorno virtual es alta en el $72 \%$, mientras que el $28 \%$ afirma que el acceso al entorno virtual es aceptable (Gráfica 60). Esto significa que los estudiantes en su gran mayoría tienen muy buena accesibilidad a los entornos virtuales; no obstante, se debe investigar para ofrecer alternativas al 28\% que su accesibilidad es aceptable.

Gráfica 60. Accesibilidad al entorno virtual

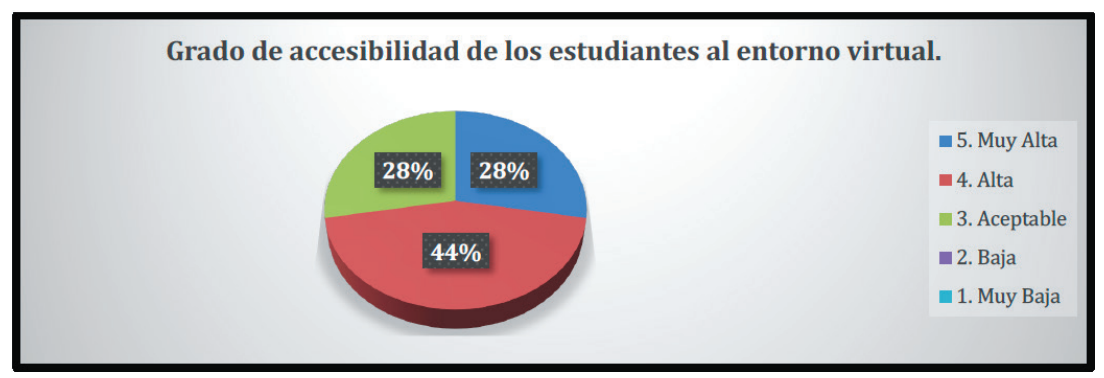

Fuente: Elaboración propia

\section{- Entorno virtual de aprendizaje}

El entorno virtual de aprendizaje es estable para el 79\%, y aceptable para el 21\% (Gráfica 61). Esto significa que la mayoría de los estudiantes tiene estabilidad en su entorno virtual para el 
aprendizaje, sin embargo, se requiere indagar y analizar alternativas para mejorar las condiciones del otro grupo de estudiantes (21\%)

Gráfica 61. Entorno virtual de aprendizaje

El entorno virtual de aprendizaje funciona de manera estable, gestionando adecuadamente los recursos.

$21 \%$

$45 \%$
5. Muy Alta

4. Alta

3. Aceptable

2. Baja

1. Muy Baja

Fuente: Elaboración propia

\section{- Herramientas Tecnológicas (Plataforma Teams)}

Sobre las herramientas proporcionadas por la universidad, el $87 \%$ afirma que son suficientes en alta proporción, y aceptable el 13\% (Gráfica 62). Sería muy pertinente profundizar en la caracterización de los requerimientos más prioritarios de los estudiantes para continuar en esta modalidad.

Gráfica 62. Herramientas Tecnológicas (Plataforma Teams)

Las herramientas proporcionadas para el desarrollo del curso son suficientes.

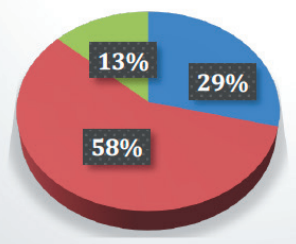

Fuente: Elaboración propia 
- Nivel de uso y apropiación de las Tecnologías de Información y Comunicaciones (TIC)

Sobre el nivel de uso y apropiación el 55\% de los estudiantes tiene altas habilidades y destrezas tecnológicas para la interacción con las TIC, mientras que para el otro $45 \%$ las habilidades y destrezas son medio altas o baja (Gráfica 63). Esto significa que hay una brecha tecnológica grande del $45 \%$, por lo tanto, estos resultados obligan a la identificación y caracterización de este grupo de estudiantes, para fortalecer sus capacidades en el manejo de las TIC a fin de evitar altos índices de deserción

Gráfica 63. Nivel de uso y apropiación de TIC

Su nivel de uso y apropiación de las tecnologias de información y las comunicaciones (TIC)

es:

40 respuestas

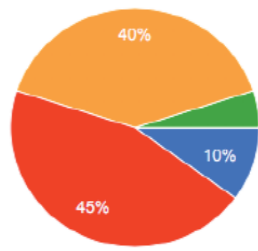

Muy alta

Alta

Medio alta

Baja

Muy baja

Fuente: Elaboración propia

- Plan de contingencia para atender problemas técnicos

Respecto de los problemas técnicos, el 56\% de los estudiantes tiene alta posibilidad de implementar plan de contingencia, mientras que el $44 \%$ no tiene esa posibilidad (Gráfica 64). Es necesario indagar esta situación de los estudiantes para plantear alternativas de solución. 
Gráfica 64. Plan de contingencia para atender problemas técnicos

Se cuenta con planes de contingencia en caso de problemas técnicos.

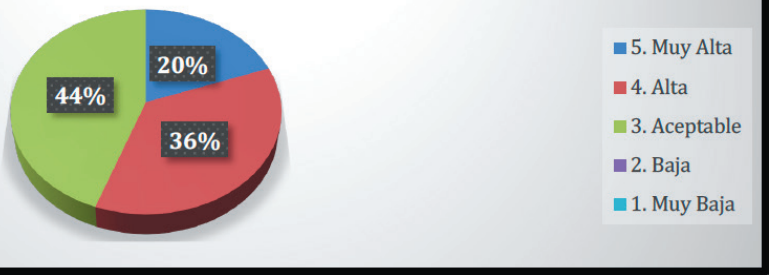

Fuente: Elaboración propia

- Habilidades, conocimientos y actitudes de los docentes en la virtualidad

Para el $85 \%$ de los estudiantes los profesores tienen altas habilidades, conocimiento y actitudes para el desempeño optimo en la virtualidad, mientras que para el 15\% estas competencias son aceptables (Gráfica 65). Si bien, la gran mayoría de los docentes tienen apropiación de las herramientas tecnológicas, sería interesante indagar sobre las brechas tecnológicas que presentan algunos docentes para capacitarlos y fortalecer sus capacidades y competencias.

Gráfica 65. Habilidades, conocimientos y actitudes de los docentes en la virtualidad

Los profesores y/o tutores tienen las habilidades, conocimientos y actitudes que les permiten tener un desempeño óptimo en el desarrollo de cursos virtuales.

$15 \%$

$33 \% \quad 52 \%$
5. Muy Alta

4. Alta

3. Aceptable

- 2. Baja

1. Muy Baja

Fuente: Elaboración propia 
- Grado de satisfacción de estudiantes en clases asistidas en plataforma Teams

Para el 79\% de los estudiantes las clases asistidas a través de la plataforma Teams fue de muy alta satisfacción, mientras que para el 21\% fue aceptable, (Gráfica 66); no obstante, es necesario implementar planes de mejoramiento para lograr mayores niveles de satisfacción en el modelo implementado.

Gráfica 66. Grado de satisfacción de estudiantes en clases asistidas en plataforma Teams

Grado de satisfacción con el curso bajo la modalidad de clases asistidas por la plataforma Teams.

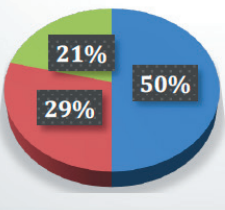

5. Muy Alta

4. Alta

- 3. Aceptable

2. Baja

1. Muy Baja

Fuente: Elaboración propia

- Viabilidad para continuar el curso mediante plataforma digital

Al 75\% de los estudiantes les gustaría seguir desarrollando este tipo de cursos mediante clases asistidas por plataformas virtuales, mientras que al otro $25 \%$ no le gustaría (Gráfica 67). El alto porcentaje de estudiantes que le gusta esta modalidad indica que hay avances importantes en la cultura digital; los estudiantes que aún no aceptan la modalidad, podrían explicarse por la correlación que existe entre el bajo nivel de uso y apropiación de las TIC, así como baja conectividad y accesibilidad. 
Gráfica 67. Viabilidad para continuar el curso mediante plataforma digital

Le gustaria seguir desarrollando éste curso bajo la modalidad de clases asistidas por plataformas virtuales?

40 respuestas

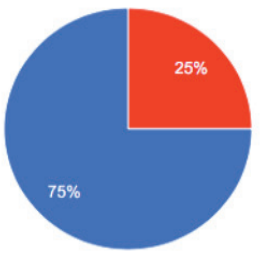

SI

- NO

Fuente: Elaboración propia

- Continuación del programa con clases mediadas por plataformas virtuales (Temas)

Sobre la continuación del programa con clases asistidas por TIC, el $80 \%$ de los estudiantes le gustaría continuar con esta modalidad, mientras que el $17,5 \%$ están medianamente de acuerdo (Gráfica 68). Como se observa, para la mayoría de los estudiantes es pertinente continuar con la modalidad de clases asistidas por TIC, no obstante, se deben identificar los requerimientos de los estudiantes que no están totalmente de acuerdo, para fortalecer sus capacidades atendiendo sus expectativas

Gráfica 68. Continuación del programa con clases mediadas por plataformas (Temas)

Considera pertinente continuar desarrollando el programa a través de la modalidad de clases mediadas por TIC en plataformas virtuales:

40 respuestas

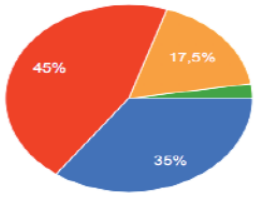

Totalmente de acuerdo

- De acuerdo

Medianamente de acuercto

En desacuerdo

Totaimonto on dosacuerdo

Fuente: Elaboración propia 
- Oportunidades de mejora para el programa con clases asistidas por TIC

Respecto a las oportunidades de mejora, el 57,5\% considera que se debe capacitar a los estudiantes en el uso y apropiación de las TIC, el 20\% mejorando la conectividad, el 12,5\% capacitando a los docentes en el uso y apropiación de las TIC y el $10 \%$ dotación de equipos tecnológicos (Gráfica 69). La capacitación de estudiantes en el uso de la plataforma y la conectividad son los requerimientos más apremiantes para resolver en esta coyuntura con los estudiantes.

Gráfica 69. Oportunidades de mejora para el programa con clases asistidas por TIC

Que oportunidades de mejora considera que se deben implementar para mejorar la interacción en la enseñanza y el aprendizaje:

40 respuestas

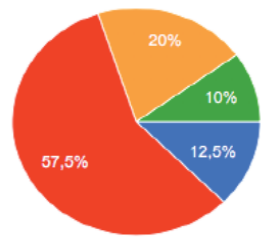

Capacitación a los docentes en el uso y apropiación de TIC

Capacitación a los estudiantes on ol uso y apropiación de TIC

Mejora de la conectividad

Dotación de equipos tecnológicos

Fuente: Elaboración propia

- Requerimientos prioritarios de estudiantes para continuar en el programa

Los requerimientos de estudiantes para continuar con el programa son variados, pero los más apremiantes son los siguientes: el 40\% requiere capacitación en manejo de plataformas y entornos virtuales, el 27,5\% mejorar su conectividad, el 20\% equipos tecnológicos, mientras que el 10\% apoyo financiero para matricula (Gráfica 70). Estos resultados son coherentes con las oportunidades mejora plateadas por los estudiantes. 
Gráfica 70. Requerimientos prioritarios de estudiantes para continuar en el programa

¿Cuál de los siguientes requerimientos serian su prioridad para continuar en condiciones adecuadas?:

40 respuestas

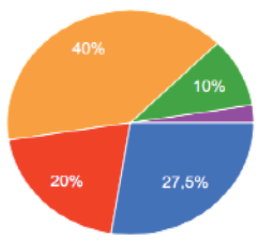

- Conectividad

Equipos tecnológicos

Capacitación en manejo de plataformas y entornos virtuales

Apoyo financiero para la matricula

- Complementar las sesiones virtuales,

con asistencias personales, ya sean virtual o presencial.

Fuente: Elaboración propia

- Preferencias de estudiantes sobre modalidad de educación

Sobre las expectativas en la modalidad de educación, el $52,5 \%$ de los estudiantes preferiría una combinación de clases presenciales y virtuales, el $25 \%$ preferiría clases virtuales y $20 \%$ clases asistidas por plataformas virtuales, (Gráfica 71). Esto indica, que la ESAP debe empezar a prepararse para implementar otras modalidades de educación tales como el B-learning (mixtura entre clases presenciales y virtuales), m-learning o u-learning.

Gráfica 71. Preferencias de estudiantes sobre modalidad de educación

Que prefiere mas:

40 respuestas

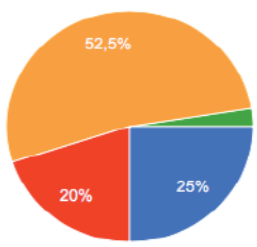

Clases virtuales.

Clases asistidas por plataformas

virtuales.

Clases presenciales y virtuales.

presenciales

Fuente: Elaboración propia 


\section{- Las TIC, entornos virtuales y calidad de la educación}

El 87,5\% de los estudiantes están de acuerdo que las TIC y los entornos virtuales contribuyen a mejorar la calidad de la educación, mientras que un $12 \%$ están poco de acuerdo o en desacuerdo con esta modalidad de educación (Gráfica 72). Estos resultados indican que la educación mediada por TIC tiene grandes oportunidades hacia el futuro

Gráfica 72. Las TIC, entornos virtuales y calidad de la educación

Considera que el uso de las tecnologias de información y las comunicaciones (TIC) y, los entornos virtuales pueden contribuir a mejorar la calidad de la educación:

40 respuestas

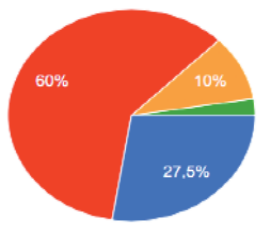

Muy de acuerdo

- De acuerdo

Poco de acuerdo

En desacuerdo

Fuente: Elaboración propia

C. Evaluación de logros obtenidos en desarrollo de las asignaturas

Aquí se evalúan de manera integral logros obtenidos en el desarrollo de las asignaturas, precisando sobre el cumplimiento de los objetivos, contenidos, actividades, recursos, transferencia de conocimientos, trabajo colaborativo, participación del estudiante y evaluación del aprendizaje

\section{- Objetivos de las asignaturas}

Para el $87 \%$ de los estudiantes los objetivos de las asignaturas son claros y comprensibles, en tanto que para el $13 \%$ no son suficientemente claros (Gráfica 73). En este sentido, es recomendable indagar en este grupo cuales son las dificultades que se presentan para implementar correctivos 
Gráfica 73. Objetivos de las asignaturas

Los objetivos del curso son claros y sencillos, de manera que pueden ser entendidos por los estudiantes.

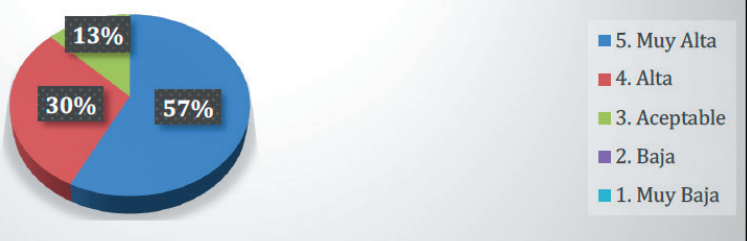

Fuente: Elaboración propia

- Correspondencia de los contenidos con objetivos de las asignaturas

El $87 \%$ de los estudiantes consideran que los contenidos se corresponden altamente con los objetivos de las asignaturas, mientras que para el $13 \%$ esta correspondencia es aceptable (Gráfica 74).

Gráfica 74. Correspondencia de los contenidos con objetivos de las asignaturas

Los contenidos se corresponden con los objetivos propuestos.

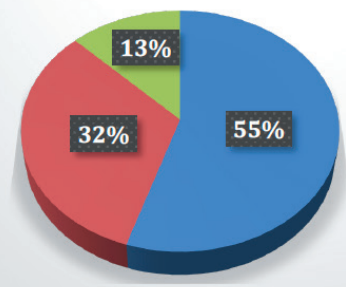

5. Muy Alta

4. Alta

3. Aceptable

- 2. Baja

1. Muy Baja

Fuente: Elaboración propia

- Coherencia de las actividades con los objetivos de las asignaturas

Con respecto a la coherencia, el $85 \%$ de los estudiantes consideran que las actividades guardan estrecha relación con los 
objetivos de las asignaturas, mientras que para el 15\% es aceptable (Gráfica 75). En este sentido, es necesario indagar en este 15\% cuales son las acciones de mejora que se deben implementar.

Gráfica 75. Coherencia de las actividades con los objetivos de las asignaturas

Las actividades tienen coherencia con los objetivos del curso.

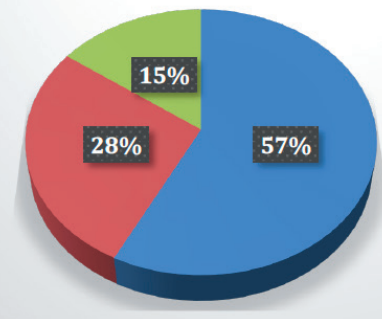

5. Muy Alta

4. Alta

3. Aceptable

2. Baja

1. Muy Baja

Fuente: Elaboración propia

- Docentes promoviendo participación de estudiantes en actividades

El $87 \%$ de los estudiantes reconocen que los profesores promueven altamente la participación de estudiantes en las actividades, mientras que el $13 \%$ consideran que es aceptable (Gráfica 76). Es necesario caracterizar este grupo de docentes para establecer oportunidades de mejora.

Gráfica 76. Docentes promoviendo participación de estudiantes en actividades

Los profesores y/o tutores promueven la participación de los estudiantes en las actividades propuestas.

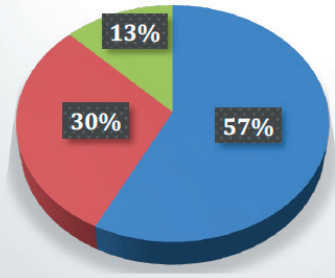

5. Muy Alta

- 4. Alta

-3. Aceptable

—2. Baja

1. Muy Baja

Fuente: Elaboración propia 
- Fomento de trabajo individual y colaborativo para la enseñanza y aprendizaje

Para el $84 \%$ de los estudiantes, las actividades fomentan el trabajo autónomo y colaborativo, mientras que el $16 \%$ consideran que es aceptable (Gráfica 77). A pesar de que los resultados son positivos, es necesario revisar cuales son las acciones a implementar.

Gráfica 77. Fomento de trabajo individual y colaborativo para la enseñanza y aprendizaje

Se diseñan actividades que fomentan el trabajo individual, colaborativo e intercambio entre los implicados en el proceso de enseñanza-aprendizaje.

\section{$16 \%$}

$33 \%$
$51 \%$

-5. Muy Alta

4. Alta

3. Aceptable

-2. Baja

—1. Muy Baja

Fuente: Elaboración propia

- Cantidad de actividades con relación al tiempo disponible de estudiantes

El $65 \%$ de los estudiantes considera que la cantidad de actividades guarda alta relación con el tiempo disponible para realizarlas, mientras que el 35\% considera aceptable el tiempo disponible (Gráfica 78). Esto significa, que es necesario revisar la cantidad de actividades asignadas para no comprometer tiempo extra de los estudiantes. 
Gráfica 78. Cantidad de actividades con relación al tiempo disponible de estudiantes

La cantidad de actividades guarda relación con el tiempo disponible de los estudiantes.

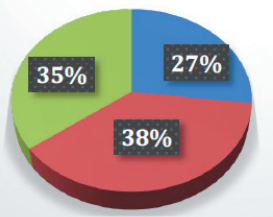

5. Muy Alta

4. Alta

-3. Aceptable

- 2. Baja

1. Muy Baja

Fuente: Elaboración propia

- Contribución de los conocimientos a la formación integral del profesional

Para el 90\% de los estudiantes, los conocimientos adquiridos en las asignaturas tienen alta contribución en la formación integral del profesional, mientras que el 10\% considera que es aceptable (Gráfica 79). De acuerdo con este resultado, la gran mayoría de los estudiantes logran aprendizajes significativos

Gráfica 79. Contribución de los conocimientos a la formación integral del profesional

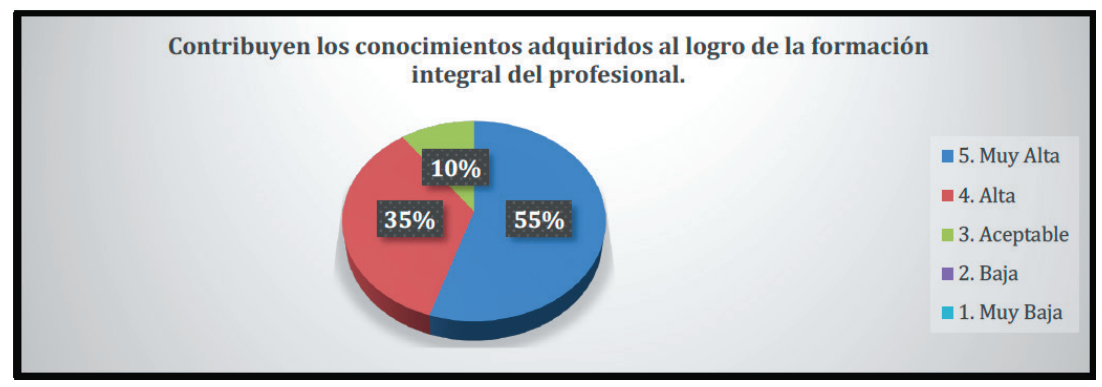

Fuente: Elaboración propia

\section{- Transferencia de conocimientos al ámbito laboral}

El 92\% de los estudiantes afirma que es alta la transferencia de los conocimientos hacia el ámbito laboral, mientras que para el $8 \%$ es aceptable (Gráfica 80 ). Esto indica que para la gran 
mayoría de los estudiantes existe una muy alta contribución de los conocimientos que se transfiere a su ámbito laboral.

Esta pregunta es pertinente para los estudiantes que tienen vinculación laboral y sus funciones están relacionadas con la estructura de contenidos de las asignaturas y la carrera en general.

Gráfica 80. Transferencia de conocimientos al ámbito laboral

Se logra la transferencia de los conocimientos adquiridos al ámbito laboral.

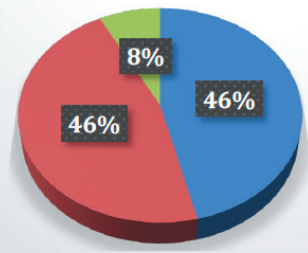

- 5. Muy Alta

4. Alta

-3. Aceptable

- 2. Baja

⒈ Muy Baja

Fuente: Elaboración propia

- Criterios para evaluación de las actividades

Con respecto a la evaluación del aprendizaje el $82 \%$ de los estudiantes afirma que son claros los criterios para evaluación de las actividades, mientras que para el 18\% los criterios de evaluación son aceptable (Gráfica 81). Vale la pena indagar sobre las posibles falencias para establecer correctivos.

Gráfica 81. Criterios para evaluación de las actividades

Se ofrece información detallada sobre los criterios de evaluación de cada una de las actividades.

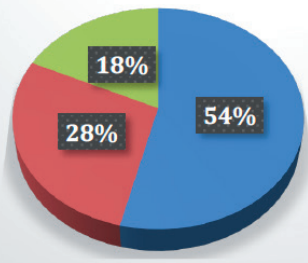


- Correspondencia de la evaluación con objetivos del curso

Para el 85\% de los estudiantes la evaluación corresponde altamente con los objetivos de las asignaturas, mientras que el 15\% considera que es aceptable (Gráfica 82)

Gráfica 82. Correspondencia de la evaluación con objetivos del curso

La evaluación responde a los objetivos del curso.

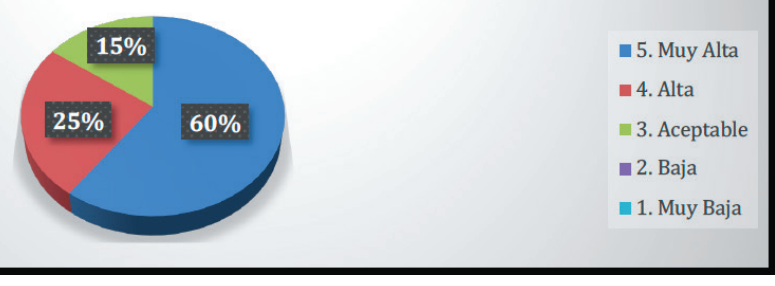

Fuente: Elaboración propia

Como síntesis de este capítulo se resalta que los resultados de la evaluación integral realizada a estudiantes de la Universidad Libre de Pereira y la Escuela Superior de Administración Pública ESP Territorial Quindío Risaralda, reflejan que el uso y apropiación de TIC en la educación es aceptable (57,7\%), que existen buenos niveles de conectividad (76,5\%), existe un buen nivel de satisfacción con el uso de las plataformas virtuales en la educación (75\%), y, que las TIC pueden aportarle alto nivel de calidad a la educación $(88,6 \%)$.

Las lecciones aprendidas durante el ciclo académico del primer semestre de 2020-1 deben constituirse en buenas prácticas para la Universidad Libre de Pereira y la Escuela Superior de Administración Pública (ESAP), si se toman en cuenta los hallazgos como oportunidades de mejora y se implementan las acciones correspondientes, para garantizar la calidad de la educación y disminuir la deserción. 


\subsubsection{Retos y desafíos de las Instituciones de Educación Superior para integración de las Tecnologías de Información y Comunicaciones (TIC) en programas educativos}

Ante la cruda realidad por la que atraviesan las Instituciones de Educación superior se demandan currículos más flexibles, una reinvención de los programas actuales y la transformación de un modelo clásico, magisterial, heredado desde la antigüedad. Esto se convierte en un gran desafío que exige realizar grandes inversiones para mejorar la capacidad instalada con equipos tecnológicos, plataformas, contenidos y herramientas virtuales alternativas que permitan hacerle frente a las exigencias de la educación del siglo XXI, a través de entornos virtuales que garanticen la calidad, accesibilidad, flexibilidad y equidad

$\mathrm{Al}$ respecto, se tienen pronunciamientos recientes de la Revista Semana tales como: “...Ahora, se impone el reto de sobreponerse a la adversidad de las circunstancias y queda en evidencia la importancia que aprender a reaprender hace la diferencia, que las tecnologías como nunca antes asisten para una adaptación rápidamente, que el conocimiento y la investigación ayudan a fortalecernos como humanidad, que las IES y sus bibliotecas contribuyen en la transformación y reconstrucción del tejido humano aportando saber, investigación, innovación y educación para el futuro del país"18.

Así mismo, desde el Observatorio de la Universidad Colombiana se tiene la siguiente premisa sobre las Instituciones de Educación Superior: “....Las que se atrevan a innovar sus modelos de oferta (más allá de algunos descuentos de matrícula); las que logren migrar rápido y propositivamente a la virtualidad; las que logren desarrollar unidades de planeación y rediseño estratégico; las que rompan unidades académicas inamovibles y alejadas de

18 Artículo Revista Semana. HABLAN LAS MARCAS |4/19/2020, p. 1-6 "Bibliotecas virtuales, la gran apuesta de las universidades". 
la negociación y de explorar nuevos conceptos; y las que sean conscientes que si se necesitaba un motivo para -patear el tableroy rediseñar la educación superior, éste es el momento"19.

Por todo lo anterior, los retos de las Instituciones de Educación Superior frente a la educación mediada por TIC, debe ser asimilado como grandes oportunidades que van desde las políticas gubernamentales impulsadas a través del Ministerios de Educación y Ministerio de las TIC, hasta lineamientos de las Instituciones de Educación Superior públicas y privadas, para la renovación de sus Proyectos Educativos Institucionales (PEI), realización de inversiones en infraestructura tecnológica, apropiación de las herramientas virtuales y capacitación a docentes para el fortalecimiento de sus competencias en estos nuevos entornos de la enseñanza y aprendizaje.

A continuación, se describen los retos y desafíos que deben afrontar las Instituciones de Educación Superior en el corto y mediano plazo, para trascender en este mundo de la globalización y la virtualización.

Desde las políticas gubernamentales se plantea:

a. Revisar los marcos normativos y las políticas de la educación, para asegurar medidas estructurales que entiendan la educación como un ciclo virtuoso donde las trayectorias educativas deben ser fortalecidas desde la primera infancia hasta la educación superior y más allá, para minimizar así la fragilidad de los estudiantes más vulnerables que llegan a la educación superior.

b. Realizar inversiones en conectividad para lograr mayor cobertura (cierre de brechas digitales), y mayor apropiación de las Tecnologías de Información y Comunicaciones

19 Articulo. Observatorio de la Universidad Colombiana. ¿Qué IES y rectores sobrevivirán a un 2020-2 sin presencialidad?. 2020, 1-3. https://www.universidad.edu.co/que-ies-y-rectoressobreviviran-a-un-2020-2-sin-presencialidad/ 
c. Cofinanciar programas con las Instituciones de Educación Superior para dotar a estudiantes y docentes de equipos, tecnologías y conectividad.

d. Generar mecanismos de concertación entre el Gobierno Nacional y las Instituciones de Educación Superior (IES) para avanzar conjuntamente en la generación de mayor capacidad de resiliencia del sector de la educación superior ante futuras crisis, cualquiera que sea su naturaleza.

\section{Desde las Instituciones de Educación Superior se requiere:}

a. Promover la reflexión interna sobre la renovación del modelo pedagógico de enseñanza y aprendizaje en la educación superior que favorezca la flexibilidad, la calidad, accesibilidad y la equidad (revisión de PEI)

b. Rediseñar los procesos de enseñanza y aprendizaje, aprovechando las lecciones aprendidas sobre el uso intensivo de las Tecnologías de Información y Comunicaciones en esta época de incertidumbre por el COVID-19

c. Diseñar currículos que ofrezcan a los nuevos profesionales las competencias para gestionar en la incertidumbre y en escenarios totalmente diferentes y desconocidos.

d. Implementar herramientas tecnológicas y de soportes (infraestructura adecuada, tanto en Apps y plataformas) necesarios para orientar procesos de aprendizaje a distancia mediados por las tecnologías, así como diversidad de acceso a la conectividad (disposición de servidores adecuados a la carga de trabajo telemática exigida y disposición del ancho de banda necesario para conectarse, entre otros aspectos) para que el proceso de enseñanza aprendizaje en línea fluya de manera efectiva.

e. Realizar inversiones en soluciones tecnológicas y contenidos para uso en diferentes equipos y en dispositivos móviles 
f. Desarrollar las capacidades de los docentes, ofreciendo capacitación, incentivos y apoyos apropiados, para que el uso de soluciones y recursos tecnológicos que pueden mejorar la calidad de su trabajo.

g. Desarrollo de capacidades técnicas, tecnológicas y pedagógicas para usar apropiadamente metodologías no presenciales, así como seguimiento de los estudiantes, en particular los más vulnerables.

h. Aprender de los errores y escalar la digitalización y la hibridación en el aprendizaje

i. Buscar nuevas formas de acceso a la Educación Superior para diferentes tipos de poblaciones.

j. Implementar nuevos modelos de financiación para los estudiantes

k. Consolidar las bibliotecas virtuales como un pilar clave para la investigación y la apropiación de metodologías para el trabajo en el mundo digital, fortalecimiento de las competencias en el manejo de recursos virtuales y trabajo colaborativo

1. De manera integral, los retos y desafíos que tienen las Instituciones de Educación Superior son mantener los indicadores de cobertura (número de matriculados), número de instituciones y programas, nivel de formación de docentes, las tasas de deserción, la financiación de las instituciones educativas, los resultados de logro académico y la eficiencia en el manejo de recursos

\section{Modelo de virtualización}

\subsection{Caso práctico de virtualización de asignaturas en la UTP}

Paraelcasodelavirtualización quees partedelatransformación que deben emprender las Instituciones de Educación Superior en Colombia se encuentra en el Departamento de Risaralda la Universidad Tecnológica de Pereira, quien en su Proyecto 
Educativo Institucional (PEI) aprobado mediante Acuerdo del Consejo Superior No. 04 del 06 de febrero de 2018 ${ }^{20}$, definió los principios de integración y flexibilización que constituyen la base de la reflexión para la renovación curricular, que debe ser congruente con las pedagogías universitarias del siglo XXI. Con respecto a las pedagogías, en el PEI de la Universidad Tecnológica de Pereira se establece que el uso de recursos y tecnologías de la información y comunicación (TIC) debe estar al servicio de los ambientes educativos y su utilidad depende del aprovechamiento efectivo en los procesos de enseñanza y aprendizaje, para que ayuden a promover habilidades y competencias de los ciudadanos y los profesionales del siglo XXI (Gutiérrez, Buriticá y Rodríguez, (2011). El reto es hacer de los espacios pedagógicos oportunidades para el diálogo, la participación, el debate, la reflexión y la renovación de la docencia a nivel institucional. Esta Universidad en su Plan de Desarrollo Institucional "Construimos Futuro" 2020 - 2028 ${ }^{21}$ aprobado mediante Acuerdo del Consejo Superior No. 37 del 06 de noviembre de 2019, en el pilar de "Excelencia Académica para la Formación Integral”, conformado por los programas de gestión curricular, acceso, inserción y acompañamiento a la vida universitaria, desarrollo docente y gestión de egresados, enfatiza en los medios y recursos de integración de Tecnologías de Información y Comunicaciones (TIC) para mejorar la calidad en los procesos educativos.

El programa seis de dicho Plan de Desarrollo Institucional "Consolidación de la Educación Virtual", busca dar cuenta de la apropiación y ejecución de procesos educativos que integren las tendencias de las Tecnologías de la Información y las Comunicaciones en una educación del sigloXXI, generando nuevas posibilidades de acceso, permanencia, aprendizaje y visibilización de logros. Sus principales alcances se centran en generar las

20 Proyecto Educativo Institucional (PEI) 2018, pág 3-56. Universidad Tecnológica de Pereira, sitio web www.utp.edu.co

21 Plan de Desarrollo Institucional (PDI) 2020-2028 Construimos Futuro, 2019, pág 12-114. Universidad Tecnológica de Pereira, sitio web www.utp.edu.co 
capacidades académicas y administrativas para la operación de la educación virtual, la oferta de programas académicos virtuales y la visibilización de logros académicos a través de credenciales digitales alternativas. Para el logro de éste gran propósito, se requiere ampliación de la oferta en las TIC pertinentes a las distintas disciplinas que contribuyan a su enseñanza en el marco de las pedagogías interactivas. En este sentido es de resaltar que la Universidad Tecnológica de Pereira cuenta con un área denominada Univirtual-UTP, que administra una plataforma a través de la cual se ofrecen servicios de asignaturas virtuales para programas de pregrado, posgrados y formación continua como diplomados en diferentes áreas del conocimiento, tales como maestro virtual y habilidades de dirección, entre otros. Al cierre del 2019 se atendieron de manera virtual 11.207 estudiantes con acompañamiento en las siguientes modalidades: Aulas Extendidas (docentes con aulas en la plataforma) 198, Focalízate (estrategia de acompañamiento a estudiantes) 6.262, Pregrado (asignaturas virtuales) 3.856, Educación Continua 724, Posgrado (Maestría) 128 y Proyectos (aulas corporativas) 39.

En este contexto, como valor agregado a este estudio se presenta el modelo práctico de virtualización de la asignatura Formulación y Evaluación de Proyectos de Inversión, en la Universidad Tecnológica de Pereira, instalado en la plataforma de Univirtual UTP, con interacción a través de LMS Moodle. Este programa está fundamentado en las fases del proceso de enseñanza aprendizaje que se presenta a continuación (Figura 1) 
Figura 1. Fases del proceso de enseñanza y aprendizaje

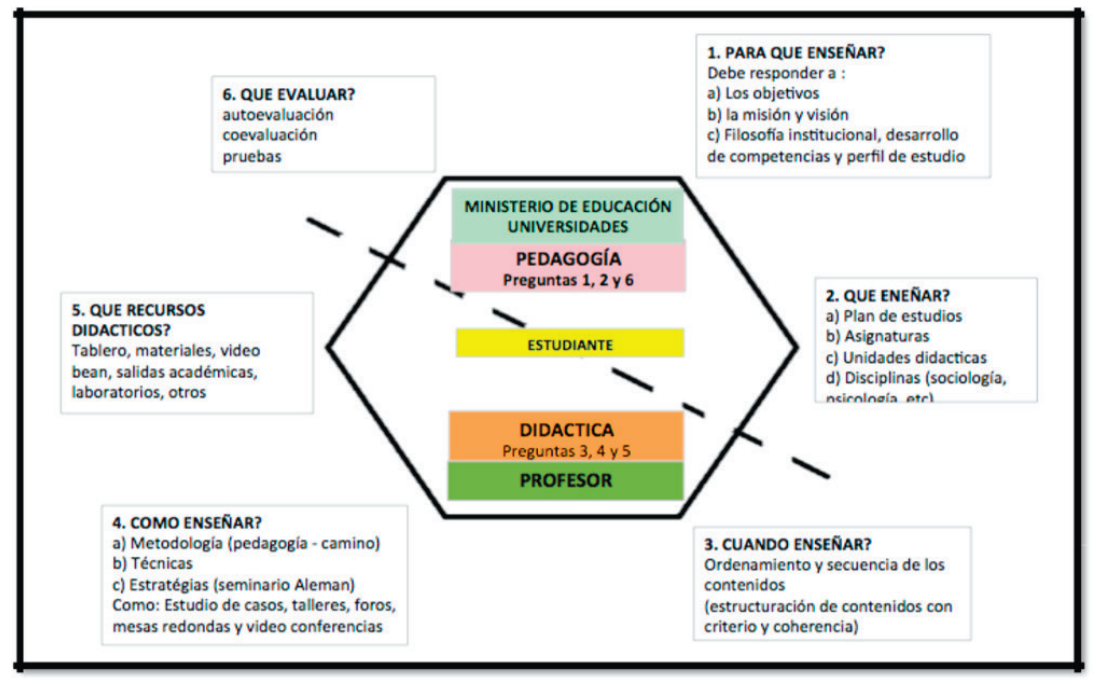

Este proceso de enseñanza y aprendizaje establece objetivos a lograr, articulando el ¿para qué enseñar?, ¿qué enseñar?, ¿cuándo enseñar?, ¿cómo enseñar? y ¿con qué recursos enseñar? Así mismo, conjuga la pedagogía bajo los lineamientos del Ministerio de Educación, el PEI de la Universidad y la didáctica aplicada como responsabilidad de los profesores. Esto con el fin de lograr mejores estándares de calidad en la educación superior.

El propósito con este proyecto es la ampliación de la oferta educativa aprovechando las Tecnologías de Información y Comunicaciones TIC, en las distintas disciplinas que contribuyan a su enseñanza en el marco de las pedagogías interactivas. En este ámbito, los aspectos a tener en cuenta fueron las necesidades de los estudiantes en las diferentes disciplinas y carreras de la Universidad para avanzar y cumplir con sus créditos académicos de manera oportuna y ágil aprovechando la movilidad y flexibilidad curricular. Esta opción les permite optimizar recursos financieros y tiempo. Este modelo de virtualización fue fundamentado en experiencias aplicadas para otras asignaturas en la Universidad 
y el proceso se desarrolló de acuerdo con la metodología de Bloom inspirado en el diseño instruccional ADDIE, consistente en la articulación sistémica de cada una de las etapas del proceso construido de manera colaborativa y participativa entre el experto pedagogo que desarrolló los contenidos educativos, en este caso Jairo Ordilio Torres y el experto en diseño del material educativo designado por la Universidad (Univirtual).

Bajo esta premisa, el Consejo Académico de la Universidad Tecnológica de Pereira, mediante Acuerdo No. 16 del 21 de marzo de $2018^{22}$, aprobó la creación de la asignatura electiva virtual denominada "Formulación y Evaluación de Proyectos de Inversión" que en su artículo primero establece: "Créase la electiva Formulación y Evaluación de Proyectos de Inversión, modalidad virtual, con tres créditos académicos y como una asignatura electiva general que podrá ser tomada por los estudiantes de todos los programas de pregrado de la Universidad dentro de la oferta de asignaturas electivas de cada programa..."

Para el diseño de la asignatura virtual se utilizó el modelo Taxonomía de Bloom (Figura 2) donde la primera etapa del diseño consiste en el análisis donde se definen los objetivos general y específicos de la asignatura, así como las tareas a realizar por los estudiantes; la segunda etapa comprende el diseño, en el cual se establece la forma como el estudiante va a cumplir con los objetivos definidos en la etapa de análisis, la tercera etapa es donde se articula el equipo de diseño y desarrollo para producir el material educativo, en la etapa de implementación se realiza el montaje del material en el aula y se realiza la matrícula de estudiantes y usuarios que participarán en el curso. La etapa final consistente en la evaluación, que realiza Univirtual a través de una encuesta de percepción aplicada a los estudiantes cada semestre,

22 Acuerdo No. 16 del 21 de marzo de 2018, 1-6. Consejo Académico Universidad Tecnológica de Pereira, sitio web www.utp.edu.co 
la cual es socializada con los docentes y equipos involucrados en el proceso de enseñanza aprendizaje, para establecer acciones de mejora continua.

Figura 2. Diseño Instruccional -Taxonomía de Bloom-

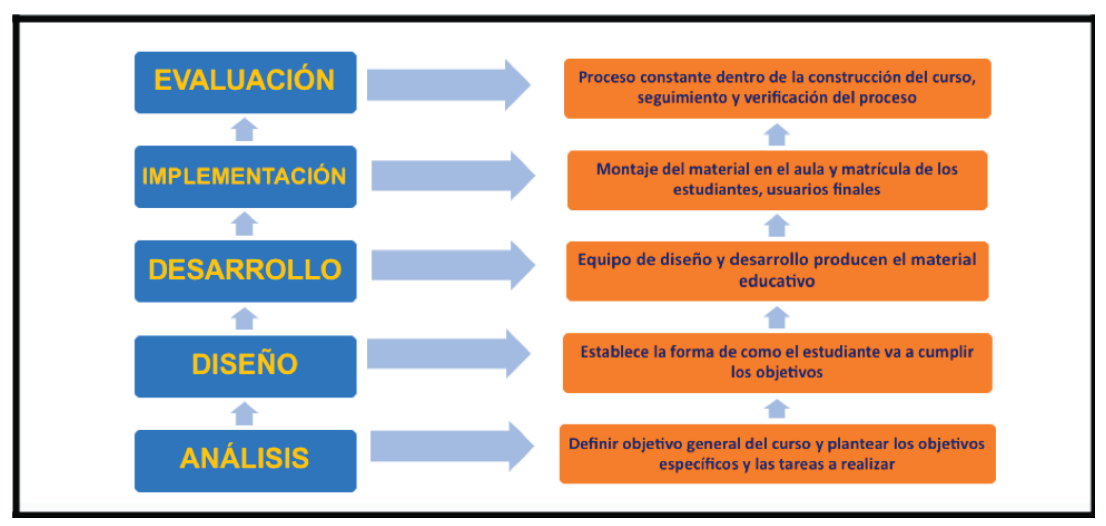

Fuente: Elaboración propia

Todo el material educativo se desarrolló con la asesoría de Univirtual, entre los que se destacan videos introductorios cortos para cada módulo, infografías, mapas mentales, foros, guías tutoriales, material didáctico, entre otros. Este material educativo desarrollado e implementado se encuentra descrito de manera detallada en el apartado 3.4 de este documento "Plataforma tecnológica - univirtual.utp.edu.co"

La estructura académica, curricular y metodológica de esta asignatura se describe a continuación: 


\section{DATOS GENERALES ASIGNATURA VIRTUAL}

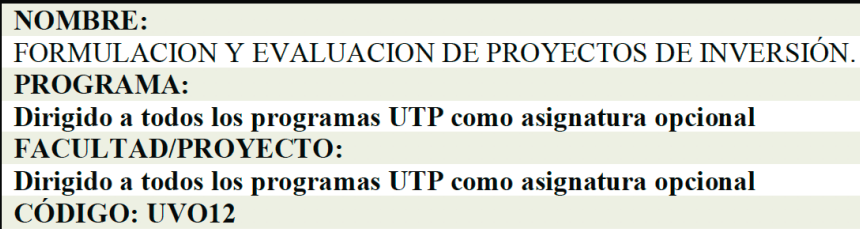

\section{DESCRIPCIÓN}

El curso está orientado a desarrollar y fortalecer las competencias para el análisis, comprensión y solución de problemas organizacionales y sociales relacionados con proyectos de inversión; permitirá trabajar de manera autónoma, colaborativa e interdisciplinar, con la participación de actores que promueven y median el aprendizaje significativo y desarrollo cognitivo, mediante el uso y apropiación de las TIC.

El alcance abarca todo el ciclo de la pre-inversión, aplicando técnicas modernas para la identificación y planteamiento del problema, desarrollo de los estudios de factibilidad como son: el estudio de mercado o estudio de necesidades, el estudio técnico y organizacional, el estudio económico y evaluación financiera priorizando las fuentes de financiación, la evaluación social y ambiental, así como, el análisis de las variables macroeconómicas que pueden afectar la viabilidad de un proyecto como los impuestos, la inflación, los tipos de cambio y las tasas de interés.

La población objetivo serán estudiantes de los diferentes programas de la Universidad, interesados en estructurar proyectos que contribuyan al crecimiento y desarrollo social, económico y ambiental. 


\section{JUSTIFICACIÓN}

Los proyectos son una disciplina del conocimiento aplicada en el quehacer profesional, que permite tomar decisiones más acertadas frente a diferentes alternativas de inversión. La formulación y evaluación de proyectos conduce a la identificación y selección de los proyectos más convenientes para invertir y que estén enmarcados dentro del plan estratégico empresarial.

Se justifica este curso dada la importancia de los proyectos para dar respuesta a los requerimientos cada vez mayores de la sociedad, a la vez que se convierten una herramienta útil para optimizar el uso de los recursos disponibles, en búsqueda de la eficiencia y eficacia en el logro de los objetivos.

Esta oferta académica está en concordancia con los lineamientos del Proyecto Educativo Institucional (PEI), aprobado mediante Acuerdo No. 04 del 8 de febrero de 2018, que dentro de sus principios orientadores de la renovación curricular establece la integración y la flexibilización. La integración se fundamenta en las experiencias de enseñanza y aprendizaje contextuales y pertinentes; por su parte, la flexibilización enfatiza en los cursos y/o seminarios electivos a los que el estudiante puede optar en distinto orden de acuerdo con la capacidad de oferta de los programas y las unidades académicas.

El propósito de la flexibilización es la articulación del conocimiento v la acción. aue da al estudiante mayores oportunidades para la selección de rutas de formación en diferentes ámbitos y direcciones. En este sentido, la flexibilización busca una formación menos rígida, con mayor vinculación e impacto en el conjunto de habilidades que orientan el desempeño profesional, de acuerdo con las exigencias de un mundo cada vez más competitivo, inestable y cambiante

De acuerdo con el PEI, los principios enunciados de integración y flexibilización constituyen la base de la reflexión para la renovación curricular, que debe ser congruente con las pedagogías universitarias del siglo XXI.

Con respecto a las pedagogías, el PEI establece que el uso de recursos y tecnologías de la información y comunicación (TIC) debe estar al servicio de los ambientes educativos y su utilidad depende del aprovechamiento efectivo en los procesos de enseñanza y aprendizaje, para que ayuden a promover habilidades y competencias de los ciudadanos y los profesionales del siglo XXI (Gutiérrez, Buriticá y Rodríguez, (2011). El reto es hacer de los espacios pedagógicos oportunidades para el diálogo, la participación, el debate, la reflexión y la renovación de la docencia a nivel institucional.

En este contexto, durante el desarrollo del curso de Formulación y Evaluación de Proyectos el estudiante adquiere competencias del saber y el saber hacer, orientadas a comprender, analizar, planear, aplicar y construir herramientas técnicas y financieras, que le permitan formular y evaluar con buen criterio un proyecto de inversión, para la toma de decisiones más acertadas, hacia la solución de problemas organizacionales y sociales.

Como herramientas técnicas se destaca la planificación de las actividades en la etapa de la preinversión para la estructuración de un proyecto, el estudio de mercado o análisis de necesidades, la evaluación financiera, así como, la comprensión de las diferentes variables macroeconómicas que pueden afectar la viabilidad y que permiten minimizar el riesgo y la certidumbre de los proyectos.

Finalmente, el estudiante estará preparado para identificar alternativas viables de inversión, enmarcadas dentro de los objetivos del Plan Estratégico Empresarial o del Plan de Desarrollo, de acuerdo con la naturaleza y características de la institución (pública o privada). 


\section{METODOLOGÍA}

- Curso virtual

- Interacción a través de LMS Moodle.

- Asesorías sincrónicas.

- Talleres in situ

- Acompañamiento al proceso.

- Actividades definidas por módulo

Se desarrolla bajo la metodología Semipresencial, $80 \%$ virtual - $20 \%$ sincrónico; las actividades, recursos y el desarrollo de contenidos encaminados al logro de los objetivos de los módulos, se realizarán bajo la intermediación del aula de Univirtual de la Universidad Tecnológica de Pereira.

Es necesario señalar que las Aulas de Univirtual cuentan con espacios de acompañamiento permanente a sus estudiantes, destinados a abrir un canal de comunicación para la solución de problemas técnicos, administrativos y/o comunicativos propios del proceso de aprendizaje. Este apoyo se brinda a través de línea telefónica gratuita 018000951010 , el servicio de Univirtual en línea, así como correos electrónicos de contacto y una guía didáctica que orientará al estudiante. En este mismo orden de ideas este curso cuenta con docentes que acompañan permanentemente al estudiante durante todo su proceso educativo y contribuyen a generar las competencias propuestas durante el curso.

Igualmente, cada docente es guiado por expertos en la implementación de estrategias didácticas mediadas por TIC, brindándole un abanico de posibilidades educativas en la construcción y ejecución del curso virtual.

\section{OBJETIVOS}

\section{Objetivo General}

Desarrollar las competencias necesarias para la formulación y evaluación de proyectos de inversión, utilizando herramientas técnicas y financieras modernas como medio eficaz para la aplicación de recursos, tendientes a la solución de problemas organizacionales y sociales

\section{Objetivos Específicos}

- 1.Planear las etapas de un proyecto de inversión.

- 2.Establecer el ciclo del proyecto, enfatizando en la pre-inversión (evaluación ex-antes)

- 3.Construir la matriz del Marco Lógico para identificar y formular el problema, estableciendo causas y efectos, que conlleve a la definición de objetivos.

- 4.Aplicar la metodología adecuada para realizar la investigación de mercado o estudio de necesidades.

- 5.Definir los requerimientos técnicos y la estructura organizacional del proyecto

- 6.Categorizar los costos de la inversión y evaluar la rentabilidad del proyecto, de acuerdo con los ingresos y costos de operación

- 7.Analizar las fuentes de financiación más convenientes para los proyectos de inversión, tanto del sector público como del sector privado 
- 8.Evaluar la bondad del proyecto en diferentes escenarios, de acuerdo con los análisis de sensibilidad

- 9.Evaluar el impacto social de los proyectos de inversión

- 10.Evaluar el impacto ambiental de los proyectos de inversión.

- 11.Demostrar la incidencia de las variables macroeconómicas en la evaluación de un proyecto (análisis de sensibilidad)

\section{ACTIVIDADES DE EVALUACIÓN}

- Desarrollo de un proyecto de inversión: Cada módulo recibe una calificación ponderada de acuerdo con el $\%$ valorado del contenido.

- El desarrollo de cada módulo implica la realización y avance del proyecto de acuerdo con la temática de módulo.

- El trabajo se realiza por equipos.

Tabla 12. Contenidos de la asignatura

\begin{tabular}{|c|c|c|c|c|c|}
\hline MODULOS & $\mathbf{H}$ & LECCION & \begin{tabular}{|c|} 
OBJETIVOS \\
ESPECIFICOS
\end{tabular} & ACTIVIDADES & $\begin{array}{l}\text { RESULTADOS } \\
\text { ESPERADOS }\end{array}$ \\
\hline \multirow{3}{*}{$\begin{array}{l}\text { 1.FUNDAMENTACIÓN } \\
\text { Y FORMULACION } \\
\text { DEL PROYECTO }\end{array}$} & \multirow[b]{3}{*}{36} & $\begin{array}{l}\text { 1.La planeación y } \\
\text { los proyectos }\end{array}$ & $\begin{array}{l}\text { Planear las etapas } \\
\text { de un proyecto de } \\
\text { inversión }\end{array}$ & $\begin{array}{l}\text { Lecturas-Taller } \\
\text { Foro -Video } \\
\text { Evaluación }\end{array}$ & $\begin{array}{l}\text { Aplicar criterios de } \\
\text { la planeación en las } \\
\text { etapas de un } \\
\text { proyecto }\end{array}$ \\
\hline & & $\begin{array}{l}\text { 2.El Ciclo del } \\
\text { Proyecto }\end{array}$ & $\begin{array}{l}\text { Establecer el ciclo } \\
\text { del proyecto, } \\
\text { enfatizando en la } \\
\text { pre-inversión } \\
\text { (evaluación ex- } \\
\text { antes) }\end{array}$ & $\begin{array}{l}\text { Lecturas-Taller } \\
\text { Foro-Video } \\
\text { Evaluación }\end{array}$ & $\begin{array}{l}\text { Caracterizar las } \\
\text { etapas de un } \\
\text { proyecto, como la } \\
\text { pre-inversión, } \\
\text { inversión, operación } \\
\text { y evaluación expost }\end{array}$ \\
\hline & & $\begin{array}{l}\text { 3.El Marco } \\
\text { Lógico }\end{array}$ & 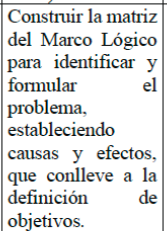 & $\begin{array}{l}\text { Lecturas-Taller } \\
\text { Foro-Video } \\
\text { Evaluación }\end{array}$ & $\begin{array}{l}\text { Aplicar la técnica } \\
\text { del marco lógico y } \\
\text { Sistematizar la } \\
\text { información del } \\
\text { problema en la } \\
\text { matriz } 4 x 4 \text {, para } \\
\text { determinar la } \\
\text { alternativa de } \\
\text { solución }\end{array}$ \\
\hline \multirow{3}{*}{$\begin{array}{l}\text { 2.ESTUDIOS DE } \\
\text { FACTIBILIDAD DEL } \\
\text { PROYECTO }\end{array}$} & \multirow{3}{*}{36} & $\begin{array}{l}\text { 1.Estudio de } \\
\text { Mercado }\end{array}$ & $\begin{array}{lr}\text { Aplicar } & \text { la } \\
\text { metodologia } & \\
\text { adecuada } & \text { para } \\
\text { realizar } & \text { la } \\
\text { investigación } & \text { de } \\
\text { mercado o estudio } \\
\text { de necesidades }\end{array}$ & $\begin{array}{l}\text { Lecturas-Taller } \\
\text { Foro - Video } \\
\text { Evaluación }\end{array}$ & $\begin{array}{l}\text { Hay que confirmar } \\
\text { que existe la } \\
\text { necesidad y hay } \\
\text { clientes potenciales } \\
\text { para demandar un } \\
\text { bien o servicio }\end{array}$ \\
\hline & & $\begin{array}{l}\text { 2.Estudio } \\
\text { Técnico y } \\
\text { organizacional }\end{array}$ & $\begin{array}{lll}\text { Definir } & \text { los } \\
\text { requerimientos } & \\
\text { técnicos y } & \text { la } \\
\text { estructura } & \\
\text { organizacional del } \\
\text { proyecto } & \end{array}$ & $\begin{array}{l}\text { Lecturas-Taller } \\
\text { Foro - Video } \\
\text { Evaluación }\end{array}$ & $\begin{array}{l}\text { Determinar si } \\
\text { técnica y } \\
\text { organizacionalmente } \\
\text { se puede ejecutar el } \\
\text { proyecto }\end{array}$ \\
\hline & & $\begin{array}{l}\text { 3.Estudio } \\
\text { Económico y } \\
\text { Financiero }\end{array}$ & \begin{tabular}{|lr} 
Categorizar & los \\
costos de & la \\
inversión y evaluar \\
la rentabilidad del \\
proyecto, rr re \\
acuerdo con & los \\
ingresos y & costos \\
de operación
\end{tabular} & $\begin{array}{l}\text { Lecturas-Taller } \\
\text { Foro - Video } \\
\text { Evaluación }\end{array}$ & $\begin{array}{l}\text { Elaborar estado de } \\
\text { resultados y flujo de } \\
\text { caja, para evaluar los } \\
\text { costos y la } \\
\text { rentabilidad de un } \\
\text { proyecto }\end{array}$ \\
\hline
\end{tabular}




\begin{tabular}{|c|c|c|c|c|c|}
\hline \multirow[t]{2}{*}{$\begin{array}{l}\text { 3.HERRAMIENTAS } \\
\text { PARA ANALISIS DEL } \\
\text { PROYECTO }\end{array}$} & \multirow[t]{2}{*}{36} & $\begin{array}{l}\text { 1.Fuentes de } \\
\text { financiación de } \\
\text { los 'proyectos }\end{array}$ & $\begin{array}{lr}\text { Analizar } & \text { las } \\
\text { fuentes } & \text { de } \\
\text { financiación } & \text { más } \\
\text { convenientes } & \text { para } \\
\text { los proyectos de } \\
\text { inversión, tanto } \\
\text { del sector público } \\
\text { como del sector } \\
\text { privado }\end{array}$ & $\begin{array}{l}\text { Lecturas-Taller } \\
\text { Foro - Video } \\
\text { Evaluación }\end{array}$ & $\begin{array}{l}\text { Seleccionar las } \\
\text { fuentes de } \\
\text { financiación más } \\
\text { convenientes para el } \\
\text { proyecto }\end{array}$ \\
\hline & & $\begin{array}{l}\text { 2. Caso práctico } \\
\text { de evaluación } \\
\text { financiera }\end{array}$ & $\begin{array}{l}\text { Evaluar la bondad } \\
\text { del proyecto en } \\
\text { diferentes } \\
\text { escenarios, de } \\
\text { acuerdo con los } \\
\text { análisis de } \\
\text { sensibilidad }\end{array}$ & Video tutorial & \begin{tabular}{|l} 
Evaluar la \\
sensibilidad \\
financiera de un \\
proyecto en \\
diferentes escenarios
\end{tabular} \\
\hline \multirow{3}{*}{$\begin{array}{l}\text { 4.EVALUACION } \\
\text { INTEGRAL DEL } \\
\text { PROYECTO }\end{array}$} & \multirow{3}{*}{36} & $\begin{array}{l}\text { 1.Evaluación } \\
\text { social }\end{array}$ & $\begin{array}{|lr|}\text { Evaluar el impacto } \\
\text { social de } & \text { los } \\
\text { proyectos } & \text { de } \\
\text { inversión } & \end{array}$ & $\begin{array}{l}\text { Lecturas-Taller } \\
\text { Foro -Evaluación }\end{array}$ & $\begin{array}{l}\text { Aplicar criterios de } \\
\text { la metodología } \\
\text { MGA para la } \\
\text { evaluación social de } \\
\text { un proyecto }\end{array}$ \\
\hline & & $\begin{array}{l}\text { 2.Evaluación } \\
\text { ambiental }\end{array}$ & 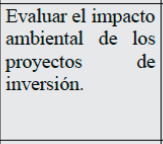 & $\begin{array}{l}\text { Lecturas-Taller } \\
\text { Foro - Video } \\
\text { Evaluación }\end{array}$ & $\begin{array}{l}\text { Aplicar criterios de } \\
\text { la metodología } \\
\text { causa-efecto para la } \\
\text { evaluación } \\
\text { ambiental de un } \\
\text { proyecto }\end{array}$ \\
\hline & & $\begin{array}{l}\text { 3.Efecto de las } \\
\text { variables } \\
\text { macroeconómicas }\end{array}$ & 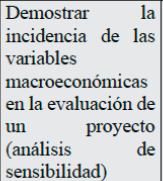 & $\begin{array}{l}\text { Lecturas-Taller } \\
\text { Foro - Video } \\
\text { Evaluación }\end{array}$ & $\begin{array}{l}\text { Analizar el impacto } \\
\text { de las variables } \\
\text { macroeconómicas en } \\
\text { la evaluación de un } \\
\text { proyecto }\end{array}$ \\
\hline
\end{tabular}

Fuente: Elaboración propia

7. BIBLIOGRAFÍA (libros, revistas, páginas web, documentos, videos, etc.)

- Armijo Marianela (2009). Manual de Planificación Estratégica e Indicadores de Desempeño en el Sector Público Santiago de Chile: Editores ILPES/CEPAL

- Baca Urbina Gabriel (2001). Evaluación de Proyectos. México, D.F: Editorial McGraw-Hill

- Berretta Nora y Kaufmann Jorge (2010). Gestión para Resultados en el Desarrollo en Gobiernos Subnacionales. Washington: Editores BID-INDES

- Candia, Jorge, Perrotti Daniel E. y Aldunate, Eduardo (2015). Evaluación Social de Proyectos. Santiago de Chile: Editores Naciones Unidas - CEPAL-

- Gómez Orea, Domingo (1999). Evaluación de Impacto Ambiental. Madrid, España: Editor Mundi-Prensa

- Miranda Miranda, Juan José (junio 2004). Gestión de Proyectos. Bogotá, Colombia: MM Editores

- Mochón Morcillo Francisco (1993). Economía Teoría y Política. Madrid España: Editor McGraw-Hill

- Villarreal Infante Arturo (1994) . Evaluación Financiera de Proyectos de Inversión. Bogotá, Colombia: Editor Norma S.A 
$\mathrm{Su}$ estructura también permite trabajar el concepto b-learning, el cual alterna e integra el aprendizaje presencial y el aprendizaje online, donde se pueden combinar actividades presenciales con instrucciones mediadas por ordenadores, ya que el uso de las tecnologías de información y las comunicaciones (TIC) permite interactuar en red en tiempo real y diferido, logrando las sinergias que se requieren en los grupos involucrados (docentes, estudiantes, expertos, grupo familiar), favoreciendo la planificación pedagógica y la flexibilidad en la educación superior.

\subsection{Plan de estudio académico asignatura Formulación y Evaluación de Proyectos}

El plan de estudios comprende los módulos, las lecciones y los resultados esperados, (Figura 3). Cada evento se demuestra con las actividades que realizan los estudiantes y que deben corresponder a la teoría aplicada en forma práctica en un proyecto que se selecciona, se formula y evalúa durante el semestre; información esta que se va registrando luego de la retroalimentación por parte del docente en el módulo denominado "Consolidación del Proyecto", al que se le asigna una calificación equivalente al 20\% del total del curso. Los resultados finales se evidencian con la respuesta de los estudiantes al desafío de estructurar un proyecto, que les puede servir como "Proyecto de Vida". Lo anterior, también se puede evidenciar con el número cada vez mayor de estudiantes que se matriculan de los diferentes programas que ofrece la Universidad. 
Figura No. 3. Plan de Estudio Académico

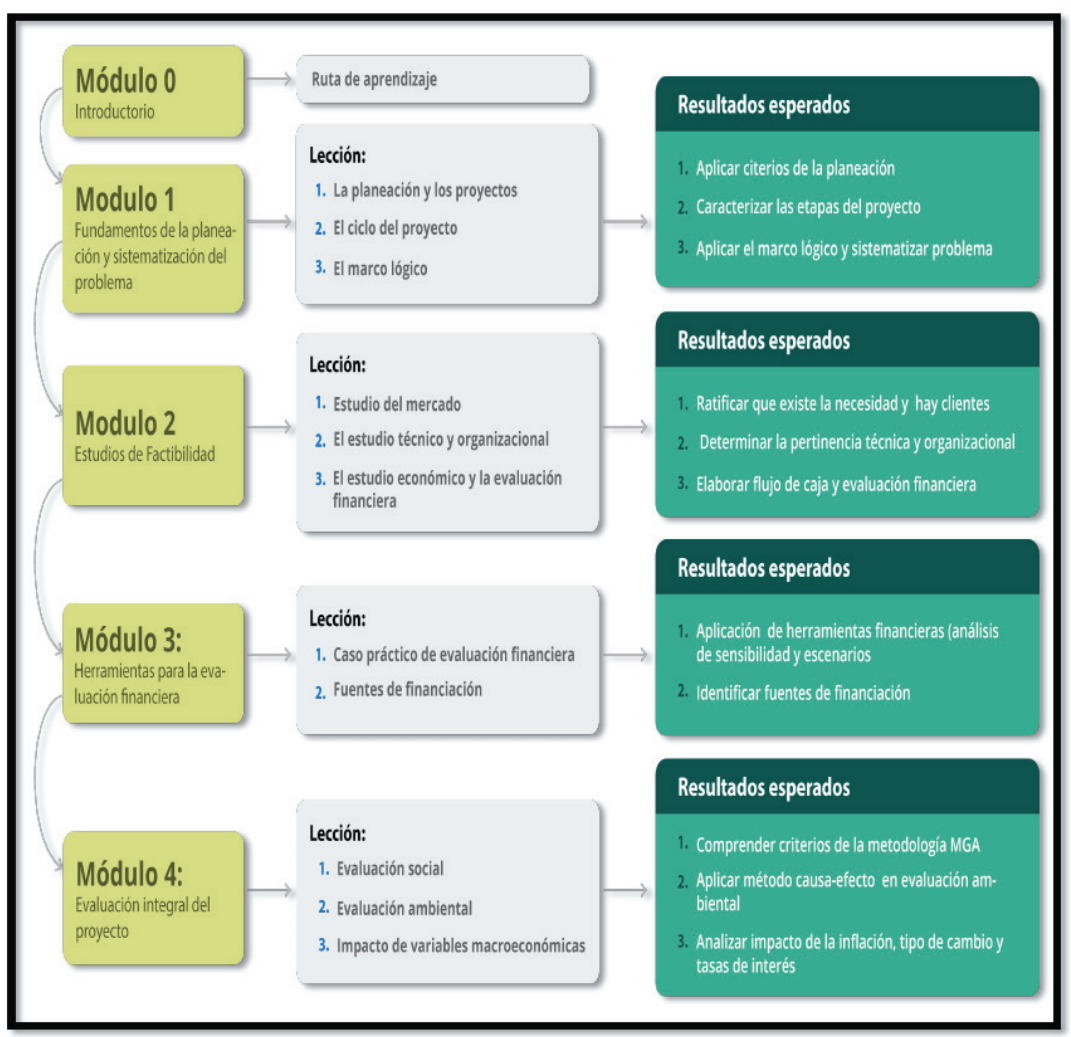

Fuente: Elaboración propia

\subsection{Cobertura asignatura Formulación y Evaluación de Proyectos de Inversión}

Esta asignatura empezó en el 2018 con un curso de 30 estudiantes y para este semestre 2020-2 se tienen matriculados 4 cursos con un número promedio de 25 estudiantes cada uno. 


\subsection{Plataforma tecnológica - univirtual.utp.edu.co}

Esta asignatura está instalada en una plataforma virtual que ofrece navegar de manera práctica y sencilla por todo el ciclo de la pre-inversión, aplicando técnicas modernas tanto para la identificación y planteamiento del problema, la formulación del proyecto y desarrollo de los estudios de factibilidad como el estudio de mercado o estudio de necesidades, estudio técnico y organizacional, estudio económico y evaluación financiera, la identificación de fuentes de financiación, evaluación social y ambiental y, el análisis de variables macroeconómicas que pueden afectar la viabilidad de un proyecto, tales como los impuestos, la inflación, los tipos de cambio y las tasas de interés. Se trata de un desarrollo pertinente y adecuado para los retos de la educación del siglo XXI porque integra de manera sistémica metodologías y recursos didácticos, que a través de las TIC logran la mediación del aprendizaje, permitiendo trabajar articuladamente los contenidos curriculares que darán respuesta a los requerimientos del contexto profesional, laboral y empresarial.

Esta es una buena práctica con lecciones aprendidas que bien podría ser replicada en la Universidad Libre, para atender requerimientos de estudiantes que por alguna circunstancia no puedan cursar esta asignatura de manera presencial.

A continuación, se presenta la manera práctica de cómo navegar en la plataforma, visualizando los módulos de la asignatura, las lecciones y el contenido básico de las lecciones. Cada módulo contiene recursos (materiales, documentos, presentaciones, videos, guías, tutoriales, bibliografía) y actividades que se deben presentar según el cronograma que está en concordancia con el calendario académico. 
Imagen 1: Ingreso a la plataforma virtual

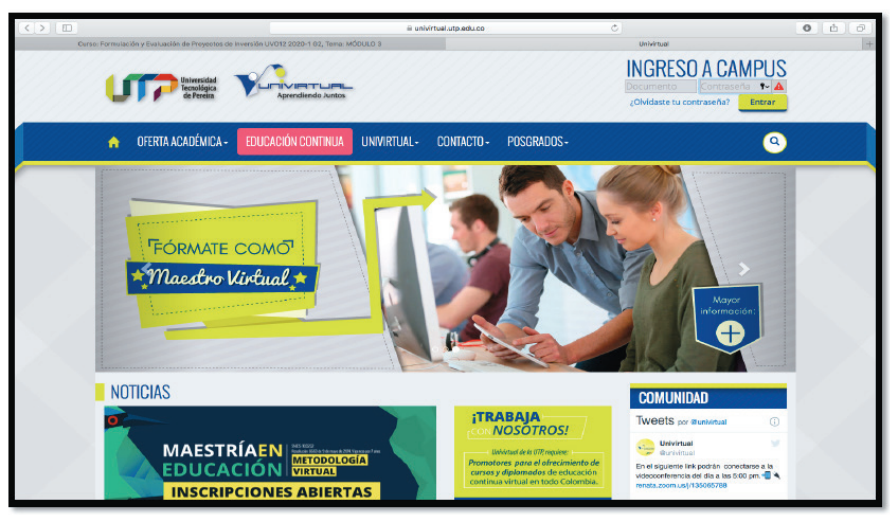

Imagen 2: Ingreso a la asignatura

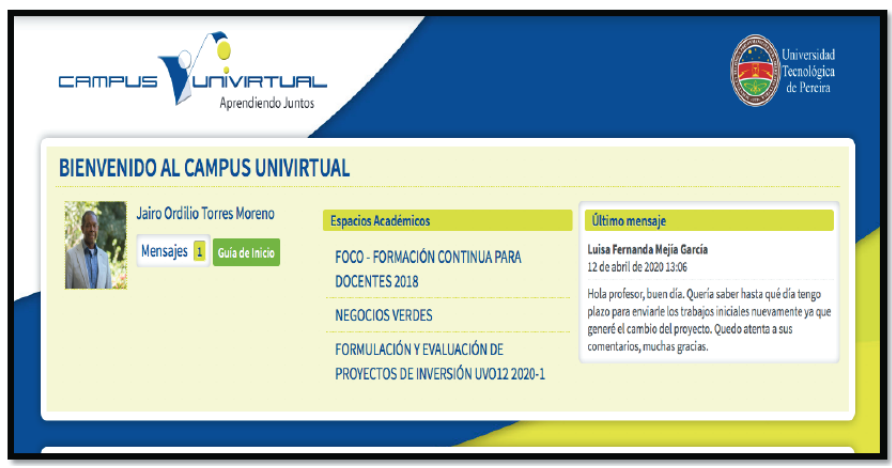

Imagen 3: Ingreso a los cursos asignados

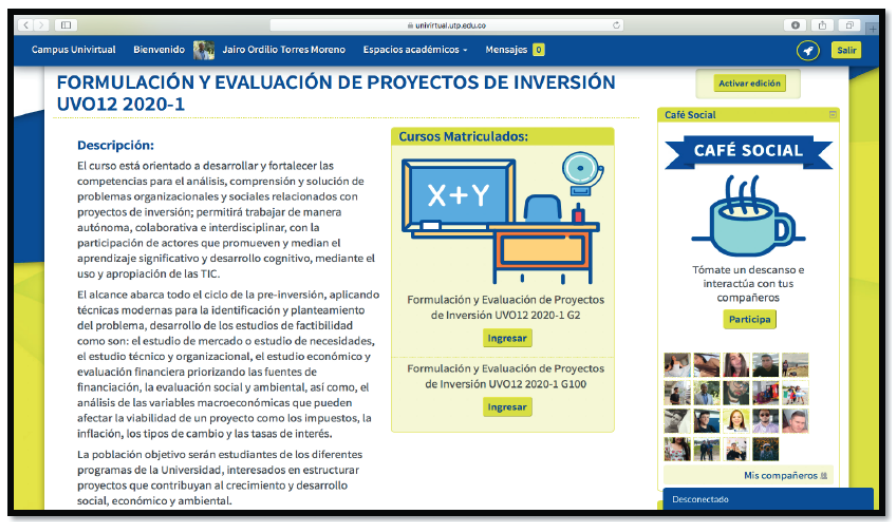


Imagen 4: Ingreso al tablero para programación de tareas y etiquetas

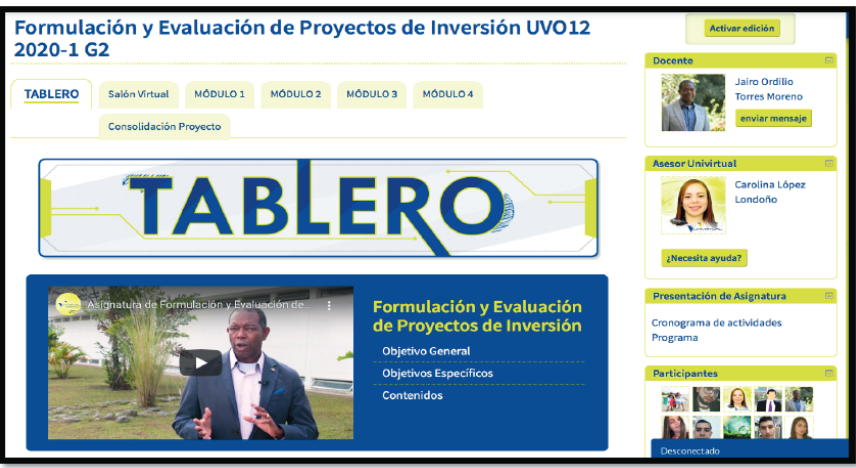

Imagen 5: Ingreso al salón virtual para programar encuentros sincrónicos

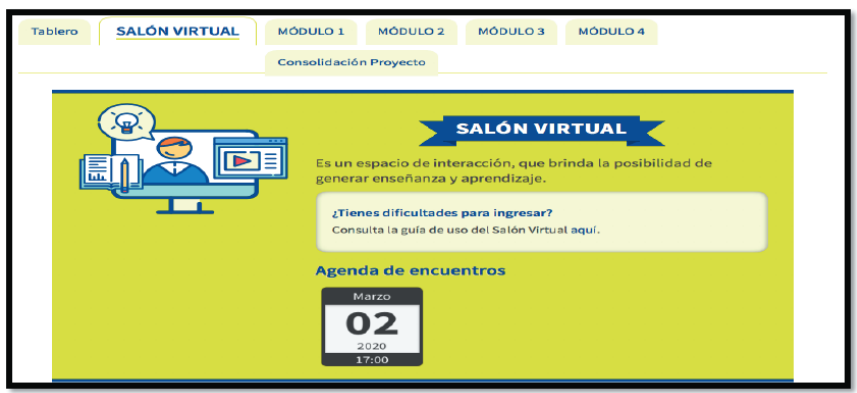

Imagen 6: Ingreso al módulo I Fundamentación y Formulación del Proyecto

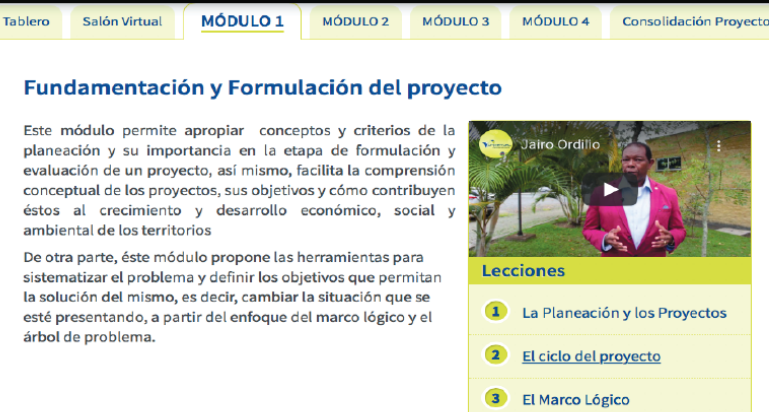

(1) La Planeación y los Proyectos

(2) El ciclo del proyecto

3 El Marco Lógico

Objetivo:

Aplicar los principios de la planeación en el ciclo del proyecto sistematizando el problema para la definición de objetivos que permitan la solución del mismo, a partir del enfoque del marco lógico y el árbol del problema 
Imagen 7: Ingreso a los contenidos de la Lección 1 La Planeación y los Proyectos - Módulo 1

Asignatura: Formulacióny Evaluaciónde Proyectos

- Módulo 1: Fundamentación y Formulación

- Lección 1: La Planeación y los Proyectos

\section{Introducción}

La planeación es una herramienta que ayuda a organizar la acción futura, definiendo cuales son los objetivos que se quieren alcanzar y que pasos son necesarios para lograrlos. En éste ámbito la planeación permite definir a dónde se quiere ir y cual es el camino que debe seguirse en la gestión de los proyectos.

La planeación aporta instrumentos tanto para garantizar que el plan se esté realizando, como, para controlar que se avance en el sentido deseado. La importancia de la planeación en el marco de los proyectos, es garantizar que se lleve a feliz término una idea, para Tabla de Contenido: Tema 1 Conceptos y Dimensiones de la planeación Tema 2:

Conceptos y Objetivos de los proyectos Tema 3:

economía resolver un problema o aprovechar una oportunidad.

Imagen 8: Ingreso a los contenidos de la Lección 2 El cíclo del proyecto - Módulo 1

Asignatura: Formulación y Evaluación de Proyectos
Módulo 1: Fundamentación y Formulación del proyecto

\section{Introducción}

El ciclo del proyecto son las diferentes etapas que recorre el proyecto desde que se concibe la idea hasta que se materializa en una obra o acción concreta, estas etapas comprenden: la preinversión, que es la fase de identificación, selección, formulación y evaluación de un proyecto; por su parte, la inversión contempla la administración de la ejecución, en tanto que la operación tiene que ver con la administración o funcionamiento del proyecto.

\section{Tabla de Contenido:}

Tema 1:

La preinversión (Evaluación ex - antes)

En el ciclo del proyecto también se encuentra la evaluación ex-post, que se refiere al análisis posterior cuando el proyecto ya ha entrado en operación.

El alcance de éste curso es profundizar en la preinversión, que es la que determina si es viable o no invertir en determinado proyecto, de acuerdo con los criterios de decisión establecidos en cada uno de los estudios de factibilidad. 
Imagen 9: Ingreso a los contenidos de la Lección 3 El Marco Lógico Módulo 1

$\begin{aligned} & \text { Asignatura: Formulación y Evaluación de } \\ & \text { Proyectos }\end{aligned}$
Introducción
del proyecto
Esta lección se fundamentanta en el marco lógico como la herramien y Formulación de uso más común en la
planificación de proyectos para el desarrollo, pues, se trata de un manual para la
planificación de proyectos orientado mediante objetivos.
Cobra importancia, porque es una manera de estructurar los principales elementos de un
proyecto, subrayando los lazos lógicos entre los insumos previstos, las actividades
planeadas y los resultados esperados.
En el recorrido de la lección se comprenderá que se trata de una herramienta que facilita el
proceso de identificación, conceptualización, diseño, ejecución y evaluación de proyectos. El
marco lógico está centrado en la orientación por objetivos y es una matriz que presenta de
manera resumida la información básica de la alternativa seleccionada para un proyecto de
inversión.

Tabla de Contenido:

Tema 1:

Enfoque del Marco Lógico

Tema 2:

Arbol del Problema

Tema 3:

Nivel de Objetivos y Matriz del Marco

Lógico (Matriz 4×4)

Tema 4:
Casos de un problema identificado $y$

situación objetivo

inversión.

Imagen 10: Ingreso al Módulo 2 Estudios de Factibilidad del Proyecto

\begin{tabular}{|llllll}
\hline Tablero Salón Virtual MÓdULO 1 MÓdULO 2 & MÓDULO 3 & MÓdULO 4 & Consolidación Proyecto
\end{tabular}

Estudios de Factibilidad del Proyecto

Los estudios de factibilidad inician con la identificación de una idea a la que luego se le da el perfil y, mediante un

proceso minucioso, culmina con la instalación física de una

planta para producción o la prestación de un servicio.

Después de la idea, cada una de las etapas siguientes es una profundización de la idea inicial, no solo en lo que se refiere a

conocimiento, sino también, en lo relacionado con

investigación, análisis y toma de la decisión. La última fase de proceso es la cristalización de la idea con la instalación física

de la planta, la producción del bien o servicio y, por último, la satisfacción de una necesidad humana o social, que fue lo que en un principio dio origen a la idea y al proyecto.

Aunque cada estudio de inversión único y distinto a todos los demás la metodología que se aplica en cada uno tiene la

posibilidad de poder adaptarse a cualquier proyecto. Las

áreas generales en las que se puede aplicar la metodología de

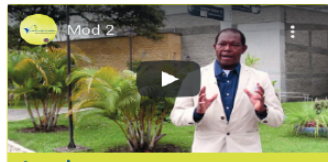

Lecciones

(1) Estudio de Mercado

(2) Estudio Técnicoy Organizacional

(3) Estudio Económico y Financiero

- Instalación de una planta totalmente nueva

- Elaboración de un nuevo producto de una planta ya existente

- Ampliación de la capacidad instalada o creación de sucursales

- Sustitución de maquinaria por obsolescencia o capacidad insuficiente

\section{Objetivo:}

Realizar los estudios de factibilidad, determinando la bondad del proyecto, desde el análisis del mercado, el estudio técnico y organizacional, la evaluación económica y financiera y, análisis de sensibilidad, para tener criterios de decisión. 
Imagen 11: Ingreso a los contenidos de la Lección 1 Estudio de Mercado Módulo 2

- Módulo 2: Estudios de Factibilidad del

- Lección 1: Estudio de Mercado

Proyectos

Proyecto

\section{Introducción}

El estudio de mercado es la parte inicial de la investigación formal de campo que se debe realizar en un proyecto, consta de la determinación y cuantificación de la demanda, la

oferta, el análisis de los precios y el estudio de la comercialización.

Aunque la cuantificación de la oferta y la demanda pueda obtenerse de fuentes de

información secundaria, siempre es recomendable la investigación con las fuentes

primarias, porque proporcionan información directa, actualizada y mucho más confiable. El

objetivo general de esta investigación es verificar la posibilidad real de penetración del

producto o servicio en el mercado. El investigador del mercado podrá percibir el riesgo que

se corre y la posibilidad de éxito que habrá con las ventas, también, podrá observar la

existencia de sus competidores actuales y potenciales en el mercado.

Tabla de Contenido:

Tema 1:

Análisis de la demanda, la oferta, los precios, la comercialización y canales de distribución

Tema 2:

Étapas de la investigación de mercado

(Diseño metodológico)

Tema 3:

Instrumentos y técnicas para recolección y procesamiento de información

Es una investigación útil para diagnosticar y analizar las variables del entorno de mercado, como es la oferta, la demanda, los precios, la competencia; sirve también para establecer la comercialización (facilidad de penetración de un producto en el mercado), identificar problema con los proveedores sobre productos similares (calidad, precio, tiempo de entrega, entre otros) y consultar sobre los hábitos de consumo en productos similares. El estudio de mercado también enfatiza en la caracterización del cliente, desce sus aspectos

Imagen 12: Ingreso a los contenidos de la Lección 2 Estudio Técnico y Organizacional - Módulo 2

\begin{tabular}{|c|c|}
\hline $\begin{array}{l}\text { Asignaturat Formulación y Evaluación de } \\
\text { Proyectos }\end{array}$ & - Lección 2: Estudio Técnico y Organizacional \\
\hline \multicolumn{2}{|l|}{ Introducción } \\
\hline 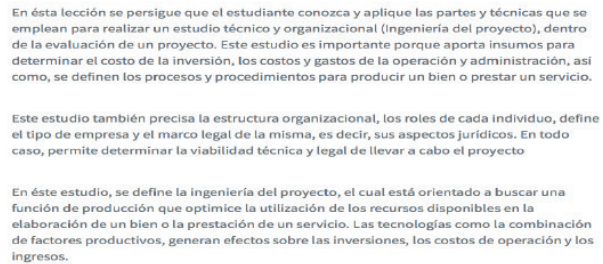 & $\begin{array}{l}\text { Tabla de Contenido: } \\
\begin{array}{|l}\text { Tema } 1 \text { t: } \\
\text { Objetivos y estructura del estudio técnico } \\
\text { y organizacional } \\
\text { Tema 2t } \\
\text { Localización del proyecto y determinación } \\
\text { del tamaño del proyecto } \\
\text { Tema } 3: \\
\text { Estructura organizacional, procesos y ciclo } \\
\text { de la gestión }\end{array}\end{array}$ \\
\hline $\begin{array}{l}\text { La transformación de insumos de producción mediante una técnica determinada de } \\
\text { combinación de factores como mano de obra, equipos, insumos materiales, métodos y } \\
\text { procedimientos, constituyen el proceso de producción, en consecuencia, dependiendo de la } \\
\text { forma como se haga esa transformación obtendremos distintos procesos. Dependiendo de }\end{array}$ & \\
\hline
\end{tabular}


Imagen 13: Ingreso a los contenidos de la Lección 3 Estudio Económico y Financiero - Módulo 2

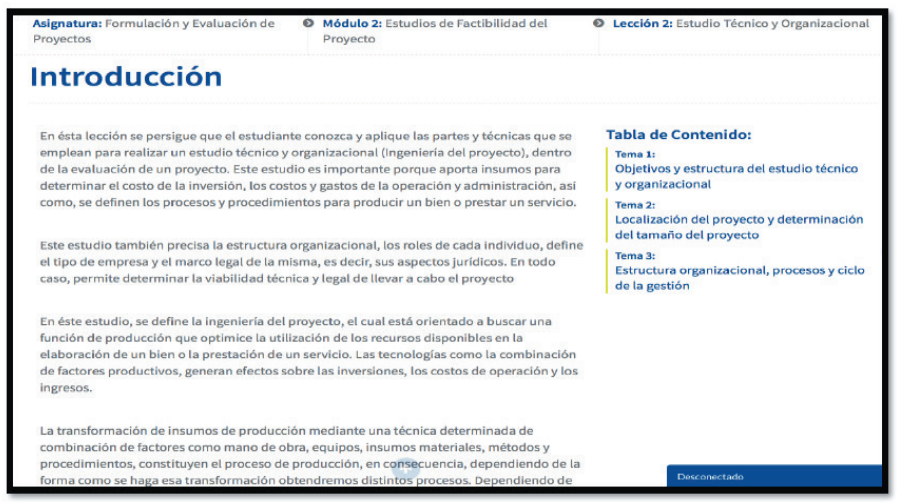

Imagen 14: Ingreso al Módulo 3 El Sistema Financiero y Fuentes de Financiación

Tablero Salón Virtual MÓDULO 1 MÓDULO2 2 MÓDULO 3 MÓDULO 4
El Sistema Fina nolidación Proyecto
Una vez realizadas las estimaciones de los costos de inversión
y funcionamiento del proyecto, se entra a estudiar las
diferentes opciones de financiación disponibles, para atender
las necesidades de capital en las distintas etapas del proyecto.
Por lo tanto, es necesario conocer la estructuray
funcionalidad del sistema financiero, las diferentes tasas de
interés, así como los organismos de regulación y control,
como el Banco de la República y la Superintendencia
Bancaria.
Dentro de las fuentes de financiación se clasifican algunas que
son exclusivas para proyectos sociales liderados por
instituciones gubernamentales, cuyos recursos provienen del
presupuesto nacional como son: Sistema General de
Participaciones (SGP), Sistema General de Regalías (SGR) u
otros fondos de los diferentes Ministerios.
Se encuentra también la opción de cofinanciar proyectos
entre instituciones públicas y privadas, a través de la figura de
Alianzas Público Privadas (APP).

Para estimar los costos de financiación del proyecto se

propone una herramienta de simulación que permitirá hacer

análisis de los costos del capital desde diferentes escenarios.

\section{Objetivo:}

Reconocer el sistema financiero y las fuentes de financiación, tanto para proyectos del sector público como para el sector privado 
Imagen 15: Ingreso a los contenidos la Lección 1 El Sistema Financiero - Módulo 3

Asignatura: Formulación y Evaluación de Proyectos

\section{Introducción}

Esta lección permite realizar un recorrido por la estructura y funcionalidad del sistema financiero, identificando las instituciones que lo conforman y las diferentes tasas de interés tanto para captación como para colocación a las que se puede acceder. Así mismo, define las autoridades responsables de administrar la política monetaria y la autoridad de vigilancia de las transacciones que se realizan en el mercado financiero.
Tabla de Contenido:

Tema 1

Estructura y Funcionalidad del Sistema

Financiero

Tema 2:

Las Tasas de Interés

Imagen 16: Ingreso al Módulo 4 Evaluación del Impacto Ambiental y Social del Proyecto

Asignatura: Formulación y Evaluación de

Proyectos

\section{Módulo 3: El Sistema Financiero y Fuentes 0 Lección 2: Fuentes de Financiación de Financiación}

\section{Introducción}

Esta lección le permite al estudiante reconocer las diferentes fuentes de financiación de los proyectos, tanto para el sector público como para el sector privado. Encontrará que las líneas de financiación pueden ser créditos con la banco ordinaria o la banca multilateral, pero también se encuentran muchos de recursos de cofinanciación a través de entidades gubernamentales como Ministerios (Mintic) y otros departamentos como Colciencias y el SENA (Fondo Emprender).

De otra parte, esta lección ofrece un simulador para estimar los costos financieros de un proyecto, de acuerdo con las diferentes tasas de interés, plazos y forma de pago de los créditos en el mercado financiero.

\section{Tabla de Contenido:}

Tema 1:

Lineas de Financiación y Créditos para

Inversión Pública y Privada 
Imagen 17: Ingreso a los contenidos de la Lección 1 Evaluación Social - Módulo 4

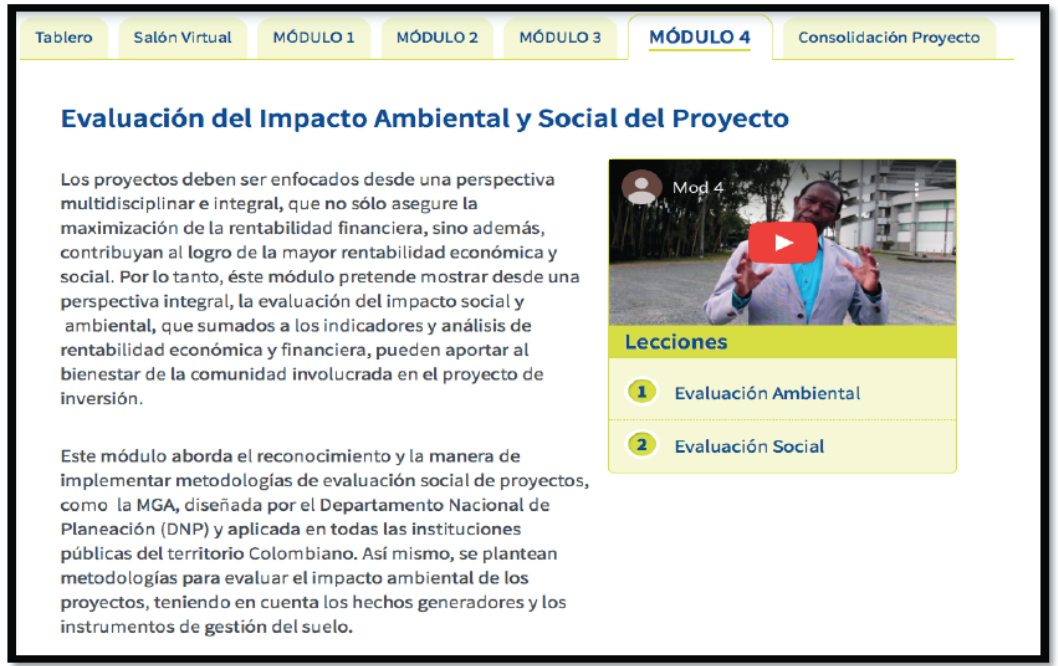

Objetivo:

Aplicar las metodologías para la evaluación integral de un proyecto, desde el ámbito social, económico y ambiental

Imagen 18: Ingreso a los contenidos de la Lección 1 Evaluación Social - Módulo 4

Asignatura: Formulación y Evaluación de $\odot$ Módulo 4: Evaluación del Impacto Social $\odot$ Lección 1: Evaluación Social
Proyectos

\section{Introducción}

La gestión de los proyectos no solo es para optimizar el uso de los recursos y alcanzar metas de crecimiento, sino especialmente, para el logro de objetivos de bienestar económico y social de las comunidades. Por consiguiente, es necesario mejorar la forma de asignación de recursos, para garantizar un desarrollo sostenible en beneficio de las generaciones futuras.

La evaluación social es un procedimiento utilizado en los proyectos del el sector público, para evidenciar el cumplimiento de indicadores de costo beneficio o costo eficiencia. Esta mide el impacto y la contribución a la mejora de la calidad de vida de los sectores sociales donde se interviene con los proyectos de inversión
Tabla de Contenido: | Tema 1:

Fundamentos y Caracteristicas de la evaluación social de Proyectos 


\section{Conclusiones}

- En los últimos ocho años en Colombia el Ministerio de Educación y el Ministerio de las TIC han venido haciendo ingentes esfuerzos a través de los Planes de Desarrollo, Planes Decenales de Educación y Políticas Educativas, para mejorar la cobertura y calidad de la educación con la integración de las TIC. No obstante, aún existe un gran rezago y amplias brechas en el campo de la virtualidad y la conectividad.

- El rezago que presenta el país en las TIC se ve reflejado también en las pymes en todos los nivele, y, en forma reiterada, confirmado por las encuestas y los estudios

- Los métodos tradicionales usados para la formación en las instituciones de educación superior no han permitido una verdadera apropiación y uso eficiente de las TIC. Por ello, en el marco de la emergencia por motivos del COVID-19, quedó evidenciado que no existe la suficiente capacidad instalada, ni están dadas las condiciones para que las instituciones de educación superior implementen modelos de formación virtual. 
- Estas circunstancias dejan grandes desafíos y oportunidades para innovar y generar cambios en los métodos didácticos $y$, el uso de herramientas y recursos alternativos para mediación de la educación.

- La coyuntura actual ha obligado a las instituciones de educación a explorar e implementar diferentes plataformas virtuales, capacitar a docentes y estudiantes en el uso de las mismas, así como dotación de equipos (computadores y simcard) para garantizar la continuidad de los programas educativos y planes de estudio y evitar la deserción

- El modelo de virtualización implementado en la Universidad Tecnológica ha sido innovador y exitoso, ya que responde a los requerimientos del entorno en el ámbito profesional, laboral y empresarial. El mismo está fundamentado en el concepto b-learning, el cual alterna e integra el aprendizaje presencial y online, favoreciendo la planificación pedagógica, flexibilidad y acceso a la educación, mejora el costo efectividad, motiva el trabajo colaborativo y contribuye a mejorar la calidad en la educación.

- La mediación de las TIC en los procesos de formación si son pertinente y pueden contribuir a mejorar los procesos de enseñanza y aprendizaje, así como el fortalecimiento de competencias para el análisis, comprensión y solución de problemas.

- Los hallazgos encontrados en los cursos evaluados en el marco de la pandemia, en la Universidad Libre y la Escuela Superior de Administración Públia ESAP Territorial Quindío Risaralda para el semestre 2020-1 demuestran que existe buena aceptación (satisfacción) de los estudiantes sobre la educación mediada por plataformas virtuales, pero también quedaron lecciones aprendidas como oportunidades de mejora para los desafíos futuros. 
- Los mayores retos y desafíos que tienen las Instituciones de Educación Superior son mantener los indicadores de cobertura (número de matriculados), número de instituciones y programas, nivel de formación de docentes, las tasas de deserción, la financiación de las instituciones educativas, los resultados de logro académico y la eficiencia en el manejo de recursos.

\section{Recomendaciones}

- Promover la reflexión interna sobre la renovación del modelo pedagógico de enseñanza y aprendizaje en la educación superior que favorezca la flexibilidad, la calidad, accesibilidad y la equidad (revisión de PEI).

- Invertir en equipos tecnológicos, plataformas y herramientas virtuales para fortalecer la capacidad instalada y la integración de las TIC en las IES

- Ajustar periódicamente los contenidos curriculares por competencias para que respondan a los requerimientos del entorno económico, social y ambiental, y que se adapten a las herramientas modernas para mediar los procesos de formación.

- Diseñar e implementar planes de capacitación para los docentes y estudiantes en el manejo de plataformas, herramientas y recursos virtuales (estrategia de maestros virtuales), para favorecer las competencias en la enseñanza.

- Realizar estudios de caracterización de estudiantes para identificar sus requerimientos en materia de entornos virtuales, para contribuir a la solución

- Implementar modelos de virtualización que favorezcan la inclusión y la flexibilidad educativa. 


\section{Bibliografía}

Baquero, R. (1995). Vygotsky y el aprendizaje escolar. Buenos Aires, Argentina: Editorial Aique

Barroso, J. \& Gallego, O. (2017a). La realidad aumentada y su aplicación en la educación superior. Revista del Salomé, 1(29), 111-124.

Bartolomé, A. (2008). Entornos de aprendizaje mixto en Educación Superior. Revista RIED, 11

(1), 15-51. Recuperado de https://scholar.google.com.co/ scholar?q=Entornos+de+aprendizaje+mixto+en+Educaci $\%$ $\mathrm{C} 3 \% \mathrm{~B} 3 \mathrm{n}+$ Superior.\&hl=es\&as_sdt=0\&as vis $=1 \&$ oi $=$ scholart\&sa $=$ X\&ved $=0$ ahUKEwiRiZGk6YrZAh UJ 3FMKHT3mClsQgQMIIzAA

Bejarano Ledesma Alejandra y Ortega Martínez Karen Fernanda (2015). Teoría de los mandos superiores 
Bustos Sánchez, Alfonso (2004). Un Modelo para blendedlearning aplicado a la formación en el

Carretero, M., "Piaget, Vygotsky y la Psicología Cognitiva”. Novedades Educativas, (74) 75-79

Carretero, M. (1994). Constructivismo y educación. Buenos Aires, Argentina: Editorial Aique

Carretero, M. (1996). Introducción a la psicología cognitiva. Buenos Aires, Argentina: Editorial Aique

CNA (1992). Ley 30 Servicio Público de la Educación Superior en Colombia. Recuperado de https://www.cna.gov.co/1741/ articles-186370_ley_3092.pdf

trabajo. México, D.F: Editor UNAM

Consejo Nacional de Educación Superior. Acuerdo No 2 del $1^{\circ}$ de julio de 2020 "Por medio del cual se actualiza el modelo de acreditación en alta calidad"

CONPES 3988 del 31 de marzo de 2020. Política Nacional para impulsar la innovación en las prácticas educativas a través de las tecnologías digitales

CONPES 3975, octubre 2019 "Política Nacional para la Transformación Digital e Inteligencia Artificial”.

Espacio el Latinocom. Teorías de la educación, Zoila Libertad García Santos 
Estudio del Instituto Internacional para la Educación Superior en América Latina y el Caribe (IESALAC) y la Organización de las Naciones Unidas para la Educación, la Ciencia y la Cultura (UNESCO)

https://www.universidad.edu.co/wp-content/uploads/2020/04/ Covid_19_Unesco.pdf

García Hoz, V. La educación liberadora según Paulo Freire, Rev. Esp. De Pedag. 32 - Págs.. 171-174

ICFES. Estudio sobre calidad de la educación en Colombia, 2012

Índice Global de Competitividad (IGC). Consejo Privado de Competitividad, 2017

J. Ricardo Puentes G (2017). Análisis de la apropiación y uso de las TIC por parte de las pymes colombianas.

Leontiev, A.R, et.al. Prólogo a la "Obra de L.S. Vygotsky" en dos tomos, Ed. Academia de Ciencias Pedagógicas URSS

Mayo, Elton y Maslow, Abraham (2012), Teoría de las Relaciones Humanas. Recuperado de http://teoriasadministrativass. blogspot.com.co/p/teoria-de-las-relaciones-humanas.html

MEN (1992). Sistema Colombiano de Formación de Educadores y Lineamientos de Política. Recuperado de https://www. mineducacion.gov.co/1759/articles-345485_anexo1.pdf

Ministerio de Educación Nacional. Visión conjunta de calidad de la educación superior, 2019

Ministerio de las TIC y Vive Fdigital en el año 2015. Uso y apropiación de las TIC en Colombia 
Oportunidad Estratégica. ¿A qué se enfrenta la educación superior en el 2020? Jorge Hernán Cárdenas S. 21 de abril de 2020

El Espectador (2020, abril 24). Educación superior en cuidados intensivos por coronavirus. El Espectador.com

Piaget Jean - Beth E. W (1980). Epistemología matemática y psicología. Barcelona, España:

\section{Editorial CRITICA}

Platón (1991), Las leyes, Epinomis, el Político, Porrúa, México

Plan Nacional de Desarrollo 2018-2022 "Pacto por Colombia", "Apuesta para impulsar una educación superior incluyente y de calidad" y se definen estrategias para la educación virtual

Revista Semana. EDUCACIÓN | 3/30/2020 6:27:00 PM .'Hoy debemos ser flexibles, innovar y trabajar en equipo': ministra de Educación.https://www.semana.com/educacion/articulo/ coronavirus-ministra-de-educacion-habla-del-impacto-enlas-clases/660324.

Tesis Doctoral "Modelo de Formación en Proyectos trazado por las TIC”(2018). Pág. 28-33 y 111-132. Torres Moreno Jairo Ordilio. Atlantic International University (AIU)

Universidad de los Andes. "La Educación Superior en Colombia: Situación actual y análisis de eficiencia" 2017 
Este libro se inspira en el análisis de los efectos ocasionados por la pandemia COVID-19, en las Instituciones de Educación Superior en el proceso de enseñanza aprendizaje, indagando sobre el estado actual de la educación superior en Colombia y los retos y desafíos para el uso de las TIC y la integración de los entornos virtuales en los procesos educativos.

El trabajo comprende un abordaje desde las teorías de la educación con sus referentes normativos, marco teórico sobre las TIC integradas al modelo de formación y estudios sobre la calidad de la educación en Colombia; así mismo, se indagó sobre el nivel de uso y apropiación de entornos virtuales en los procesos académicos, para concluir que la educación mediada por TIC estará a la vanguardia y obligará a las IES a reinventarse, ajustando Proyectos Educativos Institucionales (PEI) acorde con las exigencias de la educación del siglo XXI, generando nuevas posibilidades de acceso, permanencia, flexibilidad, calidad y costos razonables en la educación.

Se presentan resultados de la evaluación de formación mediada por plataformas(Teams y Moodle) en la Universidad Libre de Pereira y la Escuela Superior de Administración Pública (ESAP) Territorial Quindío Risaralda, en primer semestre de 2020, que confirman la premisa de avanzar hacia la virtualización de programas, lo cual exige fortalecer las capacidades tecnológicas y capacitar a docentes y estudiantes en el uso y apropiación de TIC

Finalmente, se presenta un modelo de virtualización de la asignatura Formulación y Evaluación de Proyectos de Inversión en la Universidad Tecnológica de Pereira, como una buena práctica que puede replicarse en otras universidades. 